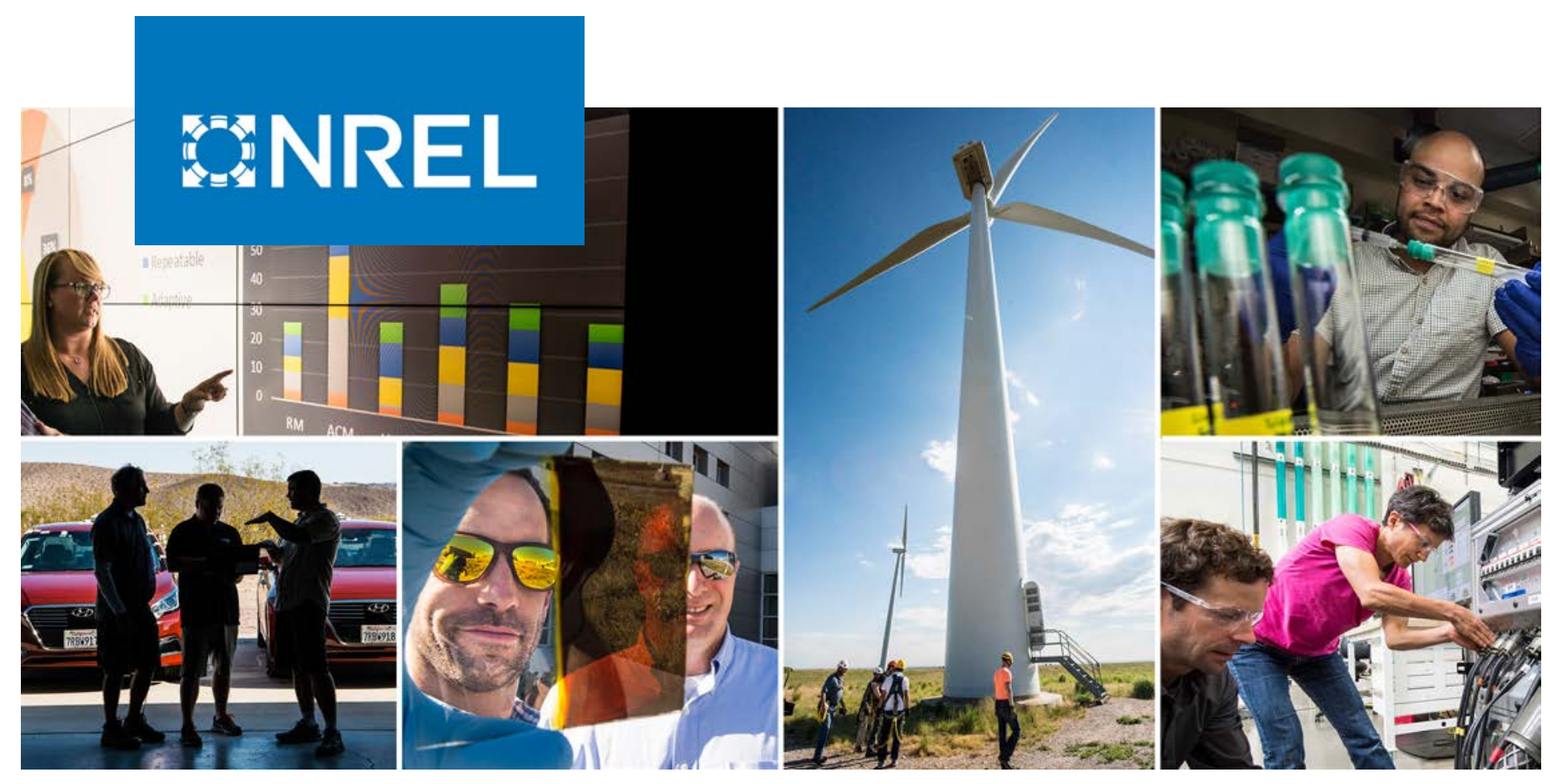

\title{
Solar-Driven Steam Topping Cycle for a Binary Geothermal Power Plant
}

Joshua D. McTigue, ${ }^{1}$ Nick Kincaid, ${ }^{1}$ Guangdong Zhu, ${ }^{1}$ Daniel Wendt, ${ }^{2}$ Joshua Gunderson, ${ }^{3}$ and Kevin Kitz ${ }^{4}$

1 National Renewable Energy Laboratory

2 Idaho National Laboratory

3 POWER Engineers

4 KitzWorks LLC (formerly with U.S. Geothermal)

NREL is a national laboratory of the U.S. Department of Energy

Office of Energy Efficiency \& Renewable Energy

Operated by the Alliance for Sustainable Energy, LLC

This report is available at no cost from the National Renewable Energy Laboratory (NREL) at www.nrel.gov/publications.
Technical Report

NREL/TP-5500-71793

November 2018 


\title{
GNREL
}

\section{Solar-Driven Steam Topping Cycle for a Binary Geothermal Power Plant}

\author{
Joshua D. McTigue,${ }^{1}$ Nick Kincaid, ${ }^{1}$ Guangdong Zhu, ${ }^{1}$ \\ Daniel Wendt, ${ }^{2}$ Joshua Gunderson, ${ }^{3}$ and Kevin Kitz ${ }^{4}$
}

1 National Renewable Energy Laboratory

2 Idaho National Laboratory

3 POWER Engineers

4 KitzWorks LLC (formerly with U.S. Geothermal)

\section{Suggested Citation}

McTigue, Joshua D., Nick Kincaid, Guangdong Zhu, Daniel Wendt, Joshua Gunderson, and Kevin Kitz. 2018. Solar-Driven Steam Topping Cycle for a Binary Geothermal Power Plant.

Golden, CO: National Renewable Energy Laboratory. NREL/TP-5500-71793.

https://www.nrel.gov/docs/fy19osti/71793.pdf.

NREL is a national laboratory of the U.S. Department of Energy Office of Energy Efficiency \& Renewable Energy Operated by the Alliance for Sustainable Energy, LLC

This report is available at no cost from the National Renewable Energy Laboratory (NREL) at www.nrel.gov/publications.

Contract No. DE-AC36-08GO28308
Technical Report

NREL/TP-5500-71793

November 2018

National Renewable Energy Laboratory 15013 Denver West Parkway Golden, CO 80401

303-275-3000 • www.nrel.gov 


\section{NOTICE}

This work was authored in part by the National Renewable Energy Laboratory, operated by Alliance for Sustainable Energy, LLC, for the U.S. Department of Energy (DOE) under Contract No. DE-AC36-08G028308. Funding provided by U.S. Department of Energy Office of Energy Efficiency and Renewable Energy, Geothermal Technologies Office. The views expressed herein do not necessarily represent the views of the DOE or the U.S. Government.

This report is available at no cost from the National Renewable Energy Laboratory (NREL) at www.nrel.gov/publications.

U.S. Department of Energy (DOE) reports produced after 1991 and a growing number of pre-1991 documents are available free via www.OSTI.gov.

Cover Photos by Dennis Schroeder: (clockwise, left to right) NREL 51934, NREL 45897, NREL 42160, NREL 45891, NREL 48097, NREL 46526.

NREL prints on paper that contains recycled content. 


\section{Acknowledgments}

This work was authored, in part, by the National Renewable Energy Laboratory, operated by Alliance for Sustainable Energy, LLC, for the U.S. Department of Energy (DOE) under Contract No. DE-AC36-08GO28308. Funding provided by the U.S. Department of Energy, Office of Energy Efficiency and Renewable Energy, Geothermal Technologies Office (GTO). The views expressed in the article do not necessarily represent the views of the DOE or the U.S. Government. The U.S. Government retains and the publisher, by accepting the article for publication, acknowledges that the U.S. Government retains a nonexclusive, paid-up, irrevocable, worldwide license to publish or reproduce the published form of this work, or allow others to do so, for U.S. Government purposes. 


$\begin{array}{ll}\text { Nomenclature or List of Acronyms } \\ \text { BES } & \text { Battery energy storage } \\ \text { CSP } & \text { Concentrating solar power } \\ \text { FCR } & \text { Fixed-charge rate } \\ \text { GBPP } & \text { Geothermal binary power plants } \\ \text { HP } & \text { High pressure } \\ \text { HTF } & \text { Heat-transfer fluid } \\ \text { INL } & \text { Idaho National Laboratory } \\ \text { ITC } & \text { Investment Tax Credit } \\ \text { LCOH } & \text { Levelized cost of heat } \\ \text { LCOE } & \text { Levelized cost of electricity } \\ \text { LP } & \text { Low pressure } \\ \text { LFC } & \text { Linear Fresnel collector } \\ \text { NREL } & \text { National Renewable Energy Laboratory } \\ \text { NSRDB } & \text { National Solar Radiation Database } \\ \text { O\&M } & \text { Operations and maintenance } \\ \text { ORC } & \text { Organic Rankine cycle } \\ \text { PFD } & \text { Process flow diagram } \\ \text { PTC } & \text { parabolic trough collector } \\ \text { PV } & \text { Photovoltaics } \\ \text { SAM } & \text { System Advisor Model } \\ \text { TES } & \text { Thermal energy storage } \\ \text { TMY } & \text { Typical Meteorological Year } \\ & \end{array}$




\section{Executive Summary}

Greater deployment of moderate-temperature geothermal binary power plants (GBPPs) and concentrating solar power (CSP) can be limited in some markets by their respective generation characteristics and/or levelized cost of electricity (LCOE). Worldwide, both geothermal power and CSP are under intense pressure from the rapidly dropping cost of solar photovoltaic (PV) and wind energy. In the United States, there is further pressure from the ongoing era of low natural gas prices. CSP can generate high-temperature thermal energy that enables high cycle efficiency and low-cost thermal storage systems, and GBPP can produce baseload power generation. Hybridization may take advantage of technical merits of both technologies to produce energy at a levelized cost of energy (LCOE) competitive in the future energy market. New approaches that can lower the LCOE of both geothermal power and concentrating solar can therefore help to increase adoption of both technologies.

In this technical report, we explore several methods of combining heat generated by a concentrating solar field with an existing geothermal binary power plant. The Raft River geothermal power plant in southern Idaho operates below its rated capacity because the reservoir is unable to deliver the design flow and temperature of geothermal energy. The GBPP is a twopressure cycle with independent high-pressure and low-pressure isopentane turbines. Solar heat may be added in several ways to this cycle and we perform a screening study and then more detailed calculations for several configurations, including:

1. Geothermal production brine directly heated by solar energy;

2. A fraction of geothermal brine extracted from some part of the binary plant, heated with solar energy, and mixed with the production fluids; and

3. The addition of a steam topping cycle, the hot exit flow of which is used to:

a. Heat brine, as in points 1 and 2, and

b. Vaporize the binary-cycle working fluid after the fluid has been preheated by the geothermal brine.

The initial screening study was performed on a large number of different cycle configurations at a single operating condition. Subsequently, a more detailed study investigated annual cost and performance. Both the screening study (using one set of modeling software) and the detailed analysis (using another software package) were calibrated against one or more aspects of the Raft River operating condition. The combined results of the screening and detailed study are shown in Table A (although the results from one model should not be compared to those of the other). 
Table A: Comparison of different hybrid plant configurations from the screening study and detailed study. '-' indicates that the configuration was not studied.

\begin{tabular}{|c|c|c|c|}
\hline \multirow[b]{2}{*}{ Cycle and Description } & \multicolumn{2}{|c|}{$\begin{array}{c}\text { Design-Point Cycle } \\
\text { Efficiency }\end{array}$} & \multirow{2}{*}{$\begin{array}{c}\text { Annual } \\
\text { Efficiency } \\
\text { Detailed } \\
\text { Study }\end{array}$} \\
\hline & $\begin{array}{l}\text { Screening } \\
\text { Study }\end{array}$ & $\begin{array}{l}\text { Detailed } \\
\text { Study }\end{array}$ & \\
\hline $\begin{array}{l}\text { Two solar steam turbines: Use high-temperature solar steam in } \\
\text { two turbines, which exhausts to HP and LP isopentane boilers. } \\
\text { Isopentane vapor is used in the GBPP isopentane turbine. }\end{array}$ & $35 \%$ & $33 \%$ & $30 \%$ \\
\hline $\begin{array}{l}\text { One solar steam turbine with steam cross-over: Eliminate the } \\
\text { small turbine to the LP isopentane boiler, and instead, use some } \\
\text { of steam from HP turbine exhaust to feed the LP isopentane } \\
\text { boiler. }\end{array}$ & - & $32 \%$ & $29 \%$ \\
\hline $\begin{array}{l}\text { One solar turbine with geo-heat bypass: All solar turbine steam } \\
\text { is used on HP side. Eliminate LP steam isopentane boiler. Reduce } \\
\text { geo-heat extraction from the HP side of the GBPP and bypass it to } \\
\text { the LP geo-boiler. }\end{array}$ & - & $32 \%$ & $29 \%$ \\
\hline $\begin{array}{l}\text { Solar steam turbine to reheat internal brine slip-stream: Use } \\
\text { one steam turbine, and then recirculate and reheat brine from } \\
\text { inside the GBPP, after either the HP or LP vaporizers. }\end{array}$ & $\begin{array}{c}27 \% \text { to } \\
30 \%\end{array}$ & - & - \\
\hline $\begin{array}{l}\text { One solar turbine to heat incoming brine: One solar turbine is } \\
\text { used to heat the entire flow of brine coming into the GBPP. This } \\
\text { raises temperature but not flow. Calcium mineral precipitation is a } \\
\text { risk. }\end{array}$ & - & - & - \\
\hline $\begin{array}{l}\text { One solar turbine to reheat brine from plant exit: A slipstream } \\
\text { of brine from the plant exit is reheated and added back to the inlet } \\
\text { flow, increasing brine flow to the plant, and possibly temperature, } \\
\text { as well. }\end{array}$ & $\begin{array}{c}24 \% \text { to } \\
27 \%\end{array}$ & - & - \\
\hline $\begin{array}{l}\text { Directly heat incoming brine with solar energy: No high- } \\
\text { temperature solar steam turbine. Heat all incoming brine with } \\
\text { direct solar energy. }\end{array}$ & $16 \%$ & $16 \%$ & $16 \%$ \\
\hline $\begin{array}{l}\text { Directly heat brine from exit with solar energy: No solar steam } \\
\text { turbine. Heat exit brine slipstream with solar energy, recirculate to } \\
\text { plant inlet. }\end{array}$ & - & $13 \%$ & $13 \%$ \\
\hline
\end{tabular}

The following are some key insights into the design of geo-solar hybrid configurations from the two modeling efforts and the table above:

1. The studies confirm that creating and using high-exergy (high-temperature, i.e., $700^{\circ} \mathrm{F}$ ) solar energy in a steam turbine creates up to twice as much net power as if the solar energy is used directly to heat brine at moderate temperatures (i.e. $<300^{\circ} \mathrm{F}$ ).

2. Multiple steam turbines and multiple steam extraction and heating points are the most efficient; but from a practical perspective, a single steam turbine and single heating point appear to be the preferred mode of converting the high-temperature steam, at least for the relatively small installation being considered at Raft River. 
3. Cycles that minimize the temperature rise of the brine exiting the GBPP are more efficient. Conceptually, increasing brine temperature implies that solar energy is used to heat the injection brine. The most efficient cycles reduce the brine temperature exiting the plant, effectively using solar energy to increase the extraction of geothermal energy.

4. The best cycles use the solar energy to vaporize the GBPP working fluid, whereas the worst cycles add heat and/or flow to the incoming brine flow to the GBPP.

5. If brine heating is undertaken, it is best to heat the incoming flow to the GBPP, rather than to recirculate and re-heat brine from within the GBPP.

6. Cycles that heat brine using a steam topping turbine are significantly more efficient than cycles that directly heat the brine with the collected solar energy.

As the study progressed, additional steam-topping cycle configurations were compared with the aim of simplifying the cycle and reducing the capital cost. The most promising configuration uses a single steam turbine whose exit flow vaporizes the binary-cycle working fluid. This cycle achieves a conversion efficiency of solar thermal power to electricity of $32.0 \%$ at the design point, and $29 \%$ over the year. The advantages of this cycle were that it reduced the number of equipment components added to the cycle, made use of the existing brine bypass to transfer heat to the low-pressure turbine, and retained the advantage of lowering the brine exit temperature when the solar turbine was operating.

The influence of geographical location was investigated, and we found that locating the hybrid geothermal-solar plant in southern California would lead to lower total power outputs than a plant in southern Idaho because of California's higher average annual wet-bulb temperatures. This effect is, in part, because the heat-rejection system for a plant located in Idaho is undersized compared to a plant located in California. However, the greater solar resource in southern California led to a 23\% increase in the addition of electricity from the hybrid plant, thereby leading to a lower LCOE— $0.118 \$ / \mathrm{kWh}$ in southern California, compared to $0.126 \$ / \mathrm{kWh}$ in Idaho, both with no U.S. tax code investment tax credit (ITC).

It is important to note that the costs given in this report include a large number of assumptions. The values are reasonable, but greater accuracy will be derived from comparing calculated costs with each other within this report, rather than with costs from outside the bounds of this particular study. On the other hand, these costs may also be high. The DOE SunShot target aims to develop low-cost solar collectors for $<75 \$ / \mathrm{m}^{2}$. The cost of collectors assumed in the study was $125 \$ / \mathrm{m}^{2}$.

Designing the solar field to return the geothermal plant to its design power output at the optimal solar irradiance of $950 \mathrm{~W} / \mathrm{m}^{2}$ means that the hybrid plant will operate off-design for a large portion of the year. Increasing the size of the solar field means that the plant can operate at or above the design point for a greater percentage of the year. Unlike conventional CSP plants, where any excess solar power from an oversized solar field must be curtailed, in the hybrid plant, the excess solar heat may be bypassed around the steam turbine and transferred directly into the geothermal plant. This option reduces curtailment and increases the annual energy generation. 
However, the geothermal power plant converts heat less efficiently than the steam turbine. Thermal energy storage (TES) may be used to avoid curtailment and still convert excess solar heat with a higher efficiency. Although thermal storage increases the capital cost of the plant, the increased annual power generation acts to reduce the LCOE. For the LCOE to be lower than a plant with no storage, it is found that the storage should have a capital cost of less than 35 $\$ / k W h_{\text {th. }}$ (Currently, two-tank TES costs 30-50 \$/kWhth, whereas other pre-commercial technologies such as packed beds may achieve lower costs.)

If subsidies are available, then the cost of the hybrid plant with TES is significantly reduced. Table B indicates that an ITC of 30\% (which is available to plants that have commenced construction before 2019) would reduce the LCOE of a hybrid plant with 4 hours of TES by 0.02 $\$ / \mathrm{kWh}$.

Table B: LCOE of a hybrid geothermal-solar power plant with four hours of TES in two locations for different values of the ITC.

\begin{tabular}{|c|c|c|c|c|}
\hline \multirow{4}{*}{$\begin{array}{l}\text { TES Cost } \\
\$ / k W h_{\text {th }}\end{array}$} & \multicolumn{4}{|c|}{ LCOE $\left(\$ / k W h_{e}\right)$} \\
\hline & \multicolumn{2}{|c|}{ Burley, ID } & \multicolumn{2}{|c|}{ Imperial, CA } \\
\hline & \multicolumn{2}{|c|}{ Tax incentive \% } & \multicolumn{2}{|c|}{ Tax incentive \% } \\
\hline & $0 \%$ & $30 \%$ & $0 \%$ & $30 \%$ \\
\hline 25 & 0.113 & 0.085 & 0.088 & 0.067 \\
\hline 50 & 0.125 & 0.093 & 0.097 & 0.073 \\
\hline
\end{tabular}

Finally, the incremental cost of the hybrid geothermal-solar power plant with TES is compared to a photovoltaic array with battery energy storage (PV+BES). We found that the hybrid plant is significantly less expensive than the PV+BES system due to the high cost and replacement rate of batteries. However, without energy storage, the PV plant has a lower LCOE (see Table C).

The low cost of stored solar energy is a significant result from this work. If validated in more detailed studies, it could have important implications for both the geothermal and concentrating solar industries. However, its greatest impact could be on the storage market and on the role that geothermal can play in dispatchable power.

Table C: Comparison of the LCOE of a hybrid plant with TES versus a PV array with BES, for different storage durations and geographical locations.

\begin{tabular}{lllll} 
& \multicolumn{2}{c}{ Levelized Cost of Storage - LCOE $(\$ / k W h e)$} \\
\cline { 2 - 5 } & \multicolumn{2}{c}{ 0 h storage } & \multicolumn{2}{c}{ 4 h storage } \\
\hline PV & Hybrid & PV+BES & Hybrid+TES \\
\hline Burley, ID & 0.074 & 0.116 & 0.187 & 0.118 \\
Imperial, CA & 0.063 & 0.092 & 0.148 & 0.091
\end{tabular}




\section{Conclusions:}

- Use of a high-pressure steam turbine to capture the high-temperature potential of solar thermal in a geothermal binary hybrid power plant doubles the efficiency of direct solar heat addition to brine options. As a result, the cost of the power generated by the hybrid is significantly reduced.

- The addition of solar thermal storage to the hybrid plant provides multiple benefits: it lowers the LCOE of the hybrid plant, and it provides dispatchability at a lower cost than photovoltaic power with batteries. This potentially opens new markets for existing and new geothermal power plants.

- Several further areas of investigation were identified that could build on the successful findings of this study. 


\section{Table of Contents}

1 Study Basis

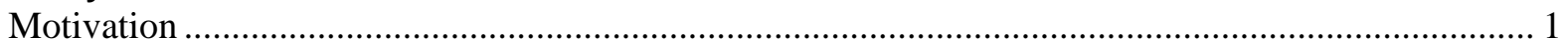

Economic and Technical Drivers for a Successful Hybrid Plant .................................................... 1

Thermodynamic and Economic Evaluation Parameters ........................................................... 2

Description of Raft River Geothermal Power Plant .................................................................... 3

2 Screening and Review of Geothermal and Solar Thermal Hybrid Technologies ........................ 6

Overview: Methods and Technologies Used for Adding Solar-Thermal to a GBPP ............................ 6

Raft River Solar/Geothermal Hybrid Cycle Screening Evaluation ................................................. 7

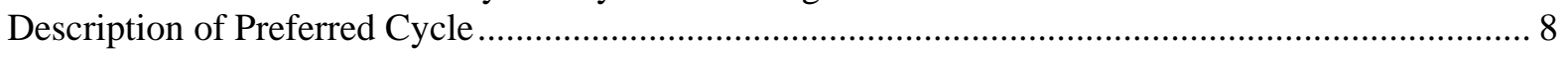

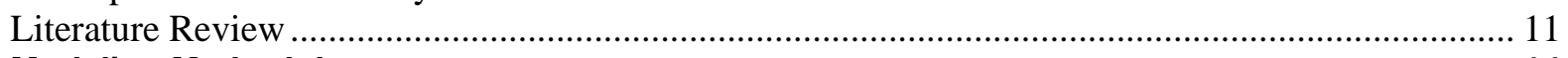

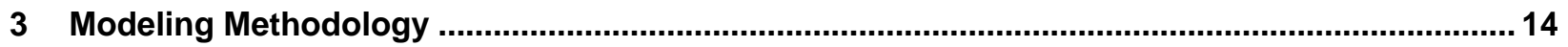

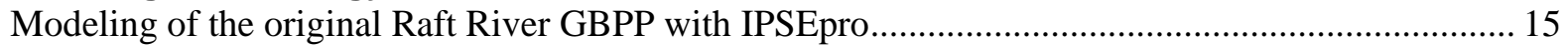

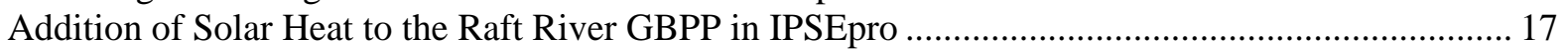

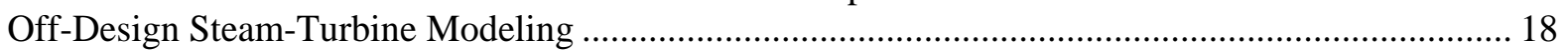

Determination of Plant Performance for a Typical Meteorological Year ........................................ 20

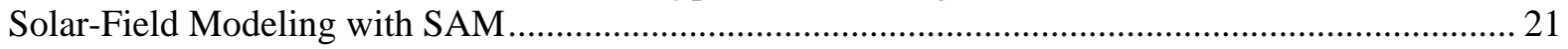

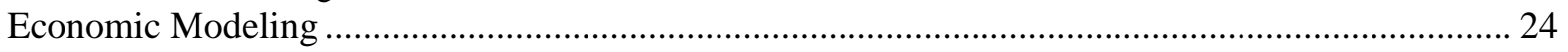

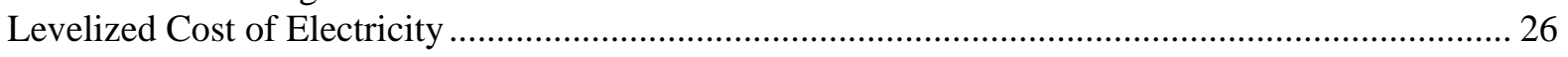

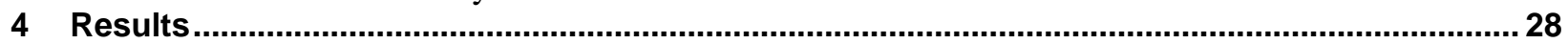

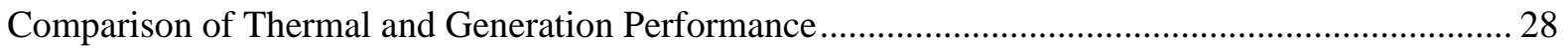

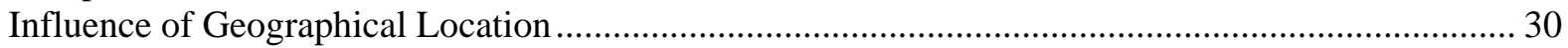

Effect of Re-Routing Excess Solar Heat around the Steam Turbine and Adding to the Vaporizer ..... 32

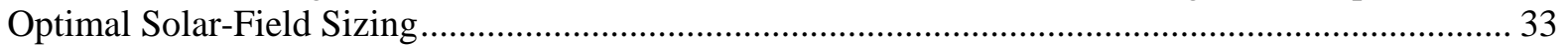

Integrating Thermal Storage with Solar-Field Sizing in the Geo-Solar Hybrid ................................. 34

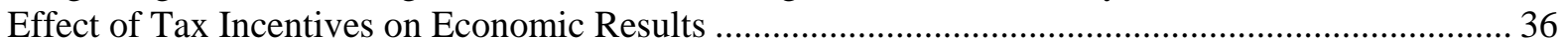

Influence of Solar-Field Costs ................................................................................................. 36

Comparison with a Photovoltaic Array with Battery Energy Storage............................................. 37

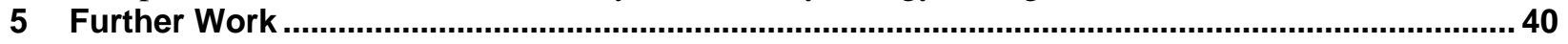

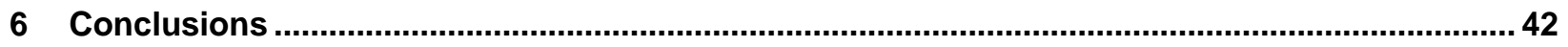

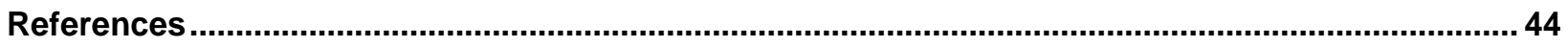

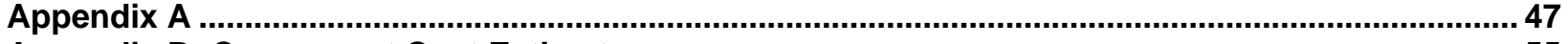

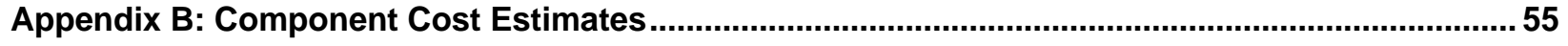




\section{List of Figures}

Figure 1. Raft River Geothermal Power Plant Process Flow Diagram. Key: CT: cooling tower; EV: evaporator; HPT: High-pressure turbine; LPT: Low-pressure turbine; PH: Preheater; CWP: Cold-water pump; PW: Production well; IW: Injection well; G: Generator; CP: Circulation

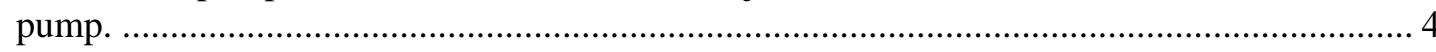

Figure 3. Case 1A-Process flow diagram of the hybrid solar-geothermal system with two steam turbines..

Figure 4. Case 1B-Process flow diagram of the hybrid solar-geothermal system with one steam turbine. Steam turbine exit flow heats both the HP and LP working-fluid cycles. ............................ 10

Figure 5. Case 1C-Process flow diagram of the hybrid solar-geothermal system with one steam turbine. Steam turbine exit flow heats only the HP working-fluid cycles........................................ 11

Figure 7. Comparison of gross power reported in Raft River plant operating data with predicted values. 17

Figure 8. Comparison of net power reported in Raft River plant operating data with predicted values..... 17

Figure 9. Off-design performance of back-pressure steam turbines. Curves are the relative efficiency compared to the design point. Data from Bahadori et al. [29] and Atlas CopCo.................... 20

Figure 10. Multiple linear-regression model of hybrid plant net power generation as function of wet-bulb temperature for varying solar-field thermal output. IPSEpro model output is included as discrete points while the regression function output is depicted as curved lines.

Figure 11. Solar-field thermal power produced for PTC 2 from SAM for a 50-MW solar field with N-S

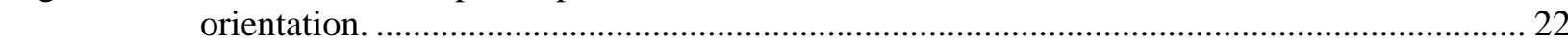

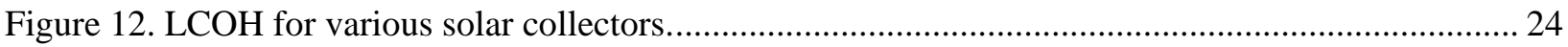

Figure 13. Solar-field thermal power output for PTC 2 comparing collector orientation during a) summer

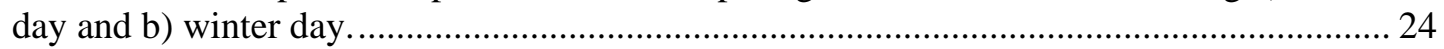

Figure 14. The solar conversion efficiency $\boldsymbol{\eta} \boldsymbol{s o l}, \mathbf{1}$ and LCOE of several hybrid-plant configurations. ... 30

Figure 15. The influence of location on the hybrid-plant performance. a) Higher average annual wet-bulb temperatures lead to lower solar conversion efficiencies. b) The geothermal power plant produces less electricity in warmer regions. However, more solar heat is generated............. 32

Figure 16. The hybrid-plant power output for several ambient temperatures as the solar thermal input varies. There is a noticeable kink at the point where excess solar heat is re-routed around the steam turbine. 33

Figure 17. The effect of solar-field size on the LCOE. Curves are shown for a hybrid plant with one turbine with the solar field oriented north-south. Curves are shown for two locations and for configurations where the solar heat is either curtailed or re-routed directly into the geothermal plant vaporizers.

Figure 18. Thermal storage increases the optimal solar multiple. a) Hybrid plant at Burley, ID. b) Hybrid plant at Imperial, CA. Results are for a hybrid plant with one steam turbine with the solar field oriented north-south................................................................................................ 35

Figure 19. The effect of the cost of thermal storage on the LCOE of the hybrid plant for a) Burley, Idaho,

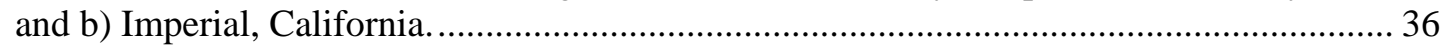

Figure 20. The LCOE of a hybrid plant with no storage and a solar multiple of 1.5 at two locations. The grey lines indicate the LCOE that may be achieved using current solar-field costs (including collectors, site improvements, and HTF system), or target costs according to the DOE CSP

COLLECTS Funding Opportunity Announcement. (Costs without tax incentives.).............. 37

Figure 21. Case 2-Geothermal production fluids are heated directly by the solar field......................... 48

Figure 22. Case 4A-Injection brine is heated in the condenser of a topping steam turbine. The hot brine is recirculated and mixed with the production fluids. ........................................................ 49

Figure 23. Case 4B-Injection brine is heated in the condensers of a three-stage topping steam turbine.

The hot brine is recirculated and mixed with the production fluids........................................ 50

Figure 24. Case 5A-Brine is extracted before the binary-cycle preheaters. It is then heated in the condenser of the steam topping cycle and then mixed with the production fluids. 
Figure 25. Case $5 \mathrm{~B}$ - Brine is extracted before the binary-cycle preheaters. It is then heated in the condensers of a three-stage steam topping cycle and then mixed with the production fluids.

\section{List of Tables}

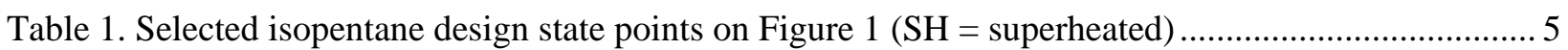

Table 2. Comparison of design and actual operating conditions and generation........................................ 5

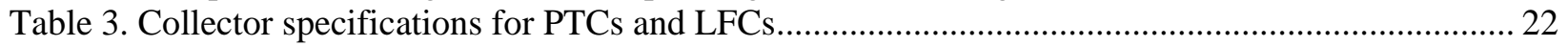

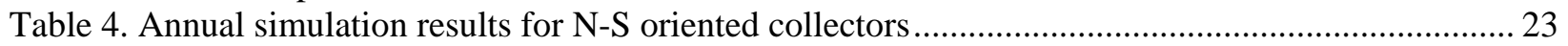

Table 5. Installed capital costs for brine-preheating, dual-turbine topping-cycle, and single-turbine topping-cycle hybrid-plant configurations ........................................................................ 26

Table 6. Economic factors used in LCOE calculations..................................................................... 27

Table 7. Solar heat input, marginal solar efficiency, and additional power generation for candidate Raft

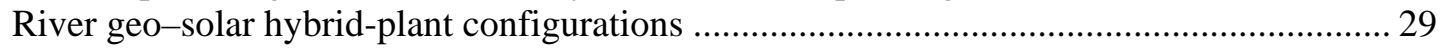

Table 8. Typical solar properties at various geothermal plant locations in the USA................................ 31

Table 9. Electrical work output, solar conversion efficiencies, and LCOEs of hybrid plants in different

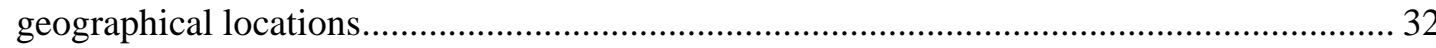

Table 10. Tax incentives reduce LCOE significantly, even for high storage costs. Systems include four

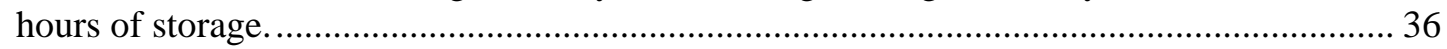

Table 11. Current solar-field costs, and target costs based on the DOE SunShot target. (Costs without tax

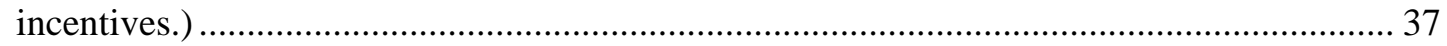

Table 12. Capital cost assumptions for photovoltaic cells and lithium-ion batteries................................ 39

Table 13. Comparison of costs and LCOEs for a hybrid plant and a photovoltaic array with batteries. Both plants are located in Burley, Idaho (without tax incentives) ................................................. 39

Table 14. Comparison of costs and LCOEs for a hybrid plant and a photovoltaic array with batteries. Both plants are located in Imperial, California................................................................................ 39

Table 15. Preliminary results comparing several hybrid geothermal-solar configurations. These results are for the case where the solar-field heat input restores the geothermal plant to its design point.

Table 16. List of equipment, equipment sizing, and installed capital costs for brine-preheating, dualturbine topping-cycle, and single-turbine topping-cycle hybrid-plant configurations ............ 55 


\section{Study Basis}

\section{Motivation}

Greater deployment of moderate-temperature geothermal binary power plants (GBPP) and concentrating solar power (CSP) may be limited in some markets by their respective generation characteristics and/or levelized cost of electricity (LCOE). Worldwide, both geothermal power and CSP are under intense pressure from the rapidly dropping cost of solar photovoltaic (PV) and wind energy. In the United States, there is further pressure from the ongoing era of low natural gas prices. CSP can generate high-temperature thermal energy that enables high cycle efficiency and low-cost thermal storage systems, and GBPP can produce baseload power generation. Hybridization may take advantage of technical merits of both technologies to produce energy at an LCOE that is competitive in the future energy market, thereby increasing the adoption of both technologies.

In this report, we describe an investigation into the addition of a steam topping cycle to an existing geothermal binary power plant named Raft River, in southern Idaho. The Raft River GBPP is currently operating below its design capacity because incoming geothermal fluid temperature and mass flow rates are lower than the design value. As a result, revenue and profitability are reduced. This problem is not unique to this plant. Although not applicable to Raft River, in some power sales contracts, the reduced output may also trigger fees or penalties [1].

The extent of any resource decline is unique to that geothermal field, if it exists at all. A survey of geothermal power plants in California and Nevada found that flash plants typically experienced a temperature decrease of $0.8 \%$ per year, and the value was $0.5 \%$ for binary plants [2]. In many cases, the reduction in temperature can be offset by an increase in flow rate, such as with makeup drilling, to keep plant output constant; however, this is not always possible. In such cases, the unfilled portion of the GBPP's power sales contract provides an opportunity to install a concentrating solar plant at reduced cost because there is also unused turbine and heat-rejection system capacity (condenser and cooling tower). This has been the motivation for this study, but also for several of the other studies described below. Consequently, the results of this work are broadly applicable to other under-performing GBPPs. Future work will examine the potential to add solar thermal to a plant from the initial design, and strategies to accommodate large variations in heat input without proportionate increases in the cost of the turbines and heatrejection system of the base GBPP.

\section{Economic and Technical Drivers for a Successful Hybrid Plant}

One intrinsic limit to lowering the LCOE of geothermal binary power is physics. The Carnot efficiency describes how much of any energy source can be converted to electricity. The higher the maximum temperature of the system, the higher the percentage of energy that can be converted to electricity. In operating GBPPs, only 12\%-15\% of the incoming energy is typically converted to electricity. The same physics applied to the relatively high temperatures of concentrating solar thermal results in 30\%, or more, of the energy being converted to electricity. Modern combined-cycle gas-turbine power plants with even higher temperatures can now achieve a $60 \%$ conversion of the available energy (on a low heating-value basis). 
Integrating solar thermal and geothermal has been proposed previously in other studies, pilot plants, and at least one commercial installation. One common approach of integrating solar thermal energy into existing geothermal projects is to heat either incoming or recycled injection brine to increase the temperature and/or flow rate of brine to the power plant. This approach results in an inefficient 15\% conversion rate of the solar energy because the heat is converted in the geothermal plant. Because the GBPP conversion efficiency in only half that of conventional solar thermal, this approach effectively doubles the cost per unit power of the solar collector. The solar collector itself is the most expensive part of a solar thermal plant, so solar brine heating has seldom been found to be economical, unless there are extraordinary financial incentives.

A new thermodynamically favorable approach was investigated, seeking to marry the high efficiency of traditional CSP into a GBPP. The intent was to develop a hybrid plant that would provide a lower LCOE than either technology could alone, thus improving market-penetration opportunities for both technologies. The CSP was designed to produce high-temperature steam. A back-pressure turbine extracts power from the high-exergy fluid and is designed such that the exhaust steam vaporizes the binary cycle's working fluid, thereby adding heat to the geothermal plant.

The CSP retrofit study was undertaken for the Raft River plant, which operates at only about $90 \%$ of the design inlet geothermal energy flow, and thus, was not making the contracted amount of power. However, the technology would be applicable to retrofit any existing under-performing geothermal binary power plant.

\section{Thermodynamic and Economic Evaluation Parameters}

Geothermal-solar hybrid plants are typically evaluated using techno-economic analysis. A variety of metrics are available for evaluating the plants, as follows.

The solar-conversion efficiency, or incremental or marginal solar efficiency, may be used to compare different cycles. It measures how effective the hybrid configuration is at converting the additional thermal input (i.e., the solar energy added) into useful work (net power, which is the gross power minus the associated parasitic loads). Two main definitions exist and differ in the denominator. In one definition, the incremental solar energy added to the cycle is that which is actually collected and transferred to the main power cycle. The second is where the incremental solar energy is that which actually falls on the collector.

Thus, the first version of the incremental solar efficiency is defined as

$$
\eta_{\text {sol, } 1}=\frac{\dot{W}_{\text {net }}-\dot{W}_{\text {net }}^{o}}{\dot{Q}_{\text {add }}}
$$

where $\dot{W}_{\text {net }}$ is the net work produced by the hybrid plant, $\dot{W}_{\text {net }}^{o}$ is the net work that would have been produced by the geothermal plant in isolation, and $\dot{Q}_{\text {add }}$ is the thermal power added to the hybrid power cycle. It does not consider the efficiency of the production of that heat, e.g., the efficiency of the solar collector. It therefore indicates the effectiveness of the hybrid power cycle. $\eta_{\text {sol,1 }}$ may be used to compare the performance of different power systems proposed in the literature without considering differences in the solar-collection technology (including projectspecific choices of collector efficiency, or advances over time in solar-collector efficiency) or 
differences in modeling of the solar field (which can be done to variable degrees of complexity). This metric can also be useful for considering heat that may have been produced and added from any other source besides solar, such as industrial waste heat or a combustion turbine.

The second definition of solar conversion efficiency includes the efficiency of generating (or collecting) the heat, and for a solar-geothermal hybrid, it is defined as

$$
\eta_{\mathrm{sol}, 2}=\frac{\dot{W}_{\mathrm{net}}-\dot{W}_{\mathrm{net}}^{o}}{\dot{Q}_{\mathrm{sol}}}
$$

where $\dot{Q}_{\text {sol }}$ is the total power incident on the solar collectors. This definition accounts for the optical and thermal efficiency of the solar field, and any other thermal losses that may occur in it. $\eta_{\mathrm{sol}, 2}$ is a measure of the complete hybrid system and necessarily $\eta_{\mathrm{sol}, 2}<\eta_{\text {sol,1 }}$.

Another common measure of the overall plant performance is given by the first or second law efficiency, which accounts for the net power produced, and the total heat (or exergy) added to the system. Care must be taken when comparing values presented in the literature because different definitions of these efficiencies exist. For instance, when considering the exergy available in the geothermal stream, some authors use the available work that could be extracted if the geothermal fluids are taken to the dead state-i.e., to ambient temperature and pressure. (Of course, ambient temperature and pressure varies from study to study.) Other authors argue that geothermal fluids are typically re-injected at reasonably high temperatures and pressures to support the geothermal resource, and that the available work in the flow is the difference between the exergy of the production and injection fluids. However, this definition penalizes the performance of an "efficient" plant that extracts considerable heat from the available geothermal flow. Because of this variability in definition - and hence, in the calculated "efficiency" - this metric is not used in this study.

The LCOE is commonly used to evaluate many types of electric power plants, including the hybrid plants of this study. Several definitions exist, and the one used in this report uses the fixed charge rate (FCR) method described in section 3.5. The LCOE is defined differently if the proposed system involves retrofitting an existing geothermal plant or installing a full hybrid system in a greenfield installation. The retrofit analysis of this study assumes that the existing plant is a "sunk" cost and not relevant to the equipment additions being considered. Comparing the LCOE among different studies is problematic because of different methods and economic assumptions (e.g., lifetime, discount rate, overhead) used in the literature, but often the costs assigned to certain components (especially the solar field) can vary widely between research articles and over time. This is particularly relevant to hybrid system retrofits, where the total capital cost is dominated by the cost of the solar field. Solar-field costs have decreased rapidly in recent years, and the LCOEs reported in articles several years old could be high, and thus, outdated. LCOEs are best used within one article, rather than comparing between research projects. A detailed review of assumptions and standardization to a single common set of parameters is required to compare LCOEs between research projects.

\section{Description of Raft River Geothermal Power Plant}

The Raft River geothermal power plant uses a dual-pressure-level binary cycle (organic Rankine cycle) and was designed and constructed by Ormat. The basic power cycle was described in 
detail in two previous publications [3], [4]. A high-pressure (HP) and low-pressure (LP) turbine are connected on either side of a common generator. Both sides are separated from each other and use isopentane as the working fluid. The heat-rejection system is a shell-and-tube condenser with a 4-cell cooling tower. Geothermal brine flows into the HP and LP vaporizers in series, and then the brine splits to feed the preheaters of both systems. The cooled brine is then injected into the geothermal reservoir. Figure 1 is a process flow diagram of Raft River plant, with selected state points in Table 1 and Table 2.

The plant began commercial operation in 2006 and has run at a high plant availability ever since. However, the reservoir was never able to provide sufficient flow to the plant; so, the output of the plant has been below the contract maximum. This reduced output was what drove the interest in the study of a solar thermal retrofit of the plant.

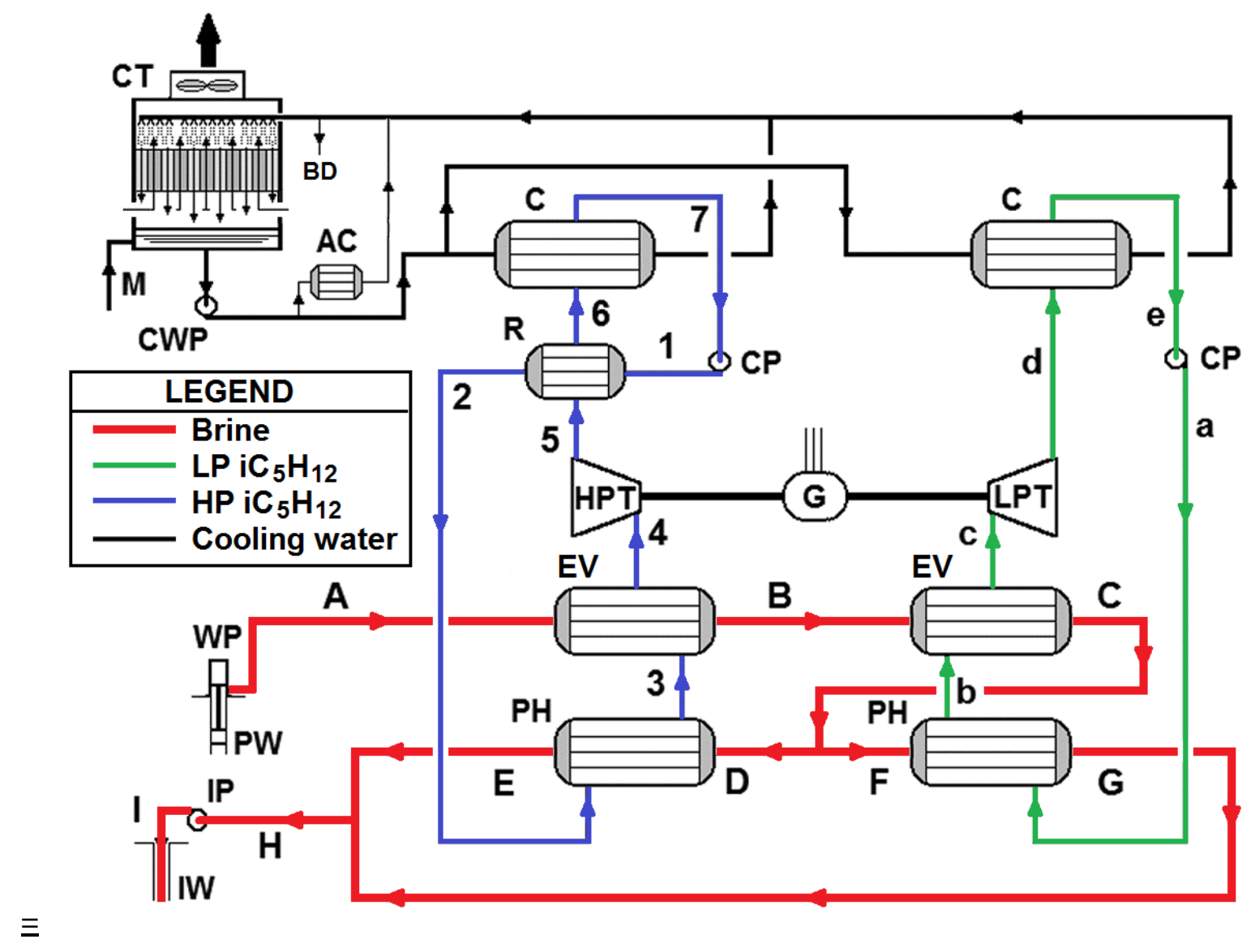

Figure 1. Raft River Geothermal Power Plant Process Flow Diagram. Key: CT: cooling tower; EV: evaporator; HPT: High-pressure turbine; LPT: Low-pressure turbine; PH: Preheater; CWP: Coldwater pump; PW: Production well; IW: Injection well; G: Generator; CP: Circulation pump. 
Table 1. Selected isopentane design state points on Figure 1 ( $\mathrm{SH}=$ superheated)

\begin{tabular}{lcrrl} 
State & Description & $P$, psia & \multicolumn{1}{l}{$T{ }^{\circ} \mathrm{F}$} & $x$ \\
\hline \multicolumn{2}{l}{ HP Isopentane Cycle } & & & \\
7 & Condensate & 13.0 & 67.80 & 0 (saturated) \\
4 & Turbine inlet & 138.7 & 236.35 & 1 (slight SH) \\
5 & Turbine exhaust & 13.0 & 144.31 & 1 (high SH) \\
LP Isopentane Cycle & & & \\
e & Condensate & 12.7 & 66.90 & 0 (saturated) \\
C & Turbine inlet & 74.3 & 184.54 & 1 (slight SH) \\
d & Turbine exhaust & 12.7 & 118.74 & 1 (mod SH) \\
\hline & & & &
\end{tabular}

Table 2. Comparison of design and actual operating conditions and generation

\begin{tabular}{lcrrrr} 
State & Description & \multicolumn{2}{c}{ Design Point } & \multicolumn{3}{c}{ Current Op. } \\
\hline \multicolumn{2}{l}{ Geothermal Brine } & Flow, Klbs/hr & T, ${ }^{\circ} \mathrm{F}$ & Flow, Klbs/hr & T, ${ }^{\circ} \mathrm{F}$ \\
A & To Plant & 3,150 & 280 & 2,700 & 272 \\
H & From Plant & 3,150 & 150 & 2,700 & 145
\end{tabular}

\begin{tabular}{|c|c|c|c|c|}
\hline Generation & $\mathrm{MW}_{\text {gross }}$ & $M W_{\text {net }}$ & $\mathrm{MW}_{\text {gross }}$ & $\mathrm{MW}_{\text {net }}$ \\
\hline Power Cycle, no brine pumps & 15.9 & 13.7 & 13.8 & $\sim 11.7$ \\
\hline
\end{tabular}




\section{Screening and Review of Geothermal and Solar Thermal Hybrid Technologies}

Several methods of integrating geothermal power and solar thermal power have been proposed, including but not limited to: using geothermal energy within a primarily solar thermal power plant, using solar thermal power in a geothermal steam power plant, and using solar thermal power in a binary geothermal power plant. This study evaluates the last option. The solar heat may be added in several ways, and potential locations are schematically illustrated in Figure 2. These options are discussed in more detail below.

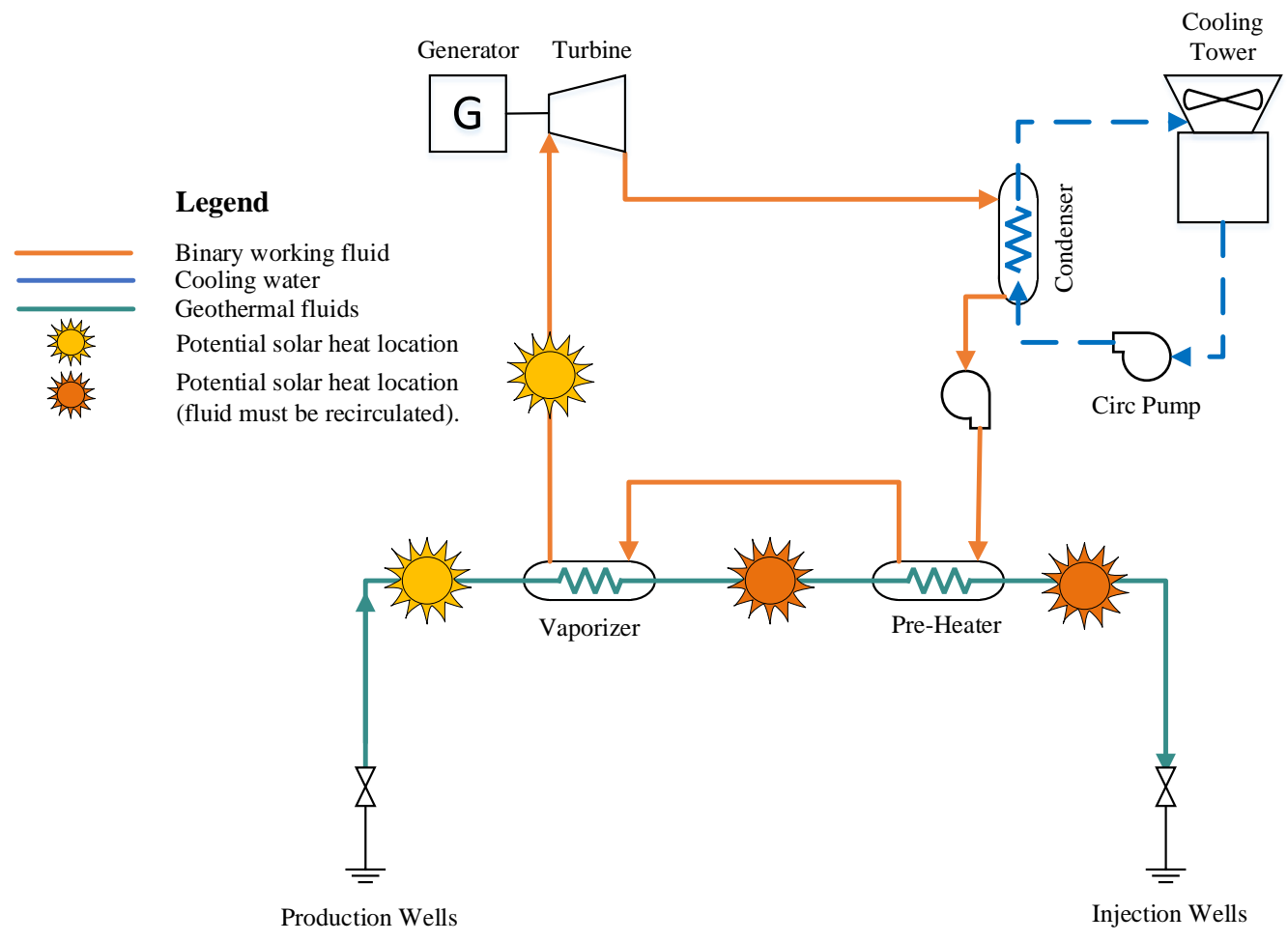

Figure 2: A simplified geothermal binary cycle with potential solar heat addition locations noted. The solar heat can be added directly, or first drive a high-temperature topping steam turbine. If cooled brine is heated, this brine is then recirculated to mix with the production fluids.

\section{Overview: Methods and Technologies Used for Adding Solar-Thermal to a GBPP}

In general, previous examinations can be grouped such that the solar heat is added to one of three places in the GBPP:

1. Heating geothermal brine: Either increase the temperature of brine from the production wells before it gets to the GBPP, or take a stream of cooled/cooler brine and increase its temperature. The former raises temperature but not flow rate, whereas the latter increases flow rate and may or may not result in an increase in brine temperature compared to the no-solar condition. 
2. Superheating working-fluid vapor: Saturated or slightly superheated vapor is produced from the GBPP, and then the vapor on the way to the turbine is superheated significantly above saturation.

3. Increasing vapor flow to turbine: The solar heat is used to vaporize the GBPP working fluid, and the additional vapor is added to the flow of vapor from the geothermal brine heat exchangers.

Typically, two primary ways of collecting solar thermal heat and adding it to a GBPP are considered:

1. Directly heating fluids going to or within the GBPP with no additional turbines and generators. This generally results in solar thermal collection temperatures slightly higher than that of the GBPP.

2. Collecting the solar heat at a much higher operating temperature than the GBPP, and then, through additional turbine/generators, directly generating solar-thermal electricity. Heat from the exhaust of the solar-thermal turbine is used to heat one of the fluids in the GBPP.

It is also worth noting in the interest of fully describing the ranges of options for hybrid technology that there are various solar-collection technologies available. For instance, solar heat may be collected in parabolic troughs, linear Fresnel reflectors, or power towers. The heat is transferred to a working fluid, which may be a thermal oil, water/steam, or molten salts. In this application, it was decided that readily available conventional technology should be used that is commonly used in these relatively small solar-thermal collectors. This led to selecting a linear collector with a thermal oil heat-transfer fluid (HTF). In Section 3.5, various parabolic troughs and linear Fresnel reflectors are compared, with parabolic trough being chosen as the study basis. The selection of collector and heat-transfer medium would be revisited in a more detailed study.

\section{Raft River Solar/Geothermal Hybrid Cycle Screening Evaluation}

Funding for this study was provided with the specific intention of evaluating a hybrid cycle with a high-temperature (exergy) solar steam topping cycle to extract net electric power from the energy collected in the solar field - after which the steam would then be cascaded to add solar heat to the GBPP to fill the plant's under-used turbine and heat-rejection system capacity. However, it was recognized that the proposed system was substantially more complex and expensive than some of the simple solar-heat addition cycles that had been studied and/or constructed. To get a feel for whether the project concept would yield a substantial improvement in economics, the initial work was a high-level screening evaluation at a single operating point using the HYSYS software package, calibrated to the original design process flow diagram (PFD).

Further details about the screening study methodology and results are provided in Appendix A. The configurations studied included brine preheating, recirculated brine heated directly by the solar field, and various configurations using a steam topping cycle where the exit flow heated either the brine or the binary-cycle working fluid. The results confirmed that the proposed cycle, 
using topping steam turbines, delivered the best performance in terms of electrical power generation and solar efficiency.

\section{Description of Preferred Cycle}

The screening study was a simplified comparison of cycle options, and it identified a system with a topping cycle as the most promising configuration-known here as Case 1. More detailed models were then developed and validated against operational data, and the underlying assumptions were refined. Exhaust heat from the steam turbines vaporizes GBPP working fluid (isopentane) to increase flow to the binary-cycle turbines. This is accomplished through a condenser/vaporizer (con/vap), which is a heat exchanger in which steam condenses on one side, which releases heat, and the isopentane is vaporized on the other side. Several variations on this cycle were considered:

\section{Case 1A: Two High-Pressure Steam Topping Turbines}

The original concept for the study was to use the solar field to generate high-pressure, hightemperature steam. The steam would be converted to power using two steam topping turbines with a backpressure saturation temperature about $20^{\circ}-30^{\circ} \mathrm{F}$ above the isopentane vaporization temperature.

The Raft River binary cycle has two pressure levels, so adding solar thermal heat to both sides was expected. Thus, the topping cycle was initially laid out with two steam turbines with different condenser pressures to produce isopentane vapor at the two different turbine inlet pressures. This configuration is referred to as Case 1A and is illustrated in Figure 3.

\section{Case 1B: One High-Pressure Steam Topping Turbine with a Steam Crossover}

When the cycle using two steam turbines was first analyzed, it was noted that little solar steam was used in the low-pressure (LP) con/vap. Consequently, an alternative option is to use a single steam turbine, referred to as Case 1B, shown in Figure 4

. The key variation of Case 1B from Case 1A is that instead of using a very small, dedicated turbine to provide the small steam load of the LP con/vap, only the steam turbine serving the HP side of the GBPP is used. Some of the steam from the HP turbine exhaust is crossed over to the serve the LP con/vap, with most of the turbine steam being used in the HP con/vap. This results in a small loss of efficiency, because the steam is throttled as it is dropped from the HP turbine exhaust to the LP con/vap. However, the amount of steam being crossed over is small, and the pressure loss is also small. Consequently, there is only a small reduction in the output of this option compared to the two-turbine option.

Case 1C: One High-Pressure Steam Topping Turbine and Reduced GBPP HP Isopentane Vapor Flow

Late in the study, another variation was considered, which was to eliminate the LP con/vap and the steam crossover valve from the discharge of the HP steam turbine. Instead of adding solar energy to bring the LP turbine back to design output, less geothermal energy was extracted from the HP portion of the GBPP, allowing more geothermal energy to be extracted by the LP side of 
the GBPP. There are at least two ways to accomplish this: reduce the flow of isopentane to the HP vaporizer, or use the HP vaporizer brine bypass line to reduce the amount of geothermal energy flowing into the HP vaporizer. A schematic diagram is presented in Figure 5.

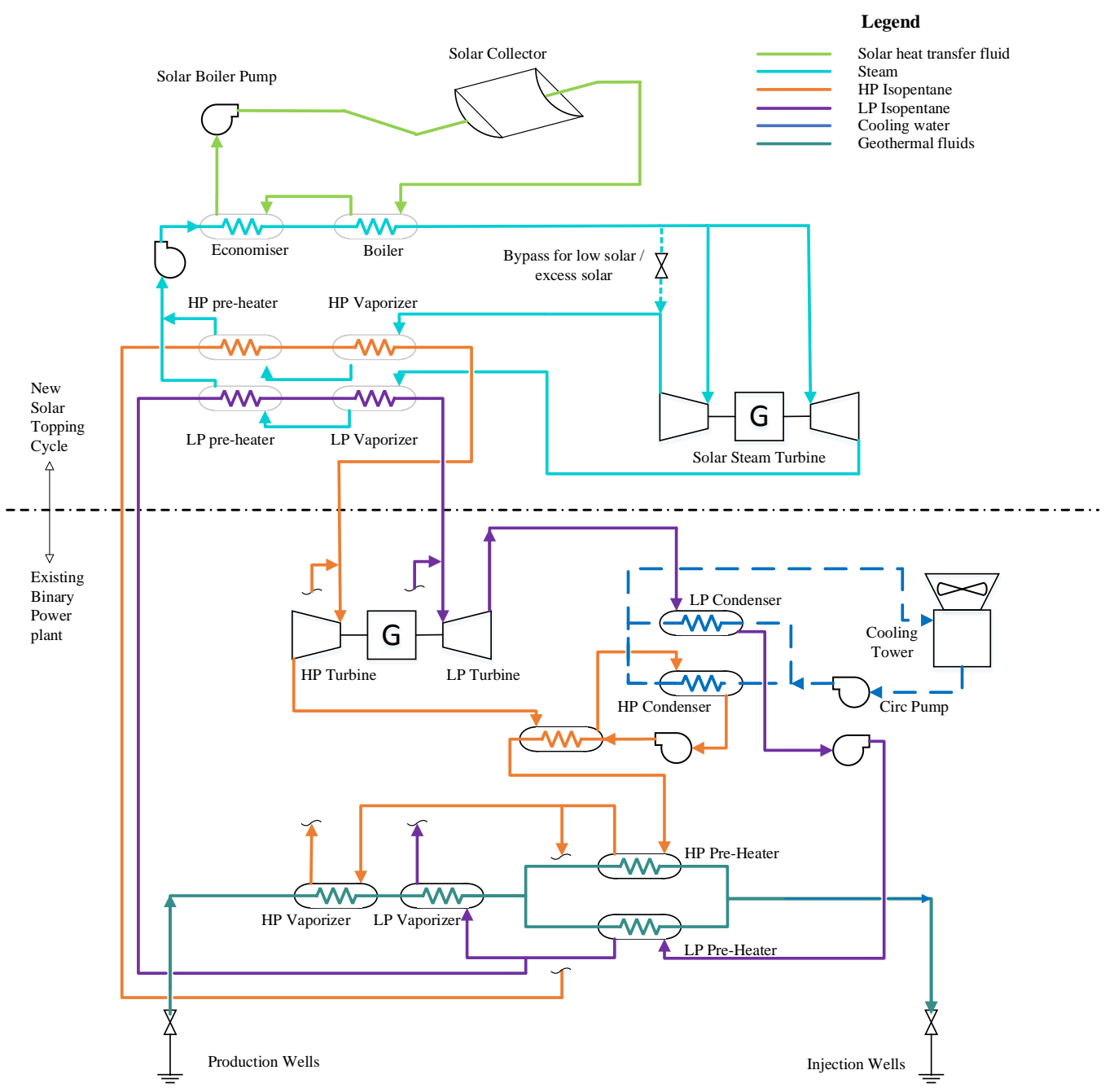

Figure 3. Case 1A-Process flow diagram of the hybrid solar-geothermal system with two steam turbines. 


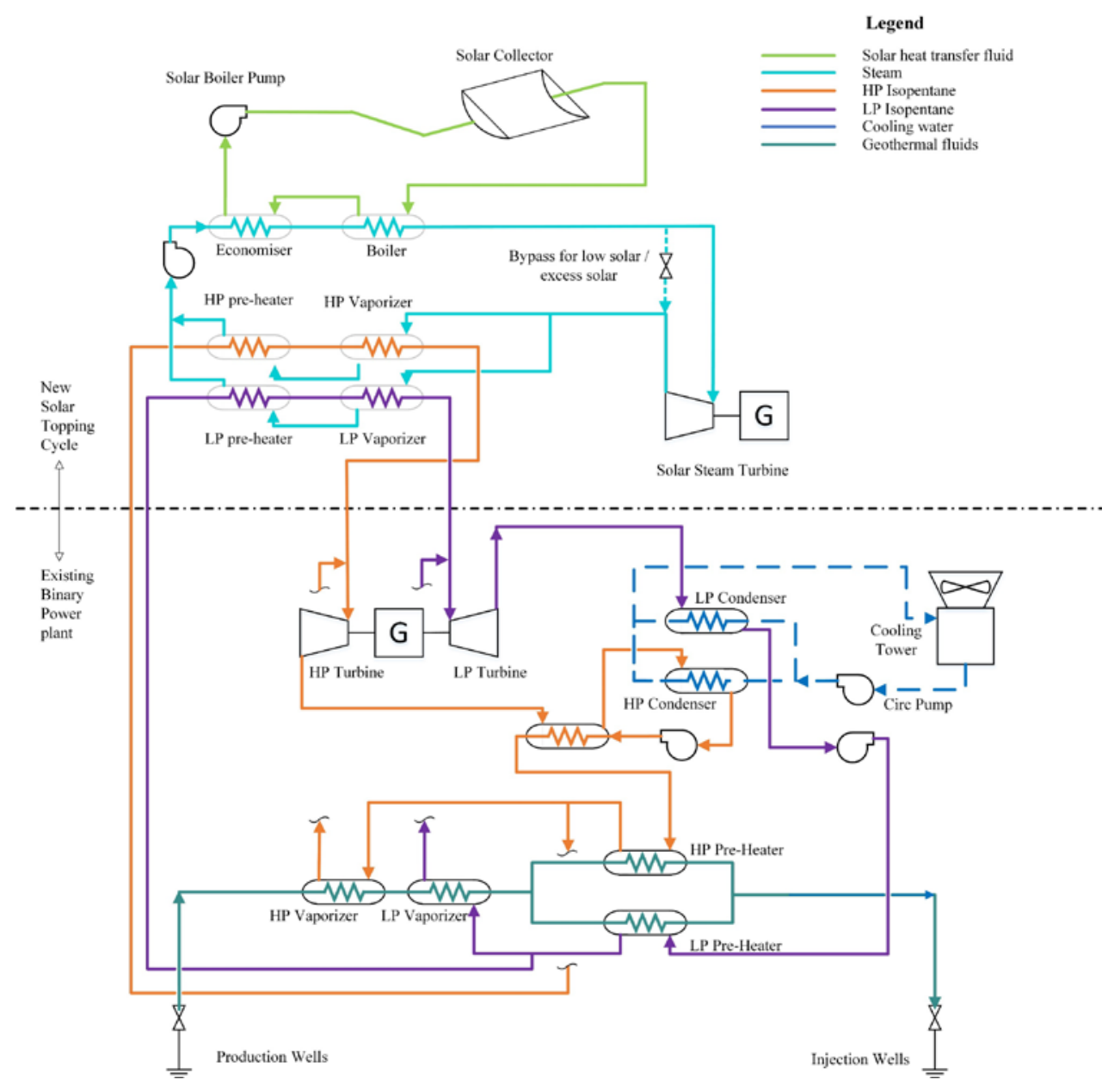

Figure 4. Case 1B-Process flow diagram of the hybrid solar-geothermal system with one steam turbine. Steam turbine exit flow heats both the HP and LP working-fluid cycles. 


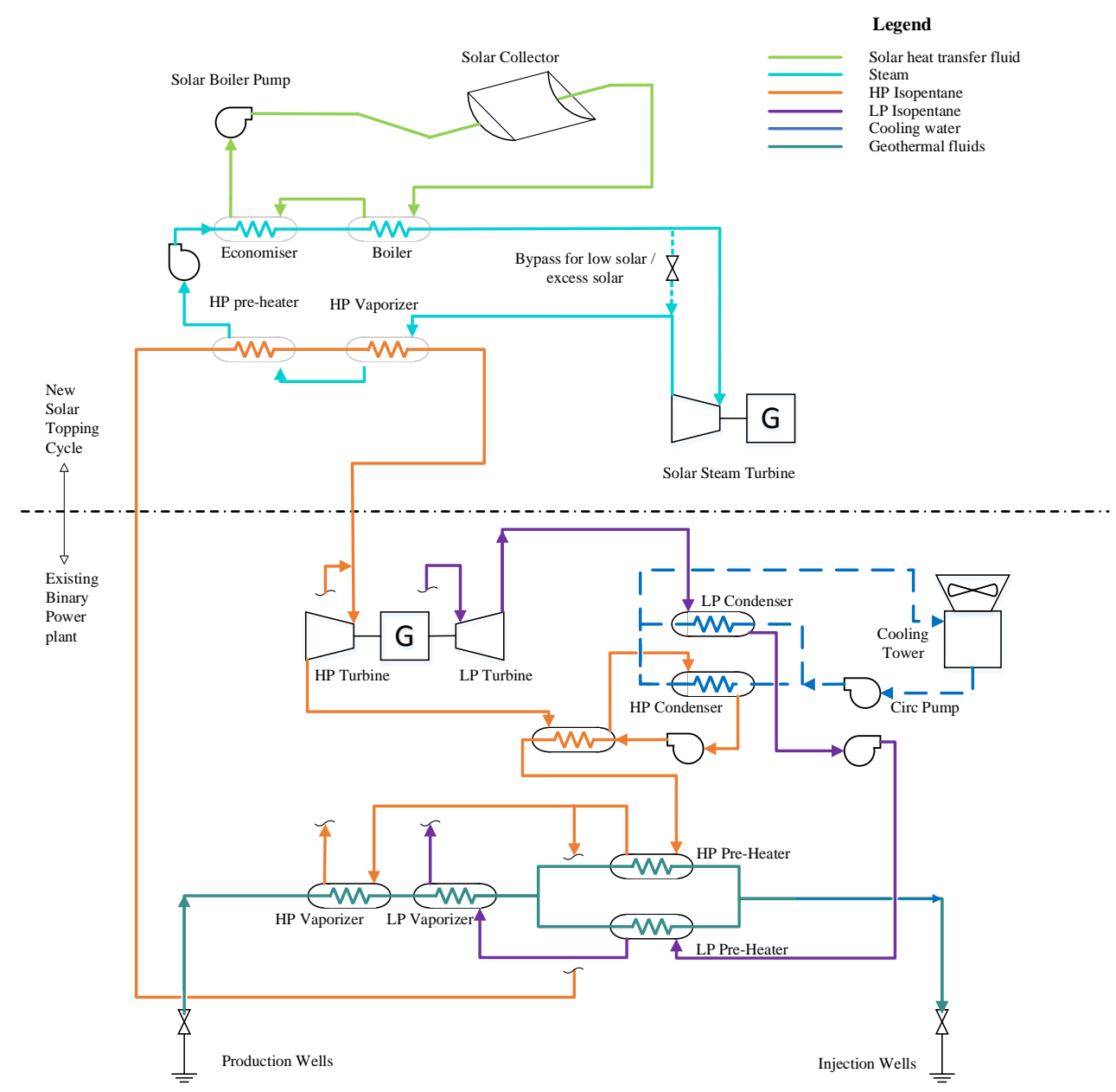

Figure 5. Case 1C-Process flow diagram of the hybrid solar-geothermal system with one steam turbine. Steam turbine exit flow heats only the HP working-fluid cycles.

\section{Literature Review}

Previous research has investigated hybrid systems using binary plants and single-/double-flash plants, and numerous methods for integrating the two systems have been proposed. The most suitable hybridization scheme is unique to each plant, depending on the geothermal fluid properties, the solar resource, and whether the plant is a new development or a retrofit of an existing system. Methods of hybridization can be broadly categorized as follows:

1. The geothermal system provides feedwater heating to a solar-driven power cycle [5], [6].

2. Solar heat is added to the geothermal fluids at some point in the cycle [1], [7]-[13].

3. Solar heat is used to vaporize and/or superheat the power-cycle working fluid [14]-[17].

4. Solar heat drives a topping cycle, with heat rejected into the bottoming geothermal cycle [18], [19]. 
Comparing results between studies is challenging because technical assumptions and economic parameters can vary widely. In the literature review that follows, most of the reported LCOEs are typically too high to be commercially viable. However, the approach may still have merit for various reasons, including different economic assumptions, and better and cheaper solarcollector systems. For instance, previous studies typically assume collector costs around 250 $300 \$ / \mathrm{m}^{2}$, whereas more recent estimates are closer to $150 \$ / \mathrm{m}^{2}$.

\section{Geothermal Heat Integration into a CSP Plant}

One of the first hybrid plants was proposed in 1979 and used geothermal heat for feedwater heating and solar heat to generate steam for a steam turbine [6]. At the time, these hybrid plants demonstrated no economic advantages over stand-alone geothermal plants. However, CSP prices have dropped significantly and it is appropriate to reconsider this technology. More recently, Turchi et al. [5] also considered a similar system that reportedly converted geothermal energy to electricity at an efficiency 1.7 to 2.5 times greater than would have occurred in a stand-alone geothermal binary power plant. Thermodynamically, this is good use of geothermal energy because the available energy is "upgraded" with more temperature to increase the efficiency of conversion. Furthermore, it is a relatively simple configuration and could reduce costs if inexpensive geothermal wells can be drilled near the CSP plant. However, geothermal heat is only used to heat the water going to the CSP boiler, whereas generating steam for the CSP plant requires significantly larger quantities of energy. Hence, the reduction in solar-collector cost resulting from the geothermal preheater is small and may not significantly change the economics of the CSP plant.

\section{Solar Integration Geothermal Power Plants by Direct Brine Heating}

The first commercial-scale geothermal-solar hybrid plant was developed at the Stillwater Power Plant, Nevada, and began operation in 2015. A solar field of parabolic trough collectors supplies

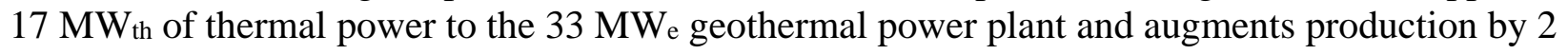
$\mathrm{MW}_{\mathrm{e}}$ [20]. Note that the incremental solar efficiency is $2 / 17=11.8 \%$, which is lower than the results from the screening study and could be due to a variety of factors, including that the screening study did not sufficiently account for the parasitic loads of the solar field. The plant also includes a 26-MWe PV solar array, which offsets the decrease in power generation that occurs at high ambient temperatures [21].

Operators of the 13.2-MWe Gümüşköy geothermal binary plant in Turkey aimed to reduce the detrimental impact of high ambient temperatures by using solar heat to augment generation [22]. Tests were conducted with a 200-kW th array of parabolic trough collectors in 2014.

\section{Solar Integration by Heating Working Fluid in a Geothermal Binary Power Cycle}

Research articles that investigated hybridizing binary cycles with solar initially concentrated on using the solar heat to vaporize (and sometimes superheat) the organic Rankine cycle (ORC) working fluid. Manente et al. [23] proposed such a hybrid cycle that could overcome variations in the geothermal fluid flow rate and temperature, and the effect of ambient temperatures. They also included thermal storage in the model and demonstrated that this could increase the quantity 
of energy generated. An LCOE analysis gave the cost of the retrofit system as $0.18-0.19 \$ / \mathrm{kWh}$. This high cost is heavily influenced by an expensive solar field at $300 \$ / \mathrm{m}^{2}$.

Although Manente et al. did not evaluate the solar conversion efficiencies, a similar hybrid system was investigated by Astolfi et al. [16], where solar heat vaporized the ORC working fluid. (Note that Astolfi et al. studied a supercritical cycle, whereas Manente et al. investigated a subcritical cycle.) Astolfi et al. achieved solar conversion efficiencies of $\eta_{\text {sol, } 1}=15.1 \%-16.8 \%$ and $\eta_{\text {sol,2 }}=8.6 \%-9.4 \%$. (This indicates that the overall efficiency of the solar collectors was $56 \%-57 \%$.) This proposed system is also a retrofit, and as such, it faces technical challenges because the turbine inlet temperature of the hybrid plant is $200^{\circ} \mathrm{C}$, compared to $150^{\circ} \mathrm{C}$ in the original plant design. The authors considered several locations for the hybrid plant in California and Italy, and they evaluated the LCOE to be $0.145-0.280$ euro/kWhe $(0.22-0.43 \$ / \mathrm{kWh})$ for a solar-field cost of 175 euro/m² $\left(268 \$ / \mathrm{m}^{2}\right)$.

Ghasemi et al. [14] and Ayub et al. [15] considered a slightly different approach to vaporizing the ORC working fluid. Rather than using the geothermal fluid to preheat the working fluid and the solar heat to vaporize it, the working fluid is preheated by the brine and then split into two streams. One stream is vaporized by the geothermal fluid and the other by the solar heat. The maximum solar efficiency achieved was $\eta_{\text {sol, } 2}=7.8 \%$. The LCOE of a new-build hybrid plant was $0.066 \$ / k W h$, compared to a stand-alone geothermal plant LCOE of $0.065 \$ / \mathrm{kWh}$.

Zhou et al. [19] also considered a system similar to those proposed above and improved the design by introducing a topping cycle. The binary-cycle working fluid was superheated by the solar collectors and then expanded through an additional turbine. The turbine outlet provided heat to the bottoming-cycle recuperators. The LCOE of a greenfield design was found to be 0.17 $\$ / \mathrm{kWh}$ with a solar-collector cost of $250 \$ / \mathrm{m}^{2}$. This was compared to stand-alone CSP systems and an enhanced geothermal power plant, which were 0.113-0.156 \$/kWhe and 0.225 \$/kWhe, respectively. If a retrofit was feasible (that is, only the solar plant required construction), then the LCOE decreased to $0.10 \$ / \mathrm{kWh}$.

Bonyadi et al. [18] also investigated retrofitting a geothermal plant with a solar-driven topping Rankine cycle. In the proposed system, the steam-turbine exit flow is used to heat up a fraction of cooled geothermal brine from the GBPP. The reheated brine is then added to the production fluids, thereby increasing the mass flow rate of brine through the geothermal plant, and increasing the power output, similar to case 3A in the screening study in Appendix A. The authors also described a system whereby the geothermal fluid mass flow rate could be kept constant. Because brine is recirculated, the rate of fluid extraction from the reservoir is reduced, which they report can increase the reservoir lifetime. This system had a solar conversion efficiency of $\eta_{\mathrm{sol}, 2}=12.2 \%$ and an LCOE of $0.163 \$ / \mathrm{kWh}$ assuming a solar-field cost of 250 $\$ / \mathrm{m}^{2}$. Furthermore, the geothermal fluid extraction over a year was reduced $17.1 \%$.

Another option for an integrated cycle meant to take advantage of high temperatures - and the efficiency they engender - was proposed by Zhou [17]. In the study, subcritical and supercritical binary cycles were designed with the geothermal fluid heating the working fluid up to around $150^{\circ} \mathrm{C}$ and the solar system increasing the temperature up to $400^{\circ} \mathrm{C}$. Zhou noted that the heat addition was more effective in supercritical cycles, which were therefore able to attain higher temperatures. The author considered designs with various sizes of solar field and found that 
larger fields led to higher solar conversion efficiencies: up to $\eta_{\mathrm{sol}, 2}=14.4 \%$. Zhou calculated the LCOE if the solar field was added as a retrofit, with costs as low as $0.10 \$ / \mathrm{kWh}$.

\section{Sizing of the Solar Field and the Use of Thermal Storage}

The above research articles provide a detailed overview of hybrid plant configurations, efficiencies, and costs reported in the literature. However, most papers seemed to size the solar field to provide the design quantity of heat at optimal solar conditions (normally 950 or 1,000 $\mathrm{W} / \mathrm{m}^{2}$ ). This means that for the majority of the year, the power plant operates at less-efficient, off-design solar heat input conditions. In conventional CSP plants, the solar field is typically oversized so that the plant can operate close to its design point for a greater portion of the year. However, if too much solar energy is available, this power has to be curtailed through defocusing of the mirrors or stored if sufficient thermal energy storage (TES) is available. These proven techniques in the CSP industry are not widely presented in the geothermal-solar hybrid literature.

An evaluation of oversized fields and storage was investigated in a previous paper by Bassetti et al. [13]. They demonstrated that these methods could increase the total electricity dispatched by the system by $5 \%-6 \%$. However, the authors did not undertake a comprehensive survey of different storage and solar-field sizes; nor was an economic analysis presented.

In section 4, oversized fields are evaluated, as well as the use of thermal storage. Both are evaluated on their ability to increase annual generation, but also, on the effect on the hybrid LCOE. It is found that oversized solar fields and TES both reduce the cost of the hybrid plant. This is a valuable approach to use in future geothermal-solar hybrid studies.

\section{Modeling Methodology}

The geothermal binary power plant was modelled with the flow-sheeting software IPSEpro. The additional heat integration from the solar field was also included in this model. The model was used to develop regression equations of hybrid plant performance with solar heat input and ambient temperature. The performance of the solar collector field was evaluated using the System Advisor Model (SAM). This model calculated hourly ambient temperatures and solar thermal heat available to the hybrid plant. The output of these two models were combined in an Excel spreadsheet and the hybrid plant performance was calculated for every hour of the year. Figure 6 gives a schematic representation of the various tools used in the modeling work. The influence of various solar field sizes and thermal storage durations was also investigated. The annual calculations were then used to evaluate the levelized cost of electricity. 


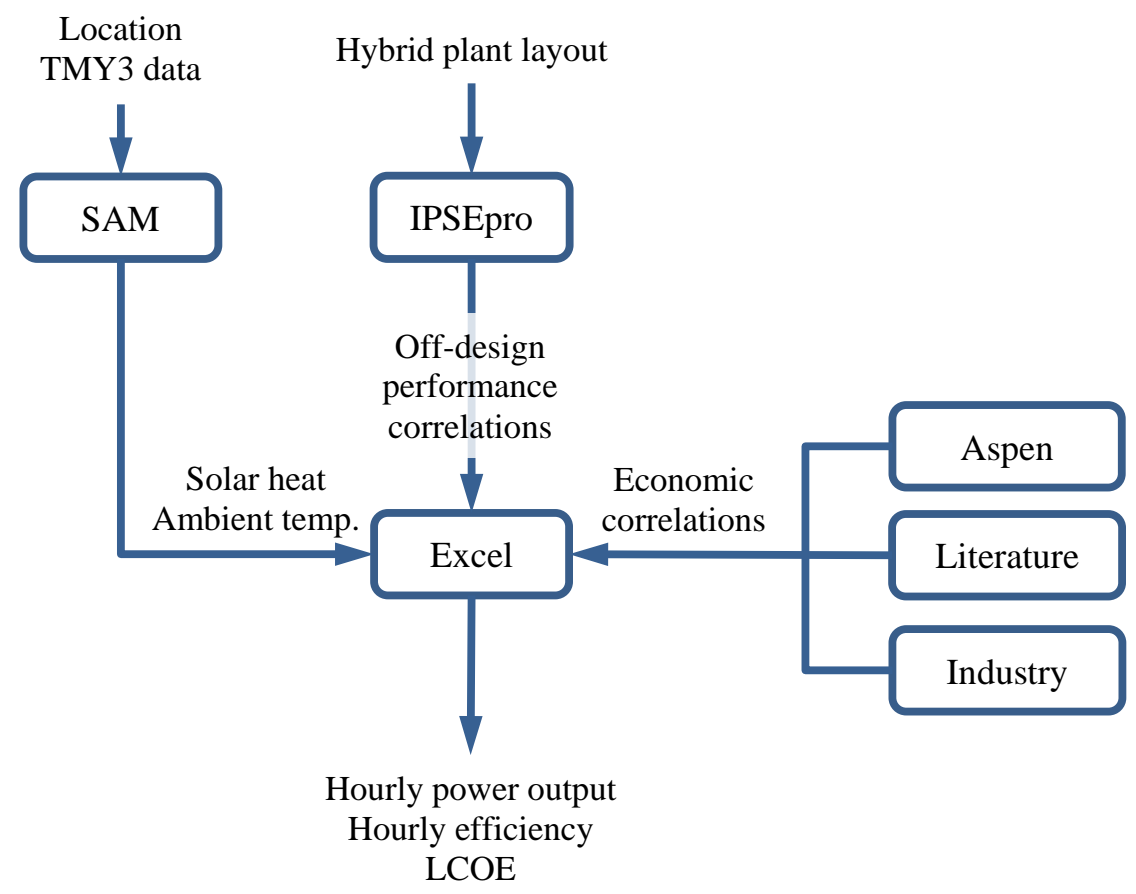

Figure 6: Analysis tools and flow of data for evaluation of hybrid plant performance.

\section{Modeling of the original Raft River GBPP with IPSEpro}

SimTech IPSEpro Process Simulation Environment version 7.0 U, Release 12, Build 1744 software was used to model the performance of the Raft River geothermal power plant-both with and without the addition of the solar topping cycle. Process flow diagrams of the Raft River power plant obtained from US Geothermal provided the mass and energy balance data used to develop the ORC power-block model. The Raft River design-point PFD was used to establish equipment sizing parameters and design-point process operating conditions and performance. The Raft River off-design PFDs were used along with additional equipment performancespecification data to adjust the model input parameters to accurately simulate off-design process performance.

The Raft River ORC power plant comprises two turbines with a shared generator configured to extract heat from a common geothermal brine feed stream using preheaters and vaporizers. Both turbines use isopentane working fluid, with the L1 unit having a higher turbine inlet pressure than the L2 unit. The L1 unit includes a recuperator at the discharge of the turbine to capture isopentane superheat, whereas the L2 unit does not. The separate L1 and L2 condensers are water-cooled.

The Raft River ORC cycle model incorporates sub-models of major process equipment including the working-fluid preheaters, vaporizers, condensers, L1 recuperator, ORC turbine-generator set, evaporative cooling tower, working-fluid feed pumps, control valves, and all associated piping. The majority of the equipment sizing parameters required to simulate the Raft River ORC performance can be determined from the PFD state point data. One exception to this is the cooling tower, which has an ambient-temperature design point that varies from that of the remainder of the power block. Separate cooling-tower design and off-design data were used to 
specify the parameters required for the cooling-tower model, which uses the Merkel method to predict cooling duty as a function of the wet-bulb temperature and fluid flow rates.

Off-design heat-exchanger performance is determined by correcting the design UA (product of the heat-transfer area and overall heat-transfer coefficient) as predicted by the appropriate heattransfer correlations, e.g., shell-and-tube heat-exchanger tube-side heat-transfer coefficients modeled as proportional to $\mathrm{Nu}^{0.8}$ [24], whereas the shell-side heat-transfer coefficients are modeled as proportional to $\mathrm{Nu}^{0.6}$ [25]. Rotating-equipment design-point efficiency was calculated from power input/output and stream data, and representative rotating-equipment performance curves from equipment manufacturers were used to estimate off-design performance. Finally, pressure loss in heat exchangers and process piping was adjusted for offdesign conditions by adjusting the pressure drop in proportion to the square of the fluid velocity in accordance with the Darcy-Weisbach equation.

Prior to incorporating the solar topping cycle into the power-plant model, the ORC model predictions were compared with actual power-plant operating data to verify the ability of the model to accurately predict plant performance. Power-plant operating data obtained from US Geothermal was filtered to include points with brine mass flow rate within $\pm 100 \mathrm{kph}$ and brine inlet temperature within $\pm 2^{\circ} \mathrm{F}$ of typical current conditions. Additionally, the simulation data were adjusted to include typical values for parasitic loads that are not included in the flowsheet. Initial comparison of the IPSEpro model and Raft River gross and net power data indicated that the IPSEpro model was under-predicting power generation. The L1 and L2 ORC turbine designpoint efficiencies were subsequently adjusted until the model predictions matched the operating data. Although the revised turbine efficiency specifications resulted in a better match between the model off-design power-generation predictions and the power-plant operating data, this modification resulted in the model's design-point power calculation being more than $1 \mathrm{MW}$ higher at design conditions than that specified in the Raft River PFDs. However, because the objective of this study was to compare cycle options, rather than specify an actual design for the Raft River GBPP, this discrepancy was not important. Other options to calibrate the model to the performance would include geothermal heat-exchanger fouling factors, and the original performance test output compared with the guarantee-point PFDs. Such an approach could result in a model with power-generation predictions matching the Raft River design-point PFD as well as the off-design power-plant operating data.

The gross and net power predicted by the off-design Raft River IPSEpro model are plotted with power-plant operating data as a function of wet-bulb ambient temperature in Figure 7 and Figure 8 , respectively. Figure 7 and Figure 8 present gross and net power on a fractional basis, where a value of 1.0 corresponds to the design-point value. The power-plant data do not cover the full range of wet-bulb temperatures necessary to predict performance over the course of a full oneyear period. But the figures indicate that the model adequately predicts plant performance over the available range of wet-bulb temperature data. 


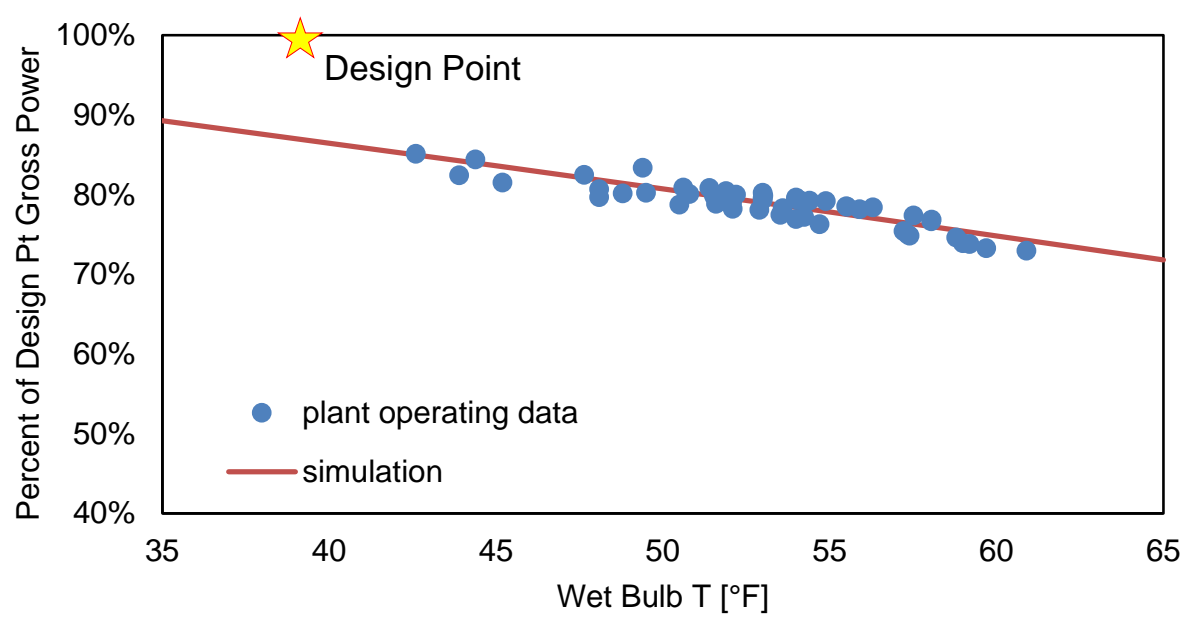

Figure 7. Comparison of gross power reported in Raft River plant operating data with predicted values.

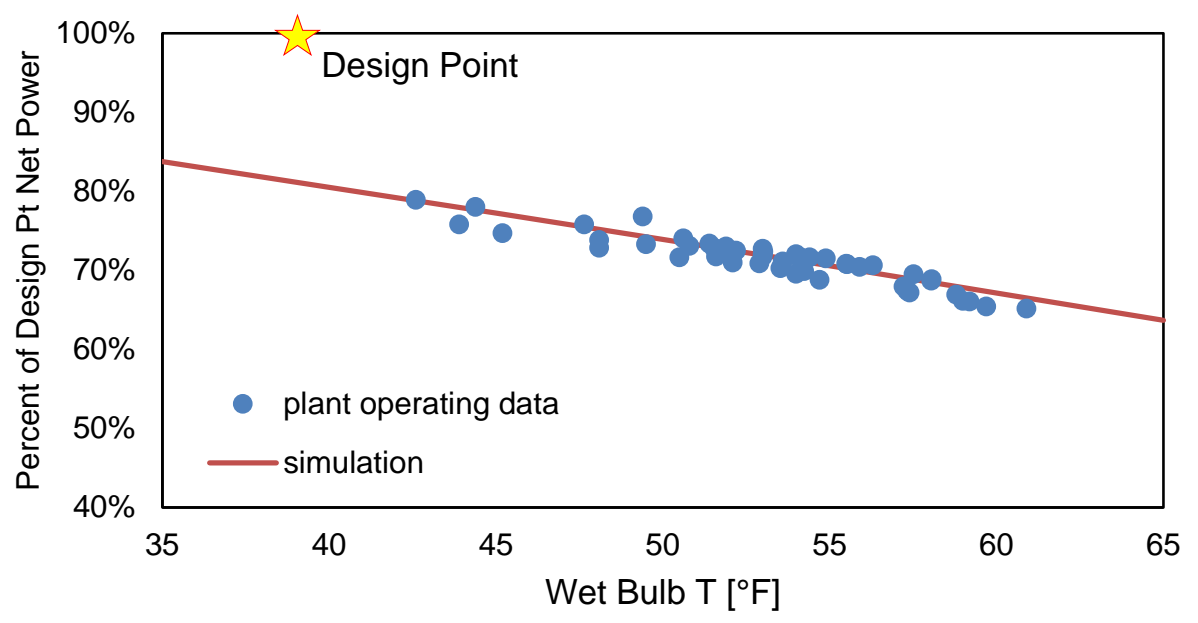

Figure 8. Comparison of net power reported in Raft River plant operating data with predicted values.

\section{Addition of Solar Heat to the Raft River GBPP in IPSEpro}

Following verification of the model's ability to adequately predict gross and net power output of the GBPP, the solar topping cycle was added to establish the integrated hybrid-plant model. As with the GBPP model, the solar topping cycle was developed with the ability to model design and off-design operating conditions. The GBPP model input parameters were specified to provide the best match with existing plant-design and operating data; but the solar topping cycle design configuration and input parameters were chosen at the discretion of the project team, with the overall goals of maximizing power output and minimizing capital costs for additional topping cycle equipment. Key solar topping-cycle design configuration and input parameters include: 
- Steam Rankine-cycle heat input is obtained via heat exchange with a heat-transfer oil that is circulated through the solar field.

- Specification of $700^{\circ} \mathrm{F}$ and 1,200 psia steam at exit of superheater.

- Turbine design isentropic efficiency of $75 \%$ specified based on personal communication with steam-turbine manufacturer.

- Minimum internal temperature approach of $5^{\circ} \mathrm{F}$ specified in steam condenser (ORC secondary working-fluid vaporizer); this specification is a primary factor in defining the size of the heat exchanger (or UA in the power-plant model).

- Total steam-cycle pressure drop of 100 psi assumed to account for losses in heat exchangers (economizer, boiler, superheater, and condenser), control valves, and piping.

In addition to the 1,200 psia steam-turbine design inlet pressure, a design inlet pressure of 700 psia was also evaluated, both at $700^{\circ} \mathrm{F}$. Although the 1,200 psia design requires equipment and piping with higher pressure ratings, it has numerous performance advantages, such as greater enthalpy drop across the turbine and lower-quality exhaust steam. These contribute to greater power generation in the steam topping cycle than with a design turbine inlet pressure of 700 psia. Annual calculations performed with an identically sized solar field indicated that a 1,200-psia topping-cycle design pressure provided greater net output and greater marginal solar efficiency than the 700-psia design. However, it remains possible that a lower inlet pressure may be preferential for one of the following reasons:

- Contract pricing of the geothermal power vs the solar-derived power.

- Availability factors of GBPP and solar field (percentage of time able to operate when fuel is present).

- Location and quality of solar resource.

- The higher exhaust enthalpy reduces the size of the solar collector, which is the most expensive component of the retrofit.

- The lower pressure rating results in significantly cheaper power-plant equipment: piping, vessels, and turbines.

- Direct-steam-generation solar collectors are used, and there is a significant difference in the resulting collector cost.

- The isentropic efficiency of the turbine improves with lower pressure and/or the type of turbine that can be used is much less expensive.

- The methods, goals, and costs of thermal storage favor one or the other option.

In summary, the selection of 1,200 psia does not represent an optimized evaluation, but it was a reasonable decision that allowed the rest of the analysis to proceed.

\section{Off-Design Steam-Turbine Modeling}

Unlike many conventional power-plant steam turbines, a steam turbine on a solar field will operate significantly off-design over a large percentage of total annual operating hours. The reasons include, but are not limited to: 
- The overall goal of maximizing generation on the solar energy that is available.

- Daily startup and shutdown at sunrise and sunset.

- Cloudy periods in which solar irradiance is diminished.

- Winter, when solar irradiation is lower even on a clear day.

- Bright clear days on which solar irradiance exceeds the design point of $950 \mathrm{~W} / \mathrm{m}^{2}$.

Off-design behavior of the steam turbine is modeled using Stodola's ellipse, which relates the mass flow rate and the inlet and outlet pressures through [26]:

$$
\dot{m}\left(\sqrt{T_{01}}\right) / p_{01}=k\left[1-\left(p_{0 e} / p_{01}\right)^{2}\right]^{1 / 2}
$$

Here, $\dot{m}$ is the mass flow rate, $T_{01}$ is the inlet temperature, $p_{01}$ is the inlet pressure, $p_{0 \mathrm{e}}$ is the outlet pressure, and $k$ is a constant of proportionality. Assuming that $k$ is constant for all cases, off-design performance may be related to design performance with the following equation [27]:

$$
\frac{\dot{m}}{\dot{m}_{\text {ref }}}\left(\sqrt{\frac{T_{01}}{T_{01, \text { ref }}}}\right) \frac{p_{01, \text { ref }}}{p_{01}}=\frac{\left[1-\left(p_{0 e} / p_{01}\right)^{2}\right]^{1 / 2}}{\left[1-\left(p_{0 e, \text { ref }} / p_{01, \text { ref }}\right)^{2}\right]^{1 / 2}} .
$$

A variety of physical mechanisms lead to entropy generation in the steam turbine, as described in [28].

Steam turbines may be operated with "sliding pressure" control or "throttling" control. In sliding-pressure control, the turbine "reacts" to the operating point set by the rest of the system. For instance, the outlet pressure may be fixed by the condenser pressure. The inlet pressure then "floats" in response to variations in the system mass flow rate, in accordance with Stodola's ellipse. Throttling control can be considered as a valve before the turbine inlet. The mass flow rate and inlet and outlet pressures are still related by Stodola's ellipse. However, the throttle is used to select an inlet pressure that allows the required mass flow rate to be passed through the turbine. This requires the fluid pressure before the valve to be sufficiently high and leads to significant losses.

Having related the inlet and outlet quantities with Stodola's ellipse, the off-design efficiency is then evaluated with a correlation, such as that provided in Bahadori [29]. Data were also obtained from a turbine manufacturer (Altas CopCo), and off-design results for a back-pressure steam turbine are shown in Figure 9. An estimate of the isentropic efficiency at the design point is also required, and discussions and calculations with Atlas CopCo suggested a value of 75\%.

There is some deviation between the manufacturer's curve and Bahadori's correlation, particularly at low mass flow rates. The reason for this difference is unclear but may be because the two turbines under consideration are not equivalent. For example, it is likely that Bahadori was using an axial-flow turbine, whereas the Atlas-Copco machine is a radial-inflow turboexpander. Also, the mode of operating the turbines may contribute to differences in the efficiency (e.g., sliding pressure vs. fixed inlet pressure), as well as where the inlet condition was 
measured (e.g., upstream or downstream of the turbine inlet control valve on an axial-flow turbine.)

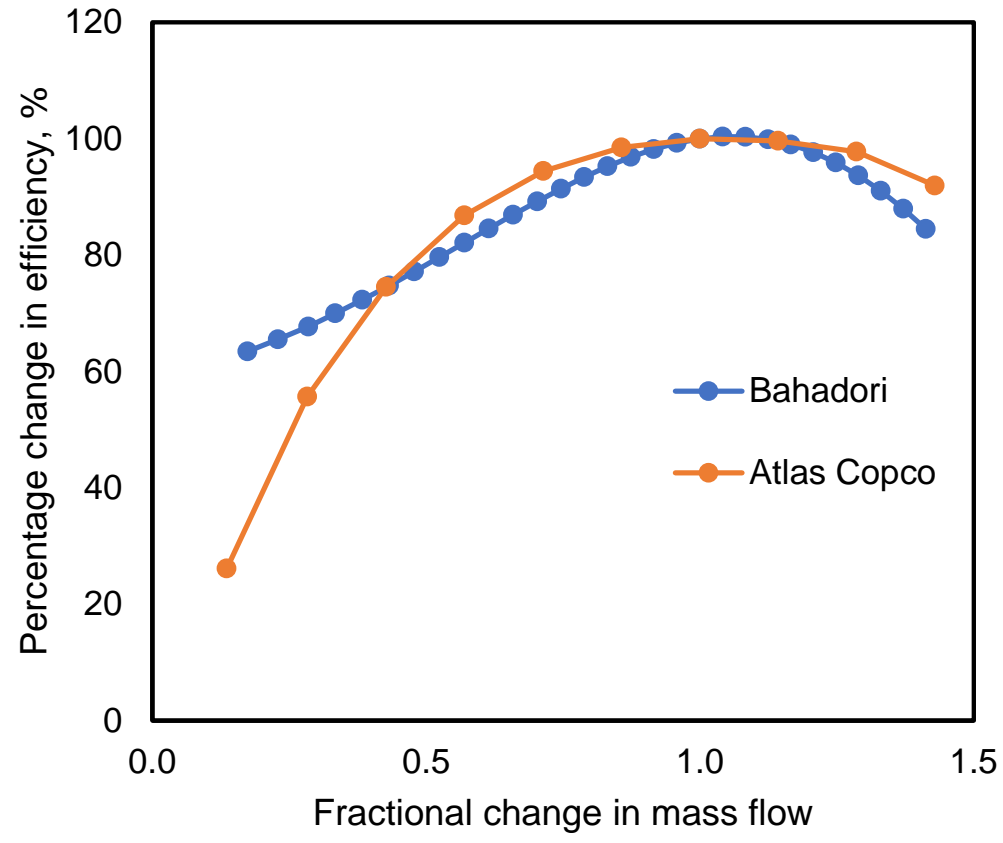

Figure 9. Off-design performance of back-pressure steam turbines. Curves are the relative efficiency compared to the design point. Data from Bahadori et al. [29] and Atlas CopCo.

\section{Determination of Plant Performance for a Typical Meteorological Year}

To fully assess the benefits of geo-solar hybridization of the Raft River geothermal plant, a determination of the amount of total additional annual power generation that would result from hybridization was necessary. This required estimation of the annual power generation for both the unmodified Raft River plant and the proposed Raft River hybrid power plant assuming identical geothermal resource and ambient-condition data. Power-plant performance for the unmodified and hybrid plants was characterized by using multiple linear-regression to establish correlations that predict net power output as functions of wet-bulb temperature and solar heat input (hybrid plant only). The hybrid-plant net power-generation data regression is shown in Figure 10. 


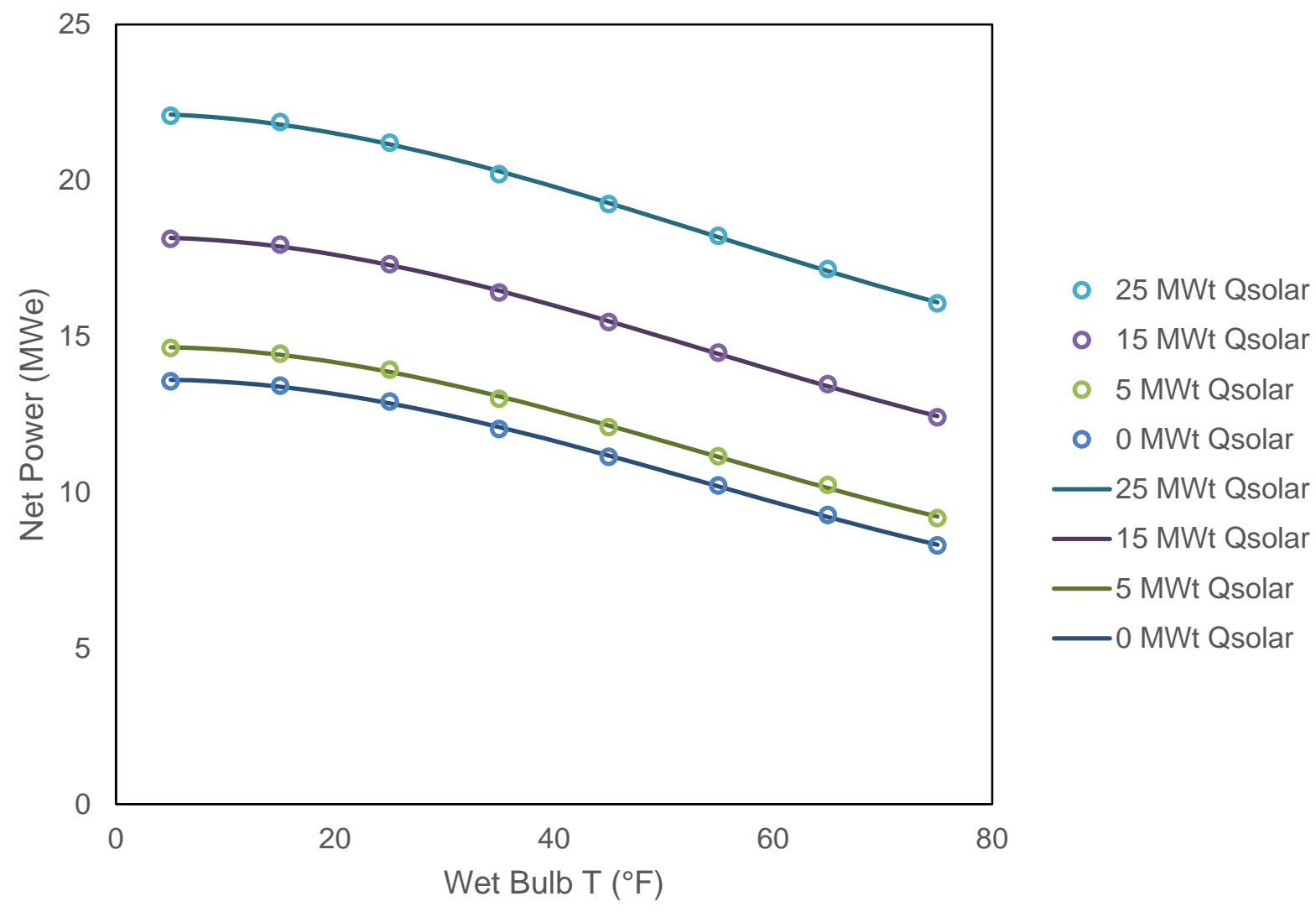

Figure 10. Multiple linear-regression model of hybrid plant net power generation as function of wet-bulb temperature for varying solar-field thermal output. IPSEpro model output is included as discrete points while the regression function output is depicted as curved lines.

Geographic site-specific typical meteorological year (TMY) data from the System Advisor Model (SAM) was used to provide hourly wet-bulb temperature data. TMY data provide solar input conditions based on expected normal hourly variations (not long-term averages) in key parameters (e.g., solar insolation, ambient temperature, wind speed). Additionally, SAM was used to simulate the solar-field operation and provide hourly solar-field heat-output estimates based on TMY data. The regression functions were then used to predict hourly power-plant net output from the wet-bulb temperature and solar-field heat-output data. Summation of the hourly power-generation data (minus hourly solar-field parasitic loads) provided an estimate of the annual net power generation for both the unmodified and hybrid power plants.

Having calculated the annual net power generation, this value is multiplied by a capacity factor of 95\% to represent maintenance or downtime. Following correspondence with the Raft River geothermal plant, this value is deemed to be conservative, with actual capacity factors being 98\%-99\%.

\section{Solar-Field Modeling with SAM}

Annual thermal output of the solar field is generated using NREL's System Advisor Model (SAM) [30]. The Physical Parabolic Trough Model in SAM is used in all parabolic trough collector (PTC) simulations and the Molten-Salt Linear Fresnel Model is used for linear Fresnel 
collector (LFC) simulations. In both models, Therminol VP-1 oil is used as the HTF and the solar-field design outlet temperature is set to $391^{\circ} \mathrm{C}$. The efficiency and cost of several different commercially available solar collectors_-four PTCs and two LFCs-were compared. Collector cost estimates and performance characteristics were obtained from a prior vendor survey conducted by NREL and are summarized in Table 3. High and low estimates represent variability in estimated raw material and labor costs.

Table 3. Collector specifications for PTCs and LFCs

\begin{tabular}{|c|c|c|c|c|c|c|c|}
\hline Collector & & PTC 1 & PTC 2 & PTC 3 & PTC 4 & LFC 1 & LFC 2 \\
\hline Geometric concentration ratio & & 26 & 24 & 25 & 24 & 25 & 55 \\
\hline$\eta_{o, \text { design }}$ & & 0.79 & 0.76 & 0.77 & 0.74 & 0.635 & 0.68 \\
\hline Estimated installed low & $\$ / m^{2}$ & 285 & 190 & 248 & 210 & 220 & 210 \\
\hline Estimated installed high & $\$ / m^{2}$ & 325 & 245 & 293 & 255 & 265 & 255 \\
\hline
\end{tabular}

To compare the different collector technologies, initial SAM simulations use Burley, ID TMY3 solar resource data from the National Solar Radiation Data Base (NSRDB) [31]. The solar field is initially sized with a solar multiple equal to one, such that the thermal output of the field is 50 $\mathrm{MW}_{\text {th }}$ under design-point conditions. The solar multiple of a field can be increased so that the size of the field is increased proportional to the solar multiple, and the desired thermal output of the field is reached even at off-design-point conditions. This may be advantageous with the addition of thermal storage, or other heat-sink possibilities that exist in the geothermal plant. The individual loop size and control system of the model is altered such that no defocusing of the solar field occurs, under the assumption that thermal energy production that exceeds the turbine's limitations can bypass the solar-field turbine and be used elsewhere in the geothermal plant or storage. The mass flow rate of the HTF is allowed to vary in order to reach the desired solar-field outlet temperature of $391^{\circ} \mathrm{C}$ during varying solar resource, which is the common method of control in CSP plants. There is assumed to be no thermal energy storage (TES) for initial simulations. Orientation is varied between North-South (N-S) and East-West (E-W). Solar-field size, TES, solar multiple, location, and orientation are all varied in later sections. A sample thermal output profile can be seen in Figure 11.

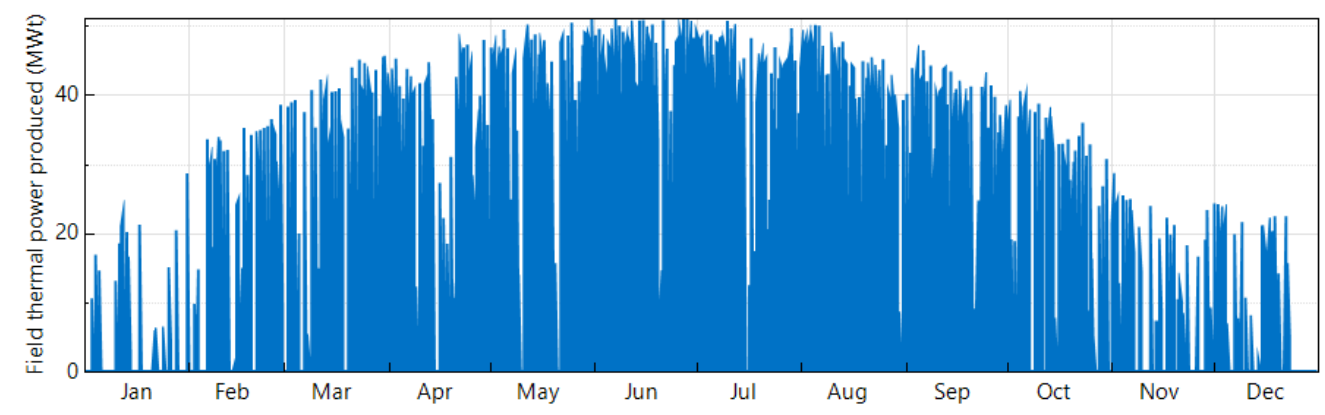

Figure 11. Solar-field thermal power produced for PTC 2 from SAM for a 50-MW solar field with N-S orientation. 
The levelized cost of heat (LCOH) is used as a metric to select a collector for further analysis in the hybrid plant simulations. The LCOH is the cost that would have to be paid by a user of the heat for every $\mathrm{MWh}_{\text {th }}$ that the collectors deliver over the lifetime of the collectors (typically 30 years). The LCOH is calculated with the FCR method, which is described (along with economic assumptions) in more detail in section 3.6. The $\mathrm{LCOH}$ is given by

$$
\mathrm{LCOH}=\frac{C_{\mathrm{cap}} \mathrm{FCR}+M}{Q_{\mathrm{SF}}},
$$

where $C_{\text {cap }}$ is the capital expenditures of the project, FCR is the fixed-charge rate, $M$ is the operations and maintenance (O\&M) cost, and QSF is the annual thermal energy produced by the solar field. More details of the FCR method can be found in SAM's documentation [30].

Results of the initial solar-field simulations can be found in Table 4 and Figure 12. Under current assumptions, PTC 2 with a N-S orientation generates the lowest LCOH of the analyzed solarfield collector technologies and is selected as the collector to be further analyzed with the hybrid system.

The orientation of the solar field for PTC 2 collectors is compared in Figure 13. The E-W orientation results in a higher $\mathrm{LCOH}$ due to lower annual energy production relative to N-S orientation. But the E-W orientation produces a more consistent production profile over the course of the year, which may be desirable. The thermal output may then be coupled with the IPSEpro power-plant model to analyze the performance and economic characteristics of the hybrid plant.

Table 4. Annual simulation results for $\mathrm{N}-\mathrm{S}$ oriented collectors

\begin{tabular}{llrrrrrr} 
Collector & & PTC 1 & PTC 2 & PTC 3 & PTC 4 & LFC 1 & LFC 2 \\
\hline Annual optical efficiency & $\%$ & 56 & 53 & 53 & 55 & 38 & 41 \\
Annual thermal efficiency & $\%$ & 85 & 82 & 83 & 80 & 84 & 90 \\
Total annual efficiency & $\%$ & 48 & 43 & 44 & 44 & 34 & 37 \\
LCOH low estimate & $\mathbb{\$} / \mathrm{kWh}_{\text {th }}$ & 3.5 & 2.8 & 3.4 & 3.0 & 4.0 & 3.6 \\
\hline
\end{tabular}




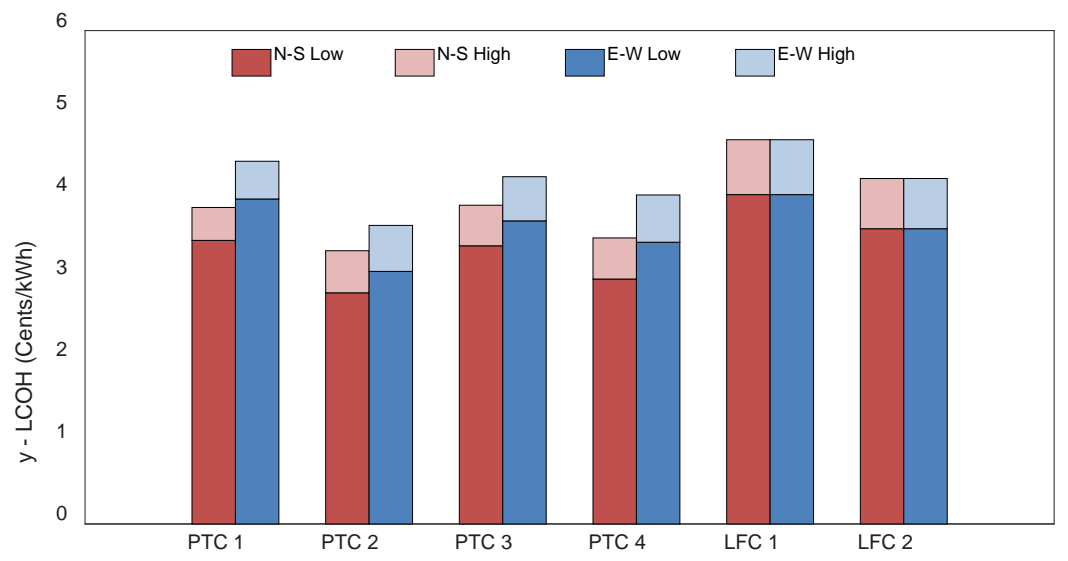

Figure 12. LCOH for various solar collectors.
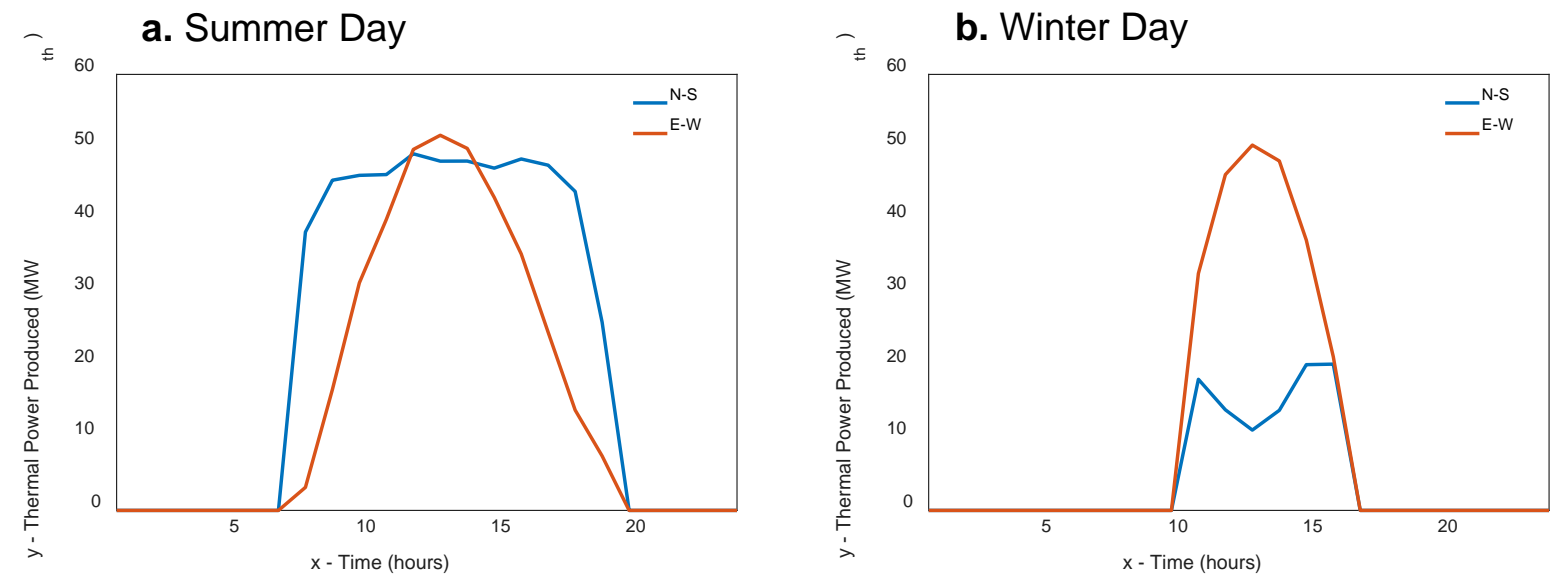

Figure 13. Solar-field thermal power output for PTC 2 comparing collector orientation during a) summer day and b) winter day.

\section{Economic Modeling}

The economic evaluation considers the costs of the additional equipment required to retrofit the Raft River GBPP with a solar heat input. It is assumed that any expenses incurred in modifying the ORC piping, instrumentation, etc. due to solar hybridization is included in the costs of installing the hybrid-plant retrofit equipment.

The capital cost estimate for the solar topping-cycle power block includes major equipment items such as heat exchangers, pumps, and turbines. The steam topping-cycle hybrid-plant configuration uses three heat exchangers for transferring heat from the solar-field HTF to the water in the steam Rankine cycle; these include an economizer, vaporizer, and superheater to generate superheated steam from the subcooled boiler feedwater. Additionally, two condensers transfer the thermal energy from the steam-condensation process to the L1 and L2 ORC working fluid. Cases with one and two steam turbines are evaluated; in the single-turbine case, the 
exhaust flow is distributed to both condensers whereas in the dual-turbine case there is a separate turbine-condenser pairing associated with each of the L1 and L2 ORC units.

The brine preheating hybrid-plant configuration requires the addition of less equipment to the existing ORC than the solar topping cycle. In the brine-preheating configuration, the additional major equipment is limited to the heat exchanger used to transfer heat from the solar-field HTF to the brine upstream of the power block.

Aspen Process Economic Analyzer V10 (1 $1^{\text {st }}$ Qtr 2016 pricing basis) was used to determine the capital costs for the heat exchangers and pumps. The heat-exchanger capital costs were determined by inputting the design-point mass and energy balances from the IPSEpro hybridplant model into Aspen Exchanger Design and Rating V10 software. Results from Aspen Exchanger Design and Rating “design (sizing)” simulations were transferred to Aspen Process Economic Analyzer to obtain equipment costs as well as total installed costs. The capital costs of the boiler feedwater pumps in the solar topping cycle were also determined using Aspen Process Economic Analyzer with the flow rate and fluid head data obtained from the IPSEpro hybridplant design-point simulation used as the basis for the pump cost estimates.

The steam topping-cycle turbine costs were based on equipment cost quotations provided by a steam-turbine manufacturer. The pricing data were specific to the single-turbine case. For the dual-turbine case, installed equipment costs of $500 \$ / \mathrm{kW}$ for the L1 turbine-generator and 1,100 $\$ / \mathrm{kW}$ for the L2 turbine-generator were estimated based on values presented in the Combined Heat and Power Technology Fact Sheet Series [32] (DOE, 2016). Based on this costing approach, the turbine-generator installed capital cost for the dual-turbine configuration is 34\% greater than that of the single-turbine configuration despite the similar gross power-generation capacity of the single and dual steam-turbine topping-cycle configurations. Steam turbine O\&M costs are assumed at $0.01 \$ / \mathrm{kWh}$ (DOE, 2016).

Based on recent developments in solar-collector design and manufacture, the solar-collector cost is assumed to be $125 \$ / \mathrm{m}^{2}$. The installation of the solar field also requires site improvements (20 $\left.\$ / \mathrm{m}^{2}\right)$ and a HTF, including piping and pumps (40 \$/ $\left.\mathrm{m}^{2}\right)$. The annual operating cost associated with the solar field is $8 \$ / \mathrm{kW}$ th. Sensitivity to the solar-field cost is investigated in section 4.6.

Design-point additional power generation, installed capital costs, and installed capital costs per unit net power generation for the brine-preheating, dual-turbine topping-cycle, and single-turbine topping-cycle hybrid-plant configurations are provided in Table 5. Table 16 in Appendix B includes a detailed listing of individual equipment component sizes and capital costs.

Note the significant reduction in capital cost per unit power when a steam turbine is included in the hybrid plant. Despite the larger amount of equipment needed for the topping turbine, the installed cost is cut by $40 \%$ over the brine-preheating option. 
Table 5. Installed capital costs for brine-preheating, dual-turbine topping-cycle, and single-turbine topping-cycle hybrid-plant configurations

\begin{tabular}{lccc}
$\begin{array}{l}\text { Hybrid-Plant } \\
\text { Configuration }\end{array}$ & $\begin{array}{c}\text { Design-Point Additional } \\
\text { Power }(\mathrm{kWe})\end{array}$ & $\begin{array}{c}\text { Installed Capital } \\
\text { Costs }(\$)\end{array}$ & $\begin{array}{c}\text { Installed Capital } \\
\text { Costs* }^{\star}(\mathrm{kWe})\end{array}$ \\
\hline $\begin{array}{l}\text { Brine preheating } \\
\begin{array}{l}\text { Solar-steam topping } \\
\text { cycle (dual turbines) }\end{array}\end{array}$ & 3,080 & $7,998,400$ & 2,596 \\
$\begin{array}{l}\text { Solar-steam topping } \\
\text { cycle (single turbine) }\end{array}$ & 8,146 & $12,688,700$ & 1,557 \\
\hline
\end{tabular}

* at hybrid-plant design conditions

\section{Levelized Cost of Electricity}

The levelized cost of electricity is the cost that, if assigned to every unit of electrical energy produced over the lifetime of the plant, will equal the total life-cycle costs when both are discounted back to the current year [33]. The total life-cycle costs include capital costs and O\&M costs. In the case of the hybrid plant where the power block and geothermal wells already exist, the annual electrical energy generated by the solar equipment addition is the marginal increase in electrical energy above the base rate provided by the geothermal plant. Similarly, the LCOE is also computed based on the annual solar power generation (assumed the same in all years) and the CAPEX/OPEX associated with the addition of the hybrid-plant equipment. The costs and power generation of the existing Raft River GBPP are not included in the LCOE calculation.

The LCOE is calculated using the fixed-charge rate method, where

$$
\mathrm{LCOE}=\frac{C_{\mathrm{cap}} \mathrm{FCR}+M}{E},
$$

where $\mathrm{C}_{\text {cap }}$ is the capital cost, $\mathrm{M}$ is the annual O\&M cost, $\mathrm{E}$ is the annual electricity generation, and FCR is the fixed-charge rate. FCR is defined as the revenue per unit of investment that must be collected annually to pay for the carrying charges of the investment. Details of how to calculate the FCR may be found in [33].

$$
\mathrm{FCR}=(\mathrm{PFF})(\mathrm{CRF})
$$

where PFF is the project financing factor and CRF is the capital recovery factor. PFF is given by

$$
\mathrm{PFF}=\frac{1-T(\mathrm{PVDEP})}{1-T}
$$

where $\mathrm{T}$ is the tax rate and PVDEP is the present value of depreciation, which is given by

$$
\operatorname{PVDEP}=\sum_{j=0}^{N} \frac{D_{j}}{(1+\mathrm{WACC})^{j}(1+i)^{j}}
$$


where $D_{j}$ is the depreciation rate in year $j, i$ is the inflation rate, and WACC is the weightedaverage cost of capital, given by

$$
\text { WACC }=\frac{1+(1-d)((1+\mathrm{RROE})(1+i)-1)+d(1-T)((1+\mathrm{RINT})(1+i)-1)}{1+i}-1,
$$

where $\mathrm{d}$ is the project debt fraction and RROE is the real return on investment, given by

$$
\mathrm{RROE}=\frac{1+\mathrm{IRR}}{1+i}-1,
$$

where IRR is the internal rate of return and RINT is the real debt interest rate, given by

$$
\text { RINT }=\frac{1+\text { NINT }}{1+i}-1,
$$

where NINT is the nominal debt interest rate. The CRF is given by

$$
\mathrm{CRF}=\frac{\text { WACC }}{1-\left(\frac{1}{1+\text { WACC }}\right)^{N}},
$$

where $\mathrm{N}$ is the lifetime of the plant in years. Assumed values for each of the economic parameters are given in Table 6.

Table 6. Economic factors used in LCOE calculations

\begin{tabular}{lll} 
Economic Parameters & \multicolumn{2}{l}{ Assumed Values } \\
\hline Lifetime & years & 25 \\
Tax rate, $T$ & $\%$ & 25 \\
Inflation rate, $i$ & $\%$ & 2.5 \\
Project debt fraction, $d$ & $\%$ & 70 \\
Internal rate of return, IRR & $\%$ & 10 \\
Nominal debt interest rate, NINT & $\%$ & 8 \\
Depreciation rate, $D_{j}$ & $\%$ & $20,32,20,14,14 ; 0$ thereafter \\
Fixed-charge rate, FCR & & 0.075 \\
\hline
\end{tabular}




\section{Results}

In this section, the calibrated thermodynamic modeling software and economic evaluation methods are brought together. The orientation of the solar field and other key geothermal resource sites at more southern latitudes are evaluated. More advanced operation, such as including thermal storage and bypassing the steam turbine when excess solar heat is available, are also considered. The influence of key economic variables such as the solar-field cost and the inclusion of an investment tax credit are investigated.

\section{Comparison of Thermal and Generation Performance}

Annual power generation and LCOE calculations are performed for several different hybridplant configurations. In all cases, the solar field was sized to restore the Raft River GBPP to the power block’s original design net generation.

Cycle 1A - Two HP steam turbines: The solar field generates HP steam that is fed to two turbines. The steam exiting each turbine condenses in a heat exchanger and vaporizes isopentane. There is a separate cond/vap for each of the L1 and L2 sides of the GBPP (see Figure 3).

Cycle 1B - One HP steam turbine: HP steam is generated in the same way as for Cycle 1A in a single turbine, but there are separate cond/vaps for L1 and L2. The steam is mostly directed to the HP cond-vap, and the rest is crossed over to feed the LP cond-vap (see Figure 4).

Cycle 1C - One HP steam turbine, simplified. In this variation, the steam cross-over and the L2 cond/vap of Cycle 1B are eliminated. Instead, enough of the incoming geothermal brine from the production wells is bypassed around the HP brine/isopentane vaporizer (using an existing brine bypass) to supply the LP brine/isopentane vaporizer with its design energy input.

Cycle 2 - Solar heating of incoming brine: The solar field is used to heat the brine going to the GBPP. The mass flow rate to the plant is unchanged, but the temperature is increased enough to restore the GBPP to its design point. At Raft River, this approach has high calcite-scaling potential when the brine temperature is raised in the solar heat exchanger, as discussed in [10], [34]. The cost of continuously injecting scale inhibitors to prevent calcite precipitation is not included in the LCOE calculations for this option.

Cycle 3 - Solar heating of a returned slipstream of cooled brine: The solar field is used to heat some of the brine exiting the GBPP to restore the design inlet flow rate and temperature. The results are presented in Table 7 , but no further consideration of this option is made because of its large required solar field and low conversion efficiency and net power increase.

These cycles were evaluated, and the results are presented in Table 7. Cycle 2 (brine preheating) is the simplest to implement, and it has the smallest solar field. But it has a much lower marginal solar efficiency and higher LCOE than the configurations that use turbines. Implementing a topping cycle allows for much more efficient use of the high-exergy flow that the solar field generates. For instance, Table 7 demonstrates that for both Cycle 1A and Cycle 1B, the solar conversion efficiency reaches $30 \%$, which is almost double that of brine preheating and more than double that of brine recirculation. 
Table 7. Solar heat input, marginal solar efficiency, and additional power generation for candidate Raft River geo-solar hybrid-plant configurations

\begin{tabular}{|c|c|c|c|c|c|c|c|}
\hline \multirow[b]{2}{*}{$\begin{array}{c}\text { Cycle } \\
\#\end{array}$} & \multirow[b]{2}{*}{$\begin{array}{l}\text { Hybrid Plant } \\
\text { Configuration }\end{array}$} & \multirow[b]{2}{*}{$\begin{array}{l}\text { LCOE } \\
\left(\$ / k W h_{e}\right)\end{array}$} & \multirow[b]{2}{*}{$\begin{array}{l}\text { Solar heat } \\
\text { input (MWth) }\end{array}$} & \multicolumn{2}{|c|}{ Marginal solar efficiency } & \multicolumn{2}{|c|}{ Additional power generation } \\
\hline & & & & $\begin{array}{l}\text { Design point } \\
\eta_{\text {sol, }, 1}(\%)\end{array}$ & $\begin{array}{l}\text { Annualized } \\
\eta_{\text {sol, }, 1}(\%)\end{array}$ & $\begin{array}{l}\text { Design point } \\
\left(\mathrm{MW}_{\mathrm{e}}\right)\end{array}$ & $\begin{array}{l}\text { Annualized } \\
\left(G W h_{e}\right)\end{array}$ \\
\hline $1 \mathrm{~A}$ & $\begin{array}{l}\text { Solar-steam topping } \\
\text { cycle ( } 2 \text { turbines) }\end{array}$ & 0.129 & 24.95 & 32.6 & 29.6 & 8.1 & 12.41 \\
\hline $1 \mathrm{~B}$ & $\begin{array}{l}\text { Solar-steam topping } \\
\text { cycle (1 turbine) }\end{array}$ & 0.126 & 24.71 & 32.0 & 28.7 & 7.9 & 12.05 \\
\hline $1 \mathrm{C}$ & $\begin{array}{l}\text { Solar-steam topping } \\
\text { cycle (1 turbine) }\end{array}$ & 0.120 & 24.63 & 32.1 & 29.4 & 7.9 & 12.34 \\
\hline 2 & $\begin{array}{l}\text { Brine preheating } \\
\text { (no turbines) }\end{array}$ & 0.158 & 18.84 & 16.3 & 15.8 & 3.1 & 6.24 \\
\hline 3 & $\begin{array}{l}\text { Recirculated brine } \\
\text { heating (no turbines) }\end{array}$ & 0.230 & 23.85 & 13.0 & 12.5 & 3.1 & 4.54 \\
\hline $\begin{array}{c}4 \mathrm{~A} / \mathrm{B} \\
\mathrm{c}, \mathrm{d}\end{array}$ & $\begin{array}{l}\text { Cycle } 3 \text { with a solar } \\
\text { steam turbine }\end{array}$ & - & $28-29$ & $24-27$ & - & $3.6-4.8$ & - \\
\hline $\begin{array}{c}5 A / B \\
c, d\end{array}$ & $\begin{array}{l}\text { Internal brine reheat } \\
\text { w/ steam turbine }\end{array}$ & - & $22-23$ & $27-30$ & - & $2.8-3.6$ & - \\
\hline
\end{tabular}

a Annual average (total additional power generation / total solar heat input)

${ }^{\mathrm{b}}$ Based on a solar field with 25-MW ${ }_{\text {th }}$ design condition output

${ }^{\mathrm{c}}$ These options were only considered in the screening study. See Appendix A.

${ }^{\mathrm{d}}$ In the screening study, the calculation basis is different, so the values are not entirely comparable, but are indicative of the magnitude.

Cycle 1A has two steam turbines. Each turbine has the same inlet conditions, but a different outlet pressure that corresponds to the temperatures and pressures that would best match the high-pressure (L1) or low-pressure (L2) ORC isopentane closed-loops of the existing Raft River GBPP. In this scenario, the steam turbine coupled to the L1 loop extracts the majority of the work. For instance, with a solar heat input of $25 \mathrm{MW}_{\text {th }}$ at ambient conditions of $15^{\circ} \mathrm{C}$, the HP steam turbine generates 4.2 $\mathrm{MW}_{\mathrm{e}}$, and the LP turbine generates $1.0 \mathrm{MW}_{\mathrm{e}}$. The outlet flow of the HP turbine then adds $16.4 \mathrm{MW}_{\text {th }}$ to the heat exchangers with the binary plant, whereas the LP turbine adds 3.4 MW $\mathrm{MW}_{\text {th }}$

Because the steam turbine feeding the L2 loop is relatively small and will increase the capital cost, a second configuration is considered that eliminates that steam turbine. The remaining steam-turbine outlet flow is split between the binary-plant L1 and L2 con/vaps depending on the requirements. For instance, restoring the binary plant to its design point requires $16.6 \mathrm{MW}_{\text {th }}$ in the L1 (HP) con/vap and 3.4 MW th to the L2 (LP) con/vap. The single steam turbine generates 5.1 MWe.

The two-turbine solution is slightly more efficient (29.6\%) than the single turbine (28.6\%). However, the two-turbine system has a higher capital cost (12.7 M\$ compared to 11.7 M\$); so, despite generating slightly more electricity annually (107.8 GWhe compared to 107.4 GWhe), the LCOE is also slightly lower for the single turbine (0.129 \$/kWhe compared to $0.126 \$ / \mathrm{kWhe})$.

The one-turbine solution was further simplified in Case 1C, where the steam-turbine exhaust only delivers heat to the HP binary-cycle vaporizer. This system results in a small reduction in 
capital cost and a corresponding increase in the LCOE. However, Case 1C was only considered late in the project and is not analyzed further in this report.

The above results are for a N-S solar-field orientation (i.e., the axis of the collectors trends N-S). Results are also presented for E-W-oriented solar fields in Figure 14 and demonstrate the same trends as for N-S-oriented fields. However, E-W fields collect 18\% less solar energy over the course of the year for the single-turbine case, which is consistent with the results of section 3.4. Furthermore, the E-W systems are less efficient at converting incident energy into thermal heat, which leads to higher LCOEs.

In summary, it was found that a single steam-turbine topping cycle has high solar-conversion efficiency compared to brine preheating and was slightly simpler and less expensive to install than a two-turbine system. Solar fields oriented along a N-S axis generated more power and had lower LCOEs than E-W-oriented fields. The most promising solution is therefore a single steamturbine hybrid plant with a north-south-oriented solar field.

\section{Influence of Geographical Location}

The results in the previous section were presented for the Raft River geothermal plant near Burley, Idaho. However, ageing geothermal binary power plants are also present in areas of the United States with better solar resources. In this section, a solar steam topping-cycle hybrid power plant is investigated in three locations-Burley, Idaho; Reno, Nevada; and Imperial, California—with average solar data presented in Table 8.
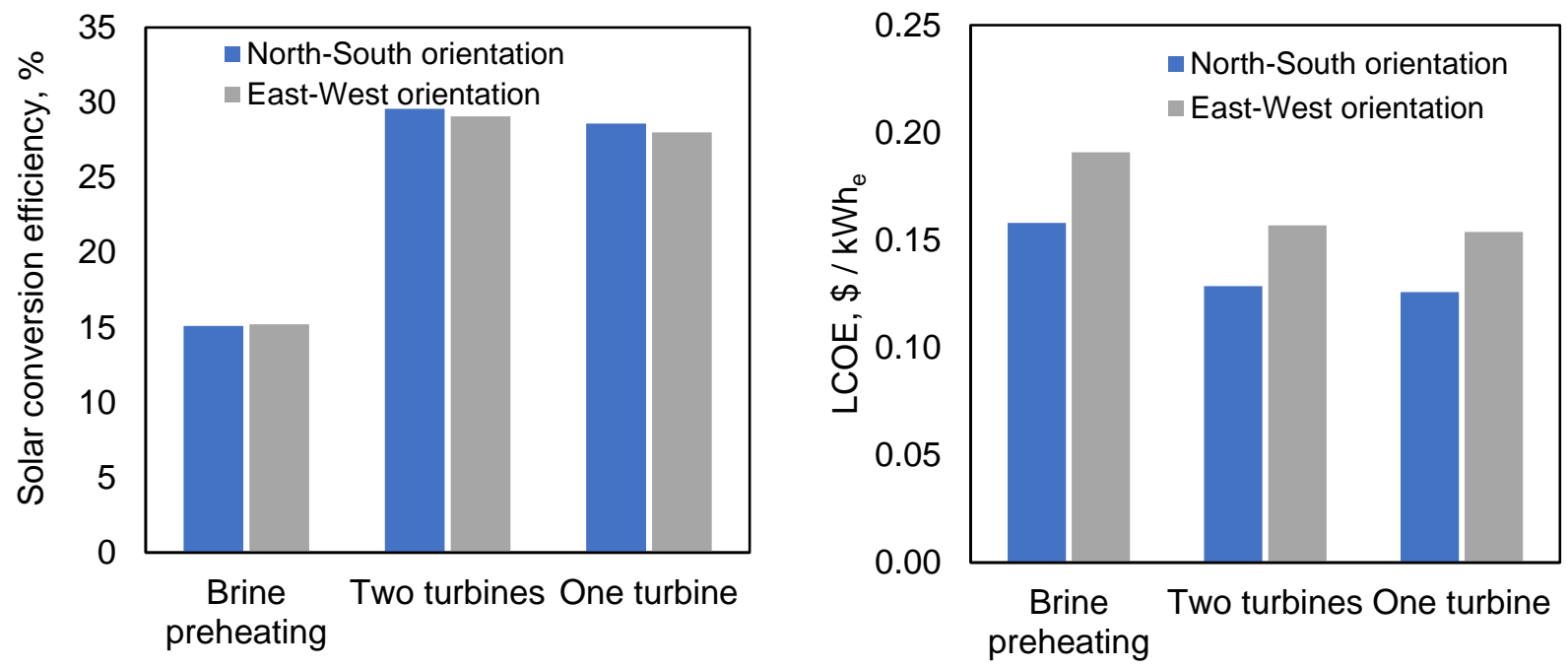

Figure 14. The solar conversion efficiency $\eta_{s o l, 1}$ and LCOE of several hybrid-plant configurations.

In each case, the binary plant is assumed to have the same characteristics as the Raft River geothermal plant. No change is made to the size of the GBPP heat-rejection system (condenser, cooling water pumps, and cooling tower), which means that it is undersized for the other two warmer locations. The purpose of this part of the study was to investigate how locations with better solar resources would perform. In reality, those locations would also have larger heatrejection systems, sized to the location's wet-bulb temperature, so the annual generation forecast is probably lower than would actually occur were a solar field of the given size installed as a 
GBPP retrofit at these locations. For Imperial, the smaller heat-rejection system of the Raft River plant may have an especially large effect on annual generation; hence, the results of this study likely indicate a much higher LCOE than would actually occur for a solar retrofit in Imperial.

Annual calculations were performed, and results are summarized in Figure 15. Ambient temperatures significantly affect the performance of the water-cooled geothermal plant, especially because it is undersized, as described above. Consequently, the hybrid plant has a lower solar conversion efficiency and produces less work from the geothermal field in Imperial due to much higher temperatures. However, the improved solar resource leads to more available solar heat, thereby generating more power in the solar steam turbines, as shown in Figure 15.

Table 8. Typical solar properties at various geothermal plant locations in the USA

\begin{tabular}{lllll} 
Annual average & & Burley, ID & Reno, NV & Imperial, CA \\
\hline Direct normal irradiance & $\mathrm{kWh} / \mathrm{m}^{2} /$ day & 5.71 & 6.39 & 7.23 \\
Global horizontal irradiance & $\mathrm{kWh} / \mathrm{m}^{2} /$ day & 4.63 & 5.06 & 5.77 \\
Wet-bulb temperature & ${ }^{\circ} \mathrm{C}$ & 5.1 & 4.8 & 14.3 \\
Wind speed & $\mathrm{m} / \mathrm{s}$ & 3.8 & 2.8 & 3.3 \\
Elevation & $\mathrm{m}$ & 1,267 & 1,341 & -17 \\
Latitude & ${ }^{\circ} \mathrm{N}$ & 42.533 & 39.500 & 32.833 \\
Longitude & ${ }^{\circ} \mathrm{E}$ & -113.767 & -119.783 & -115.583 \\
\hline
\end{tabular}

Despite the hybrid plant in California producing less electricity annually, it has the lowest LCOE as shown in Table 9. This is because the LCOE for the hybrid plant is calculated using the electricity generated in addition to the existing geothermal plant.

Table 9 shows that the Californian plant has the highest percentage increase in work output, thereby leading to low LCOEs.

Note that the solar conversion efficiency shown here is $\eta_{\text {sol,1 }}$ and is a measure of the total increase in electricity divided by the solar thermal heat input to the hybrid plant. Another measure uses the total power incident on the solar collector and is referred to as $\eta_{\mathrm{sol}, 2}$, as discussed in Section 1.1. The annual average solar-field performance (including optical and thermal efficiencies) for the solar field considered here is around $45 \%-48 \%$, leading to values of $\eta_{\text {sol, } 2}$ in the range of $12.7 \%-13.7 \%$, which are comparable with $\eta_{\text {sol,2 }}$ values proposed by other authors for hybrid plants with a solar topping cycle; see section 1.3 [18]. 
a.

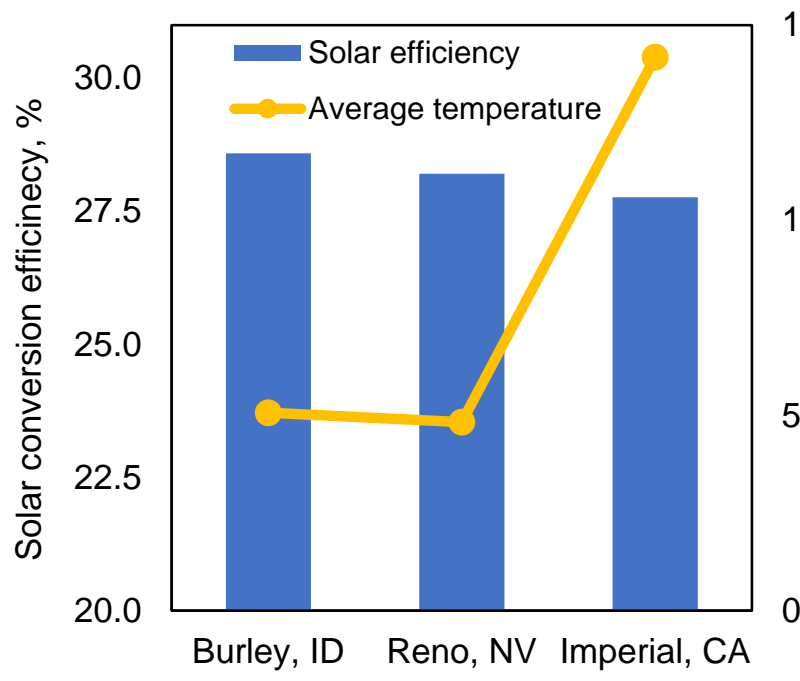

b.

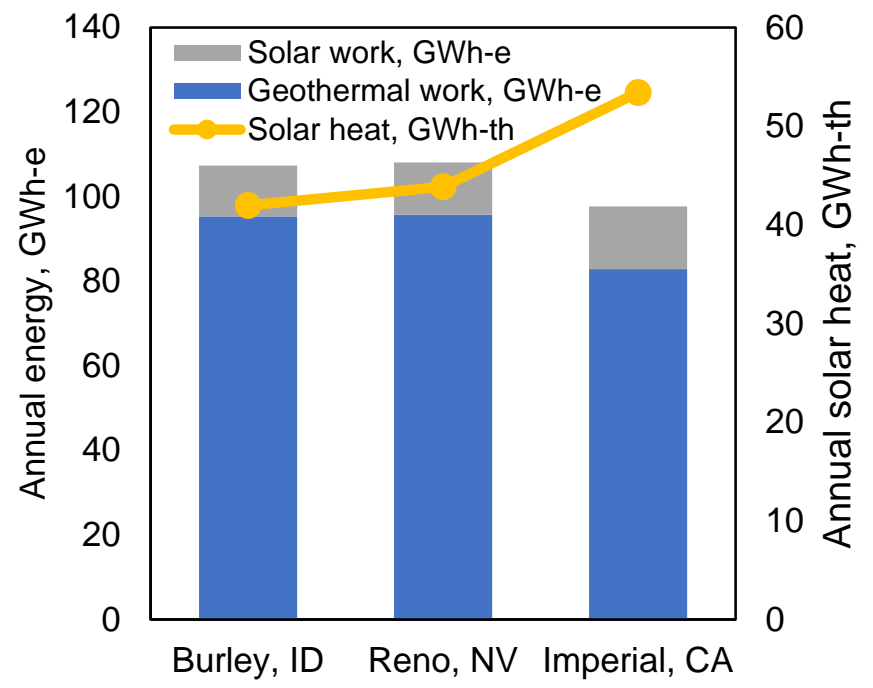

Figure 15. The influence of location on the hybrid-plant performance. a) Higher average annual wet-bulb temperatures lead to lower solar conversion efficiencies. b) The geothermal power plant produces less electricity in warmer regions. However, more solar heat is generated.

Table 9. Electrical work output, solar conversion efficiencies, and LCOEs of hybrid plants in different geographical locations

\begin{tabular}{llrrc} 
& & Burley, ID & Reno, NV & Imperial, CA \\
\hline Stand-alone geothermal work & GWhe & 95.4 & 95.7 & 82.4 \\
Additional work & GWhe & 12.0 & 12.4 & 14.8 \\
Total work & GWhe & 107.4 & 108.1 & 97.7 \\
Percentage increase & $\%$ & 12.6 & 13.0 & 18.6 \\
& & & & \\
Solar conversion $\eta_{\text {sol, } 1}$ & $\%$ & 28.6 & 28.2 & 27.8 \\
Solar conversion $\eta_{\text {sol, }, 2}$ & $\%$ & 13.7 & 12.7 & 13.4 \\
Solar field efficiency & $\%$ & 47.9 & 45.0 & 48.2 \\
& & & & \\
LCOE & $\$ / k W h$ & 0.126 & 0.122 & 0.118 \\
\hline
\end{tabular}

\section{Effect of Re-Routing Excess Solar Heat around the Steam Turbine and Adding to the Vaporizer}

The steam turbine has a design thermal power of $25 \mathrm{MW}$ th and it was assumed that it can be over-rated by $10 \%$ to $27.5 \mathrm{MW}$ th, which is a common design margin. When the solar field generates heat above this value, the heat may be curtailed, probably through defocusing in the solar field. However, the heat could potentially be used in the GBPP instead. For example, the hot steam can be bypassed around the steam turbine and mixed with the steam-turbine outlet flow (requiring a large pressure drop through a valve). This option is illustrated with a dashed 
line in Figure 4. The hybrid-plant power output as a function of solar heat is shown in Figure 16, and a noticeable kink (at 27.5 $\mathrm{MW}_{\text {th }}$ ) indicates the point at which excess solar heat is diverted to the binary plant. At this point, the steam-turbine power output is fixed, but the binary-plant power increases as a result of higher mass flow rates through the ORC vaporizers. Extracting work in a steam turbine is more effective than in the lower-temperature binary plant, which explains the sudden decrease in solar conversion efficiency; but Figure 16 clearly indicates that it is better to use the excess solar heat in the binary plant than to curtail it.

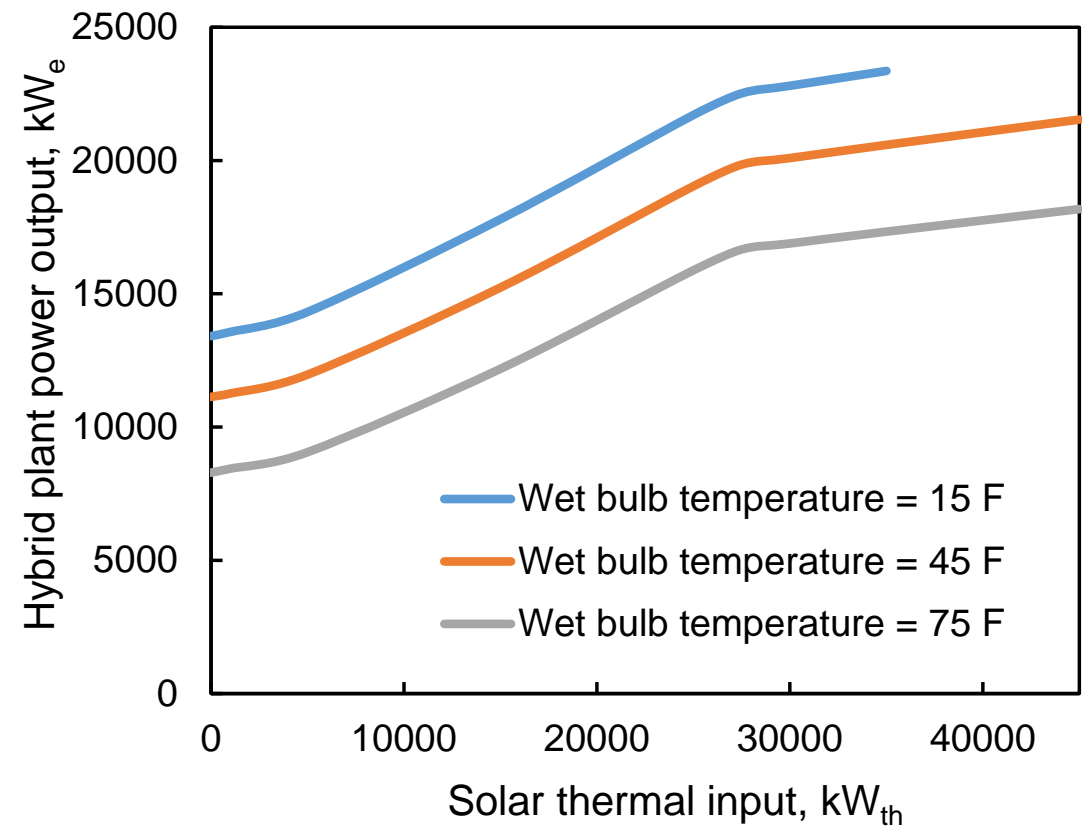

Figure 16. The hybrid-plant power output for several ambient temperatures as the solar thermal input varies. There is a noticeable kink at the point where excess solar heat is re-routed around the steam turbine.

\section{Optimal Solar-Field Sizing}

The solar field is sized to produce $25 \mathrm{MW}$ th at a solar irradiance of $950 \mathrm{~W} / \mathrm{m}^{2}$ and at these conditions will restore the design performance of the binary cycle. The solar field has a solar multiple of 1 . These design conditions occur only some of the time during the year so that the system would operate below design conditions for much of the year. To improve the number of hours that the integrated GBPP operates at or above the design conditions of the hybrid plant, the solar-field area may therefore be increased, and the solar multiple increases proportionally.

Increasing the solar multiple increases the quantity of heat available to the hybrid plant, and the LCOE therefore initially reduces despite the increased capital cost. Curtailment of excess solar heat leads to an optimal solar-field size of around 1.25 according to Figure 17. When excess heat bypasses the steam turbine, the optimal solar multiple increases slightly, and the optimum LCOE is slightly reduced.

Note that there is a limit to the quantity of solar heat that the binary plant can absorb before energy is curtailed. In this example, the maximum solar-field thermal power is $45 \mathrm{MW}_{\text {th }}$ 
compared to $27.5 \mathrm{MW}_{\text {th }}$ in the conventional case, and it occurs when both the solar and geothermal portions of the hybrid plant reach an arbitrary output of $110 \%$ of the design value. At a greenfield geothermal plant, the $10 \%$ limit could be raised. On an existing GBPP, it is possible that re-blading the turbine would also provide a means to raise the design limit.

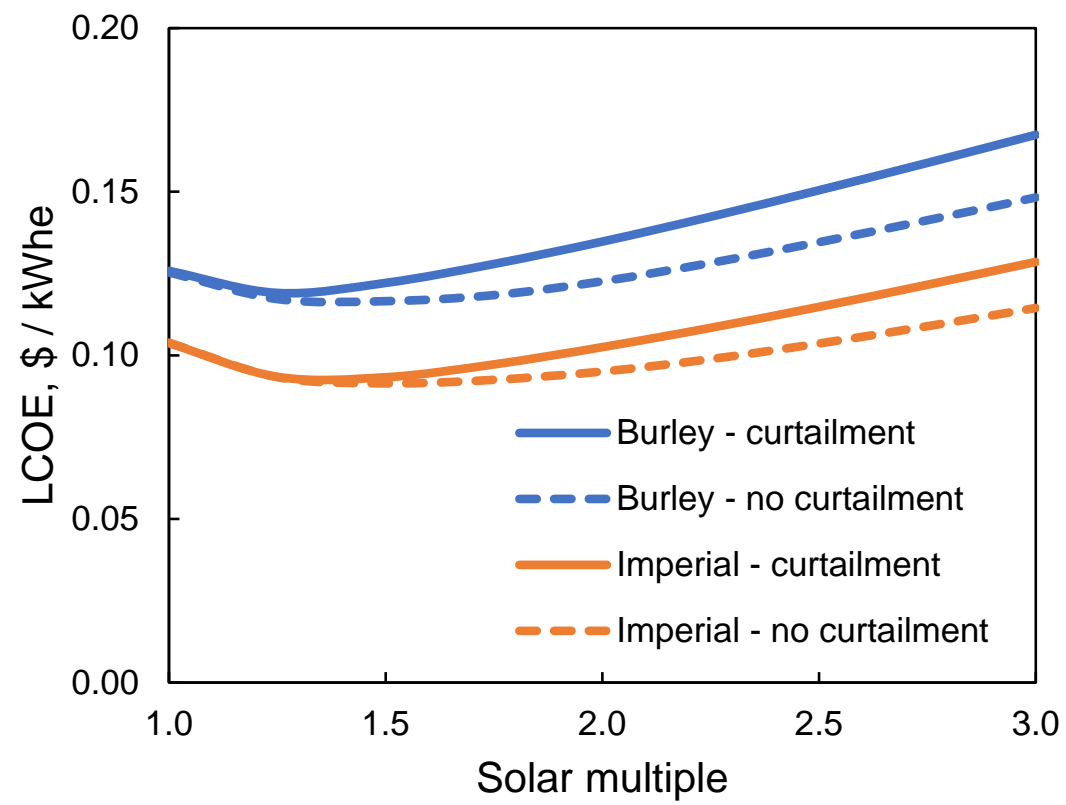

Figure 17. The effect of solar-field size on the LCOE. Curves are shown for a hybrid plant with one turbine with the solar field oriented north-south. Curves are shown for two locations and for configurations where the solar heat is either curtailed or re-routed directly into the geothermal plant vaporizers.

\section{Integrating Thermal Storage with Solar-Field Sizing in the Geo-Solar Hybrid}

As noted above, the solar conversion efficiency when excess solar heat directly enters the vaporizer is lower than extracting the energy in the steam turbine. Thermal energy storage provides a way to avoid curtailment while also converting solar heat at higher efficiencies. Figure 18 shows the impact of TES on the LCOE of hybrid plants located in Burley, ID, and Imperial, CA, for different solar multiples. The TES is designed to deliver power at the design rate of 25 $\mathrm{MW}_{\text {th, }}$ and it absorbs solar energy whenever the solar steam turbine has reached $100 \%$ of its design value. The storage duration (either 4 or 8 hours in this example) determines the energy capacity of the TES. All excess solar heat enters the TES, and once the TES is full, the excess is curtailed. (Further research should consider combining thermal storage and re-routing excess heat into the vaporizer.) Whenever the solar heat decreases below $25 \mathrm{MW}_{\text {th }}$, the stores are discharged until they are completely depleted.

The storage is in the form of two liquid tanks that contain the solar HTF. One of these tanks is used to store excess capacity of hot HTF whereas the second tank is used to manage the inventory of cooled HTF. This type of storage is comparatively straight-forward technologically and has been previously deployed at CSP plants. It is assumed that the tanks have been 
sufficiently insulated so that heat leakage losses are negligible over the storage duration (several hours).

The figures indicate that thermal storage increases the optimal solar multiple to around 1.5 for 4 hours of storage and to about 2.1 for 8 hours of storage. Furthermore, when storage has a capital cost of $25 \$ / \mathrm{kWh}$, the optimal LCOE is slightly lower than the system without storage, although this configuration requires greater investment.
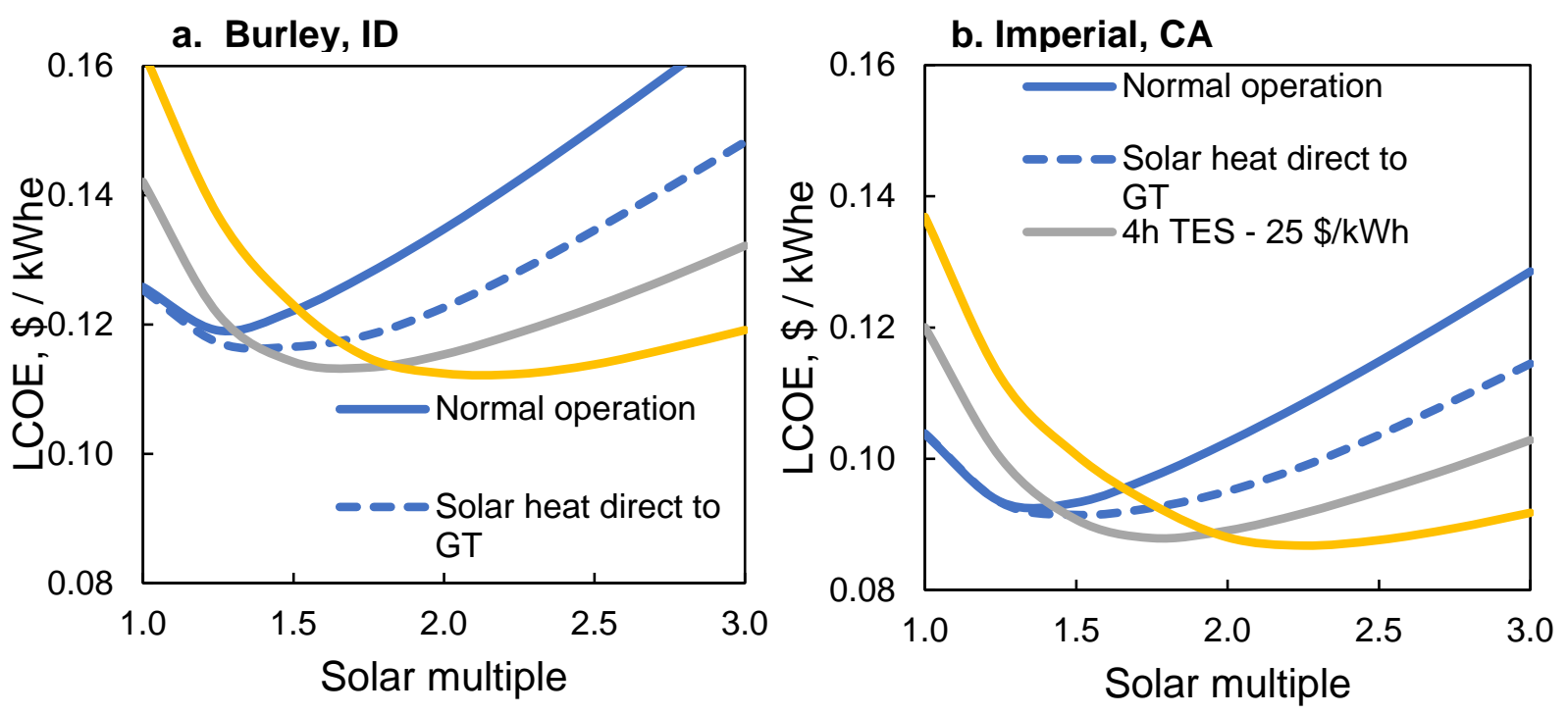

Figure 18. Thermal storage increases the optimal solar multiple. a) Hybrid plant at Burley, ID. b) Hybrid plant at Imperial, CA. Results are for a hybrid plant with one steam turbine with the solar field oriented north-south.

Figure 19 illustrates the influence of storage costs on the LCOE and the optimal solar multiple for a hybrid plant with four hours of storage. The optimal solar multiple does not change considerably with increases in storage cost. This graph illustrates that if the storage costs more than $35 \$ / \mathrm{kWh}_{\mathrm{th}}$, then the optimum LCOE is higher than the system with no storage. It should be noted that $25 \$ / \mathrm{kWh}_{\text {th }}$ is quite an optimistic value. More realistic values for two-tank liquid storage fall in the range of $30-50 \$ / \mathrm{kWh}$ th.

Other thermal storage systems exist, such as packed beds. These are containment vessels filled with a packing material such as rocks or ceramic. Heat is transferred to the bed by the HTFs. Packed beds are more compact than two-tank systems because only one tank is required. The quantity of HTF is also reduced and thereby reduces system costs (HTF is the most expensive component in two-tank liquid storage). A previous study indicated that packed beds may be less than half the cost of two-tank liquid storage [11]. However, packed beds have complicated transient behavior and require detailed models to accurately assess the appropriate size and cost. Given the results of this section, this may be a worthwhile area for further study.

In this example, all electricity is sold at the same price. Thermal storage would allow the system to dispatch energy at the most profitable times and potentially increase the revenue. 
a. Burley, ID

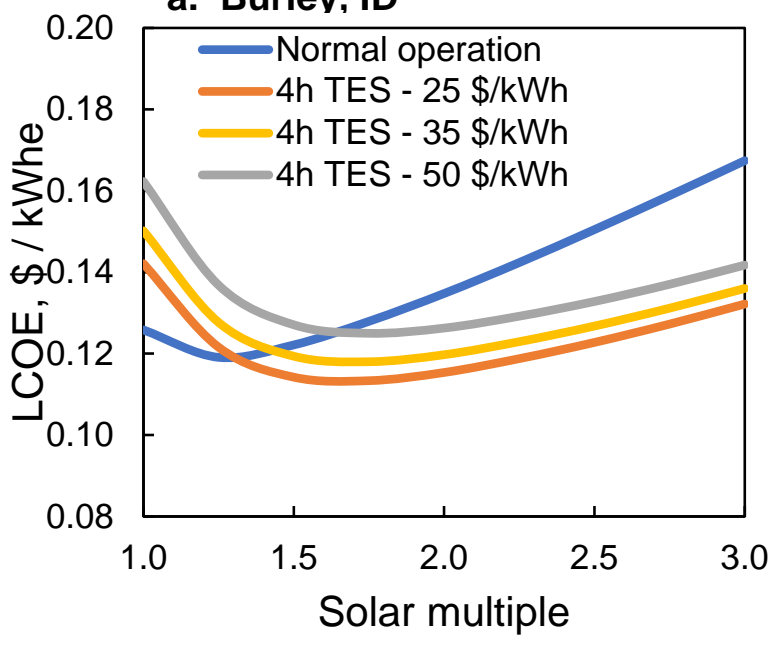

b. Imperial, CA

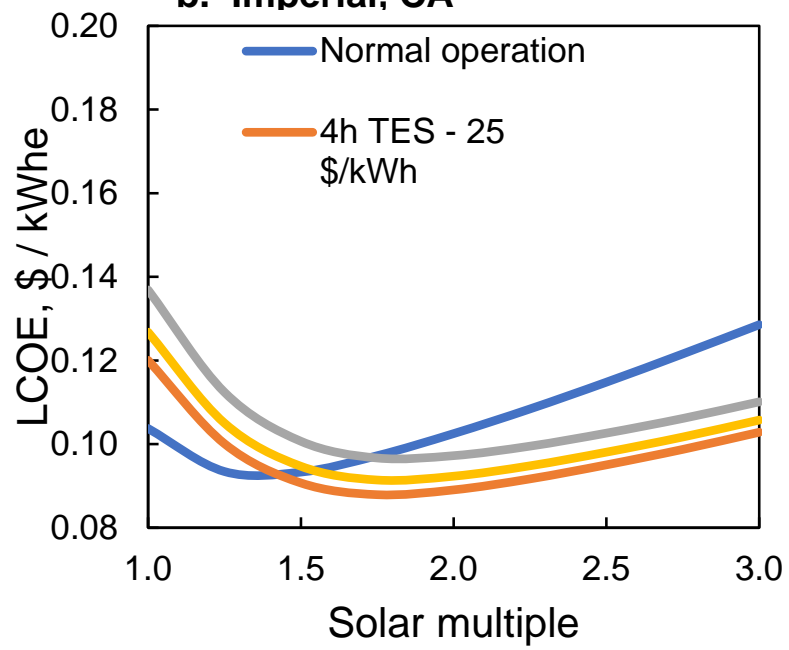

Figure 19. The effect of the cost of thermal storage on the LCOE of the hybrid plant for a) Burley, Idaho, and b) Imperial, California.

\section{Effect of Tax Incentives on Economic Results}

The results presented so far have been for the full expected capital costs of the retrofit, without any tax incentives. A hybrid geothermal-solar plant may be eligible for subsidies such as the investment tax credit (ITC). The ITC was extended in 2016 and has a value of 30\% for solar installations that have commenced construction before 2019 [35]. The value of the ITC then decreases to a value of $10 \%$ by 2022. The LCOE for hybrid plants with four hours of thermal storage that take advantage of the ITC are given in Table 10. The tax incentives are sufficiently large that the LCOE is quite competitive even when storage costs are high.

Table 10. Tax incentives reduce LCOE significantly, even for high storage costs. Systems include four hours of storage.

\begin{tabular}{|c|c|c|c|c|c|c|}
\hline \multicolumn{7}{|c|}{ 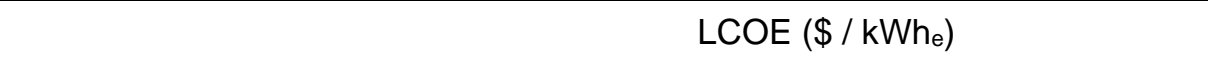 } \\
\hline & \multicolumn{3}{|c|}{ Burley, ID } & \multicolumn{3}{|c|}{ Imperial, CA } \\
\hline $\begin{array}{l}\text { TES } \\
\text { Cost }(\$ / k V\end{array}$ & $0 \%$ & $10 \%$ & $30 \%$ & $0 \%$ & $10 \%$ & $30 \%$ \\
\hline 25 & 0.113 & 0.104 & 0.085 & 0.088 & 0.081 & 0.067 \\
\hline 35 & 0.118 & 0.108 & 0.088 & 0.091 & 0.084 & 0.069 \\
\hline 50 & 0.125 & 0.114 & 0.093 & 0.097 & 0.089 & 0.073 \\
\hline
\end{tabular}

\section{Influence of Solar-Field Costs}

The cost of the solar field dominates the capital cost of the hybrid plant. For instance, the solar field accounts for $75 \%$ of the total capital cost for a hybrid plant with a solar multiple of 1.5, with excess heat re-routed around the steam turbine, with no storage, at Burley, Idaho. With four hours of storage at $25 \$ / \mathrm{kWh}$ the solar field accounts for $64 \%$ of the cost, whereas the storage accounts for $14 \%$. The current analysis has assumed a total solar-field cost of $185 \$ / \mathrm{m}^{2}$, which 
includes the collectors, receivers, site improvements, and HTF system. Concentrating solar-field costs have reduced significantly in recent years, and further cost reductions may be possible. The effect of solar-field costs on the LCOE (without tax incentives) is investigated in Figure 20 for hybrid plants at Burley, ID, and Imperial, CA. The LCOE decreases below $0.10 \$ / \mathrm{kWh}$ e when the solar field costs less than $135 \$ / \mathrm{m}^{2}$, which may be a realistic target in the coming years. For instance, the DOE SunShot target is a solar-collector cost of $75 \$ / \mathrm{m}^{2}$. Reducing the cost of site improvements and the HTF system proportionally (as in Table 11), Figure 20 indicates that these target low-cost solar fields could achieve LCOEs as low as $0.07 \$ / \mathrm{kWh}$.

Table 11. Current solar-field costs, and target costs based on the DOE SunShot target. (Costs without tax incentives.)

\begin{tabular}{llrr} 
& & Current & Target \\
\hline Solar collector & $\$ / \mathrm{m}^{2}$ & 125 & 75 \\
Site improvements & $\$ / \mathrm{m}^{2}$ & 20 & 12 \\
HTF system & $\$ / \mathrm{m}^{2}$ & 40 & 24 \\
Total & $\$ / \mathrm{m}^{2}$ & 185 & 111 \\
\hline
\end{tabular}

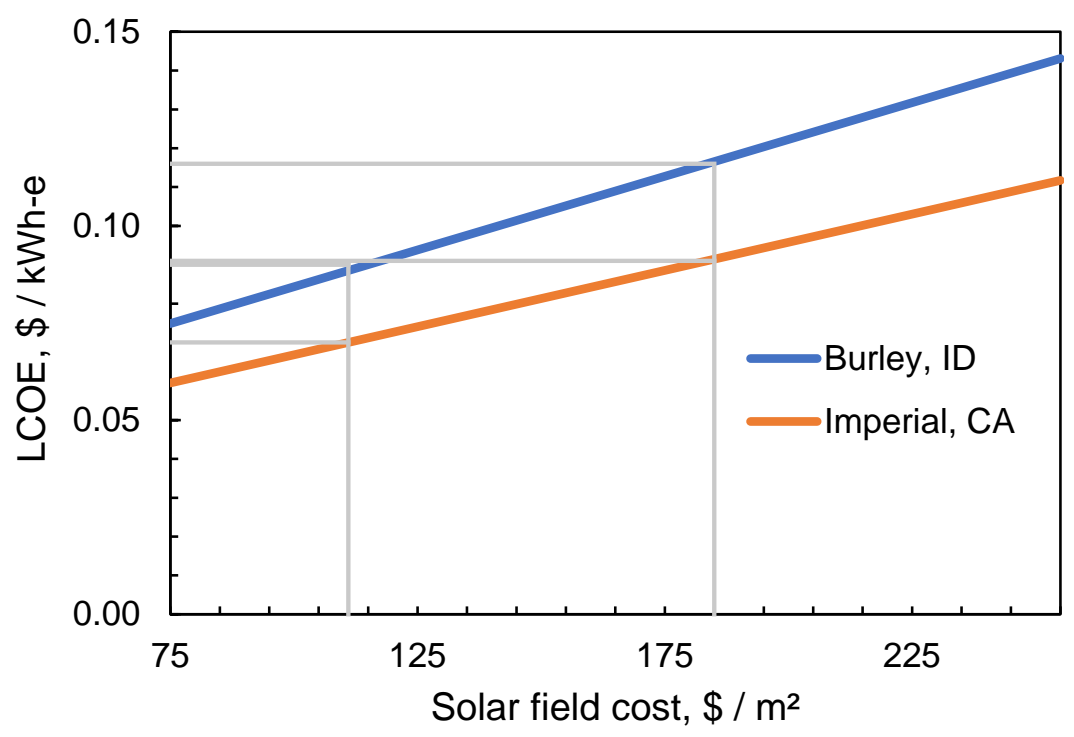

Figure 20. The LCOE of a hybrid plant with no storage and a solar multiple of 1.5 at two locations. The grey lines indicate the LCOE that may be achieved using current solar-field costs (including collectors, site improvements, and HTF system), or target costs according to the DOE CSP COLLECTS Funding Opportunity Announcement. (Costs without tax incentives.)

\section{Comparison with a Photovoltaic Array with Battery Energy Storage}

Costs have so far been presented for a variety of solar-thermal geothermal hybrid configurations. In this section, the LCOE is evaluated for equivalently sized photovoltaic (PV) arrays with battery energy storage (BES). A wide range of economic assumptions and techniques are used in the literature, so this approach allows a fair comparison of technologies. 
The performance of the PV plant is assessed using SAM's Photovoltaic (detailed) model with the default module (SunPower SPR-E19-310-COM) and inverter (SMA America: SC750CP-US 342 V). The DC-to-AC ratio is set to 1.2 and a 1-axis tracking system is enabled. Shading losses are included and depend in part on the ground-coverage ratio (GCR), which is 0.4 . The systemdesign DC power is varied until the annual energy generation is equal to a hybrid plant in the same geographical location. Two locations are considered: Burley, Idaho, and Imperial, California.

The PV+BES system is compared to hybrid plants that have a solar multiple of 1.75 and a thermal storage duration of 4 hours because the above analysis indicated that these plants are the most economically viable. Plants with no storage are also considered. The BES system is rated with a power of $8.5 \mathrm{MW}_{\mathrm{e}}$ because this is the additional electrical output of the hybrid plants when the 25-MW th thermal storage is discharged. It is assumed that all the electrical energy generated by the PV array is dispatched to the grid and that none is curtailed. The storage therefore provides dispatchability options and other energy storage services.

The PV cell capital costs are estimated from NREL's Annual Technology Baseline [37]. Storage costs are obtained from Lazard's Levelized Cost of Storage [38] report and are for lithium-ion (Li-ion) batteries operated in the "Peaker Replacement" market. Li-ion batteries have a lifetime of about 10 years, but the assumed lifetime of the power plant is 30 years. The batteries are therefore replaced in the $10^{\text {th }}$ and $20^{\text {th }}$ years, with the battery costs discounted appropriately. High, medium, and low capital costs are presented in Table 12, and the LCOE is calculated for each case. The average LCOE is then evaluated. Similarly, thermal storage is assumed to cost either 25 or $50 \$ / \mathrm{kWh}_{\text {th }}$, and the average LCOE is calculated. The LCOE is calculated using the FCR method and uses the same economic assumptions detailed in Table 6.

Results are presented in Table 13 for Burley, ID, and Table 14 for Imperial, CA. For plants with no storage, the PV array is significantly cheaper than the hybrid system, with an LCOE of 0.074 $\$ / \mathrm{kWh}$ at Burley, ID, compared to the hybrid-plant value of $0.116 \$ / \mathrm{kWh}$. The hybrid plant performs particularly poorly, in part because for a given plant size, the system produced less annual electricity than the PV array. This is due to curtailment of the thermal energy, whereas no PV electrical energy is curtailed (which may not be a realistic assumption).

Storage is an important component for the hybrid plant because it increases the electrical energy that is dispatched. Furthermore, it allows the plant to operate flexibly. This is also an important requirement for PV because the rapid deployment of PV in California has led to a surplus of power in the afternoon. This results in the so-called "duck-curve" whereby flexible power must be rapidly dispatched during the late-afternoon hours. PV should be installed with storage to help reduce this issue. However, as shown in Table 13 and Table 14, batteries significantly increase the LCOE of the PV system-primarily the result of the high cost of batteries, coupled with the requirement to replace them every 10 years.

It is also notable that the PV system requires a smaller area of panels than the CSP system does of mirrors. However, the large spacing of PV cells that is required to reduce shading losses means that the PV system occupies significantly more land area. 
Table 12. Capital cost assumptions for photovoltaic cells and lithium-ion batteries

\begin{tabular}{lllll} 
& & Low & Medium & High \\
\hline PV capital cost & $\$ / k W_{e}$ & 1000 & 1300 & 1700 \\
Operations cost & $\$ / k W_{e}$ & 14 & 14 & 14 \\
Storage capital cost & $\$ / \mathrm{kWh}_{\mathrm{e}}$ & 290 & 350 & 425 \\
\hline
\end{tabular}

Table 13. Comparison of costs and LCOEs for a hybrid plant and a photovoltaic array with batteries. Both plants are located in Burley, Idaho (without tax incentives)

\begin{tabular}{llrrrr}
\hline & & Hybrid & Hybrid + TES & PV & PV + BES \\
\hline Storage duration & $\mathrm{h}$ & 0 & 4 & 0 & 4 \\
Annual electricity & GWhe & 18.3 & 22.1 & 22.0 & 22.0 \\
Capital cost & $\mathrm{M} \$$ & 17.7 & 21.5 & 14.7 & 39.4 \\
LCOE & $\$ / \mathrm{kWh}$ & 0.116 & 0.118 & 0.074 & 0.187 \\
Aperture/module area & $\mathrm{m}^{2}$ & 73,690 & 73,690 & 57,835 & 57,835 \\
Land area & $\mathrm{m}^{2}$ & 103,165 & 103,165 & 144,473 & 144,473 \\
\hline
\end{tabular}

Table 14. Comparison of costs and LCOEs for a hybrid plant and a photovoltaic array with batteries. Both plants are located in Imperial, California.

\begin{tabular}{llrrrr} 
& & Hybrid & Hybrid + TES & PV & PV +BES \\
\hline Storage duration & $\mathrm{h}$ & 0 & 4 & 0 & 4 \\
Annual electricity & $\mathrm{GWh}$ & 24.0 & 28.9 & 28.9 & 28.9 \\
Capital cost & $\mathrm{M} \$$ & 17.7 & 21.5 & 16.3 & 41.0 \\
LCOE & $\$ / \mathrm{kWh}$ & 0.092 & 0.091 & 0.063 & 0.148 \\
Aperture/module area & $\mathrm{m}^{2}$ & 73,690 & 73,690 & 64,353 & 64,353 \\
Land area & $\mathrm{m}^{2}$ & 103,165 & 103,165 & 161,066 & 161,066 \\
\hline
\end{tabular}




\section{Further Work}

In this report, we have demonstrated the technical and economic feasibility of hybridizing a geothermal plant with a solar-driven topping cycle. Several research activities may follow on from this work and include the following.

Generating steam/water directly in the solar collectors: The capital cost of the system is dominated by the solar-field cost. Reducing solar-field costs will make the plant more economically attractive. In this report, the solar HTF is a thermal oil, such as Therminol VP-1. Thermal oils are relatively expensive (especially if thermal storage is required) and require a heat exchanger between the solar field and the solar steam cycle. It is potentially more cost-effective to generate steam or pressurized water directly in the solar collectors. However, modeling these systems is not trivial because steam generation in the collectors is complicated by the influence of the varying solar resource that can affect the location of steam generation. Such systems may require sophisticated control strategies and transient modeling. Alternatively, pressurized water could be heated in the collectors, and then flashed to steam. However, such a system would be limited to lower temperatures than the design value used in this report, which is above the critical temperature of water $\left(373.9^{\circ} \mathrm{C}\right)$. Even generating pressurized water at $300^{\circ} \mathrm{C}$ would require pressures of 85.9 bar, which would substantially increase the cost of the solar collectors.

Comparison of hybrid plant to conventional technologies: Values of the LCOE have been presented in this report. Although this is informative about the potential of the hybrid system, it can be challenging to compare the economic feasibility with other systems that exist because of the wide range of methodologies and assumptions used in the literature. Therefore, it would be more appropriate to undertake further LCOE analysis of other conventional technologies (such as PV arrays with BES, and stand-alone CSP and geothermal plants) using the same assumptions and techniques, to evaluate how the proposed hybrid system compares. Recent work on a hybrid solar-geothermal plant (using double-flash) technology undertook such analysis and indicated that the hybrid system was preferable to PV+BES and to stand-alone CSP plants [11]. Similar conclusions were obtained by Zhou et al. for a binary cycle with a steam topping cycle [19]. However, the systems and locations are quite different and further analysis is required.

More sophisticated modeling of thermal storage: In this report, we briefly consider the impact of including thermal storage in the hybrid plant and find that it can increase the electricity generation. However, the results are quite sensitive to the cost of the storage and imply that storage capital costs should be less than $30 \$ / \mathrm{kWh}$ th. Further analysis is required to determine whether this cost is feasible. Previous research indicates that values in the range 30-50 $\$ / k W h t h$ are realistic for two-tank liquid storage [11]. Costs could potentially be reduced by using alternative technologies, such as a single tank with a thermocline or solid baffle, or a packed bed.

Alternative heat-integration strategies: Several methods of hybridizing the geothermal plant with solar were considered in this report, including brine preheating, and topping cycles with either one or two turbines. However, a variety of other integration strategies could be investigated, and some of these have been proposed in the literature. For instance, rather than using the steamturbine exit flow to vaporize the binary-cycle working fluid, it could be added to the geothermal fluid as in [18], or elsewhere in the cycle. Another option is to modify the binary cycle to operate at supercritical conditions rather than subcritical conditions, in a similar way to [17]. For 
example, a supercritical expander could be added to the binary cycle (or the existing turbines could be upgraded, if possible). The working fluid would be pumped to high pressures, then heated first by the geothermal fluid, then by the solar field. Heat exchange would occur directly between the solar field and the binary cycle, therefore reducing the number of heat exchangers in the system compared to the case with the steam topping cycle.

Time-of-delivery scheduling: Thermal storage enables the plant to dispatch power at optimal times and take advantage of fluctuations in electricity prices. A further study could investigate the required control strategies and the economic benefit of a hybrid plant that reacted to market signals.

Performance of hybrid plants that use air-cooling: This analysis considered the retrofit of a geothermal binary cycle that uses evaporative cooling towers. Many geothermal binary cycles use air-cooling and their performance is highly influenced by changes in ambient temperature, with high ambient temperatures leading to lower power outputs. The solar-steam topping cycle could be particularly beneficial when coupled with air-cooled binary plants because the additional solar heat input would coincide with periods of the day in which ambient temperature is elevated and stand-alone geothermal power-plant output is decreased. Additional heat input into the binary cycle during these time periods is likely to significantly improve plant performance, with the additional power generation per unit solar heat input expected to be greater than in the case of a wet-cooled power plant. The addition of a solar-steam topping cycle to an air-cooled geothermal binary power plant may therefore provide increased power generation and a consequently lower LCOE relative to the wet-cooled power plant investigated in this analysis.

Evaluation of hybrid-plant performance for a range of resource design conditions (and the resulting power-plant designs/configurations): The geothermal resource temperature and ambient temperature have a significant impact on the design of a geothermal power plant, influencing major design choices such as the plant type, plant configuration, working-fluid selection, and cooling medium. In this analysis, the performance of a hybrid-plant retrofit of the Raft River power-plant design was considered; it is expected that the performance and costs of hybrid-plant retrofits of other geothermal power plants (with differing geothermal resource, solar resource, and ambient-temperature design points) would differ from Raft River. Further evaluation of the hybrid-plant performance for a range of geothermal resources, solar resources, and ambienttemperature design points would allow the geothermal power industry to more readily select geothermal power plants that would most greatly benefit from solar topping-cycle hybridization.

Applicability of hybrid plant with various levels of geothermal-resource productivity decline: Geothermal power plants frequently encounter resource productivity decline, which may occur in the form of a brine temperature decrease, brine flow rate decrease, or both. In this analysis, the performance specification of one specific off-design geothermal resource condition was considered. For this analysis to be more broadly applicable to the geothermal power industry, it would be instructive to evaluate the performance and LCOE for a solar steam topping-cycle retrofit for a range of brine flow rates and temperatures that deviate from the design point by varying amounts. 


\section{Conclusions}

In this report, we have investigated retrofitting a geothermal binary cycle with a solar steam topping cycle. The waste heat from the steam cycle is used to return the binary cycle to its design point. We develop design and off-design models of the geothermal plant (and verify against operational data), solar field, and topping cycle. These models account for variations in ambient temperatures and solar resource. We undertake annual simulations to evaluate the additional electricity generated and levelized cost of electricity.

We compare three different methods of hybridization and find that a system with a single steam turbine that acts as a topping cycle to the geothermal plant has the best performance and simplicity. We find that solar fields with a north-south orientation outperform fields oriented east-west. The hybrid plant with a single steam turbine and a north-south-oriented solar field is then investigated in further detail. For example, we calculate the LCOE for a hybrid plant located in three locations: Burley, Idaho; Reno, Nevada; and Imperial, California. The annual average ambient temperature significantly affects the performance of the geothermal plant (which uses an evaporative cooling tower), with the Californian geothermal plant generating the least incremental electricity because of the higher wet-bulb temperature that the cooling tower experiences. However, the solar resource is greater in Imperial, CA, than at the other two locations, leading to a higher quantity of additional electricity produced due to the solar field by the hybrid plant. Consequently, the LCOE, without tax incentives, of a hybrid plant in California is lower (0.118 $\left.\$ / \mathrm{kWh}_{\mathrm{e}}\right)$ than the other two locations (0.126 $\$ / \mathrm{kWh}$ at Burley, ID).

An advantage of hybrid geothermal-solar power plants is the ability to use all the available solar energy. In a conventional CSP system, the solar field is typically oversized so that the plant can operate close to the design point for a greater proportion of the year. However, excess solar energy then has to be either curtailed or stored. In a hybrid system, this problem may be avoided. When the topping turbine reaches its maximum capacity, excess solar energy can be bypassed around the turbine and added directly to the geothermal plant. This reduces the quantity of energy that is curtailed. We find that this mode of operation increases the optimal solar multiple to be around 1.5 and slightly decreases the LCOE.

However, this mode of operation is less efficient than extracting work at high temperatures in the solar field. Therefore, it is preferable to install thermal storage so that power can be extracted at higher efficiencies at later times. Thermal storage also improves the dispatchability of the plant and may enable it to take advantage of fluctuating prices. The solar multiple that minimizes the LCOE increases when thermal storage is added. Four hours of storage has an optimal solar multiple of 1.75, and eight hours has an optimal value of 2.0. We find that storage should cost less than $30 \$ / \mathrm{kWh}_{\mathrm{th}}$ in order for the minimum LCOE to be lower than that of a hybrid plant with no storage.

We consider the impact of subsidies and future developments in solar technology on the LCOE. Tax incentives such as the ITC reduce the capital cost between $10 \%$ and $30 \%$, significantly reducing the LCOE. For instance, for a hybrid plant with four hours of storage in Imperial, CA, a solar multiple of 1.75 and a tax incentive of $30 \%$ has an LCOE of $0.067 \$ / k W h$ e. Solar-field costs are also expected to decrease in coming years. The DOE SunShot target is for collectors to cost significantly less than those used in this report (75 $\$ / \mathrm{m}^{2}$ rather than $\left.125 \$ / \mathrm{m}^{2}\right)$. The solar 
field accounts for up to $75 \%$ of the total capital cost, and reducing solar-field costs by half leads to a $30 \%$ reduction in the LCOE.

The cost of the hybrid geothermal-solar power plant is compared to a photovoltaic array with battery energy storage. It is found that the hybrid plant is significantly less expensive than the $\mathrm{PV}+\mathrm{BES}$ system due to the high cost and replacement rate of batteries. For instance, with four hours of storage, the LCOE of the hybrid plant is $0.091 \$ / \mathrm{kWhe}$ compared to $0.148 \$ / \mathrm{kWh}$ for a plant in California (without subsidies). This suggests that a hybrid solar-geothermal power plant with storage may provide a path to provide inexpensive, dispatchable geothermal power. However, without energy storage, the PV plant has a lower LCOE than the geothermal-solar hybrid. 


\section{References}

[1] D. S. Wendt and G. L. Mines, "Use of a Geothermal-Solar Retrofit Hybrid Power Plant to Mitigate Declines in Geothermal Resource Productivity,” GRC Transactions, vol. 38, 2014.

[2] D. M. Snyder, K. F. Beckers, K. R. Young, and B. Johnston, “Analysis of Geothermal Reservoir and Well Operational Conditions using Monthly Production Reports from Nevada and California," GRC Transactions, vol. 41, 2017.

[3] R. Dipippo, Geothermal Power Plants, $4^{\text {th }}$ edition. Butterworth-Heinemann, 2016.

[4] R. Dipippo and K. Kitz, "Geothermal Binary Power Plants at Raft River , San Emidio , and Neal Hot Springs : Part 1 - Plant Descriptions and Design Performance Comparison,” GRC Transactions, vol. 39, no. Part 1, pp. 833-846, 2015.

[5] C. Turchi, G. Zhu, M. Wagner, and T. Williams, "Geothermal / Solar Hybrid Designs: Use of Geothermal Energy for CSP Feedwater Heating,” Geotherm. Resour. Counc. $38^{\text {th }}$ Annu. Meet., pp. 1-16, 2014.

[6] P. N. Mathur, "An assessment of solar-geothermal hybrid system concepts,” SAN-110114/1, 1979 .

[7] J. Miguel Cardemil, F. Cortés, A. Díaz, and R. Escobar, "Thermodynamic Evaluation of Solar-Geothermal Hybrid Power Plants in Northern Chile," Energy Convers. Manag., vol. 123, pp. 348-361, 2016.

[8] S. Handal, Y. Alvarenga, and M. Recinos, "Geothermal Steam Production by Solar Energy,” Geotherm. Resour. Counc. 31 ${ }^{\text {st }}$ Annu. Meet., vol. 31, 2007.

[9] Y. Alvarenga, S. Handal, and M. Recinos, "Solar Steam Booster in the Ahuachapan Geothermal Field," Geotherm. Resour. Counc. 32 ${ }^{\text {nd }}$ Annu. Meet., vol. 32, 2008.

[10] J. McTigue, J. Castro, G. Mungas, N. Kramer, J. King, and C. Turchi, "Retrofitting a Geothermal Plant with Solar and Storage to Increase Power Generation,” Trans. GRC, vol. 41, 2017.

[11] J. D. McTigue, J. Castro, G. Mungas, N. Kramer, J. King, C. S. Turchi, and G. Zhu, "Hybridizing a Geothermal Power Plant with Concentrating Solar Power and Thermal Storage to Increase Power Generation and Dispatchability,” Appl. Energy, In submission, 2018.

[12] A. Lentz and R. Almanza, "Solar - Geothermal Hybrid System," Appl. Therm. Eng., vol. 26, pp. 1537-1544, 2006.

[13] M. C. Bassetti, D. Consoli, G. Manente, and A. Lazzaretto, "Design and Off-Design Models of a Hybrid Geothermal-Solar Power Plant Enhanced by a Thermal Storage," Renew. Energy, 2017. 
[14] H. Ghasemi, E. Sheu, A. Tizzanini, M. Paci, and A. Mitsos, "Hybrid Solar - Geothermal Power Generation : Optimal Retrofitting,” Appl. Energy, vol. 131, pp. 158-170, 2014.

[15] M. Ayub, A. Mitsos, and H. Ghasemi, “Thermo-Economic Analysis of a Hybrid SolarBinary Geothermal Power Plant,” Energy, vol. 87, pp. 326-335, 2015.

[16] M. Astolfi, L. Xodo, M. C. Romano, and E. Macchi, "Geothermics Technical and Economical Analysis of a Solar - Geothermal Hybrid Plant Based on an Organic Rankine Cycle,” Geothermics, vol. 40, no. 1, pp. 58-68, 2011.

[17] C. Zhou, "Hybridisation of Solar and Geothermal Energy in Both Subcritical and Supercritical Organic Rankine Cycles,” Energy Convers. Manag., vol. 81, pp. 72-82, 2014.

[18] N. Bonyadi, E. Johnson, and D. Baker, “Technoeconomic and Exergy Analysis of a Solar Geothermal Hybrid Electric Power Plant Using a Novel Combined Cycle,” Energy Convers. Manag., vol. 156, no. September 2017, pp. 542-554, 2018.

[19] C. Zhou, E. Doroodchi, and B. Moghtaderi, “An In-Depth Assessment of Hybrid Solar Geothermal Power Generation,” Energy Convers. Manag., vol. 74, pp. 88-101, 2013.

[20] D. S. Wendt and G. L. Mines, "Stillwater Hybrid Geo-Solar Power Plant Optimization Analyses,” Geotherm. Resour. Counc. 39 ${ }^{\text {th }}$ Annu. Meet., vol. 39, pp. 891-900, 2015.

[21] G. Dimarzio, L. Angelini, W. Price, C. Chin, and S. Harris, “The Stillwater Triple Hybrid Power Plant: Integrating Geothermal, Solar Photovoltaic and Solar Thermal Power Generation,” in Proceedings World Geothermal Congress, 2015, April, pp. 1-5.

[22] O. C. Kuyumcu, O. S. C. C. Özalevli, D. K. Baker, and S. K. Somek, “Design and Implementation of the Gümüşköy Hybrid Geothermal and Solar Thermal Power System,” Trans. - Geotherm. Resour. Counc., vol. 38, pp. 811-816, 2014.

[23] G. Manente, R. Dipippo, and R. Field, International Mechanical Engineering Congress and Exposition, IMECE2011-6 3665, pp. 1-11, 2017.

[24] E. Sieder and G. Tate, “Heat Transfer and Pressure Drops of Liquids in Tubes,” Ind. Eng. Chem., vol. 28, pp. 1429-1435, 1936.

[25] D. A. Donohue, “Heat Transfer and Pressure Drop in Heat Exchangers,” Ind. Eng. Chem., vol. 41, no. 11, pp. 499-511, 1949.

[26] L. S. Dixon and C. A. Hall, Fluid Mechanics and Thermodynamics of Turbomachinery. Elsevier Science, 2010.

[27] D. H. Cooke, “On Prediction of Off-Design Multistage Turbine Pressures by Stodola's Ellipse 1,” J. Eng. Gas Turbines Power, vol. 107, pp. 596-606, 1985.

[28] J. D. Denton, “Loss Mechanisms in Turbomachines,” J. Turbomach., vol. 115, no. October 1993, 2017. 
[29] A. Bahadori and H. B. Vuthaluru, "Estimation of Performance of Steam Turbines Using a Simple Predictive Tool,” Appl. Therm. Eng., vol. 30, no. 13, pp. 1832-1838, 2010.

[30] National Renewable Energy Laboratory, “System Advisor Model V. 2017.9.5.” 2017.

[31] National Renewable Energy Laboratory, "National Solar Radiation Database (NSRDB)."

[32] United States Department of Energy, "Combined Heat and Power Technology Fact Sheet Series,” DOE/EE-1334, 2016.

[33] W. Short and D. J. Packey, "A Manual for the Economic Evaluation of Energy Efficiency and Renewable Energy Technologies,” NREL Tech. Rep. NREL/TP-462-5173, no. March, 1995.

[34] Y. Nakao, Y. Mugikura, K. Ogata, and N. Katsuki, "Development of Hybrid Geothermal Power Plants in Japan,” in Transactions - Geothermal Resources Council, 2017, vol. 41.

[35] T. Mai, W. Cole, E. Lantz, C. Marcy, and B. Sigrin, "Impacts of Federal Tax Credit Extensions on Renewable Deployment and Power Sector Emissions," Tech. Rep. NREL/TP6A20-65571, no. February, 2016.

[36] Department of Energy, "Concentrating Solar Power: Concentrating Optics for Lower Levelized Energy CosTS (COLLECTS),” Funding Oppor. Announc. DE_FOA-0001268, 2015.

[37] NREL, “2017 Annual Technology Baseline.” 2017.

[38] Lazard, “Lazard’s Levelized Cost of Storage Analysis - Version 3.0,” 2017. 


\section{Appendix A}

Funding for this study was provided with the specific intention to evaluate a hybrid cycle with a high-temperature (exergy) solar steam topping cycle to extract net electric power from the energy collected in the solar field, after which the steam would then be cascaded to add solar heat to the GBPP to fill the plant's under-used turbine and heat-rejection system capacity. However, it was recognized that the proposed system was substantially more complex and expensive than some of the simple solar-heat addition cycles that had been studied and/or constructed. To get a feel for whether the project concept would yield a substantial improvement in economics, the initial work was a high-level screening evaluation at a single operating point using the HYSYS software package, calibrated to the original design PFD.

Throughout this project, various configurations have been considered. Some of these were evaluated in both a screening study and the detailed modeling work of this report, whereas some were only considered in this study. A full list of considered configurations are now given, as well as the study they appear in:

Case 1A: Schematic shown in Figure 3. A steam topping cycle rejects heat into the binary cycle and vaporizes the working fluid. There are two turbines operating with different condenser pressures to match the temperatures and properties of the two pressure levels in the binary cycle. Evaluated in screening study and detailed study.

Case 1B: Schematic shown in Figure 4. The steam topping cycle rejects heat into the binary cycle and vaporizes the working fluid. There is only one steam turbine, and the exit flow pressure corresponds to the high-pressure level in the binary cycle. The exit flow is split between the two pressure levels. Only considered in detailed study_see Table 7.

Case 1C: Schematic shown in Figure 5. The same as Case 1B except that the steam turbine exit only preheats the binary-cycle fluid in the high-pressure level. Only considered in detailed study-see Table 7.

Case 2: This is the simplest configuration, and a schematic is shown in Figure 21. The solar field directly heats the production fluids. There may be problems with mineral deposition in the heat exchanger. This is not an effective use of the high-exergy fluid produced in the solar field. Evaluated in screening study and detailed study.

Case 3: A fraction of the injection brine is heated directly by the solar field. It is then mixed with the production fluids. Only considered in detailed study - see Table 7-and found to have very low solar conversion efficiencies.

Case 4A: A steam topping cycle rejects heat into injection brine, which is recirculated and mixed with the production fluids-see Figure 22. Considered in screening study.

Case 4B: The heat exchange between the brine and the condensing steam in Case 4A is not effective due to large temperature differences that occur. Using a three-stage steam turbine and passing the brine through condensers operating at increasing pressures (and therefore increasing temperatures) improves the heat-transfer process-see Figure 23. Considered in screening study. 
Case 5A: Case 4 increases the binary-cycle performance by increasing the mass flow rate of brine, and therefore, the binary-cycle mass flow rate. Rather than heating injection brine, in Case $5 \mathrm{~A}$, some brine is extracted earlier in the process-see Figure 24. Because this brine is hotter than the injection brine, the increase in mass flow rate for a given solar heat input is increased. This leads to a higher solar conversion efficiency. Considered in screening study.

Case 5B: The effectiveness of the topping-cycle heat rejection is improved by using a threestage steam turbine-see Figure 25. Considered in screening study.

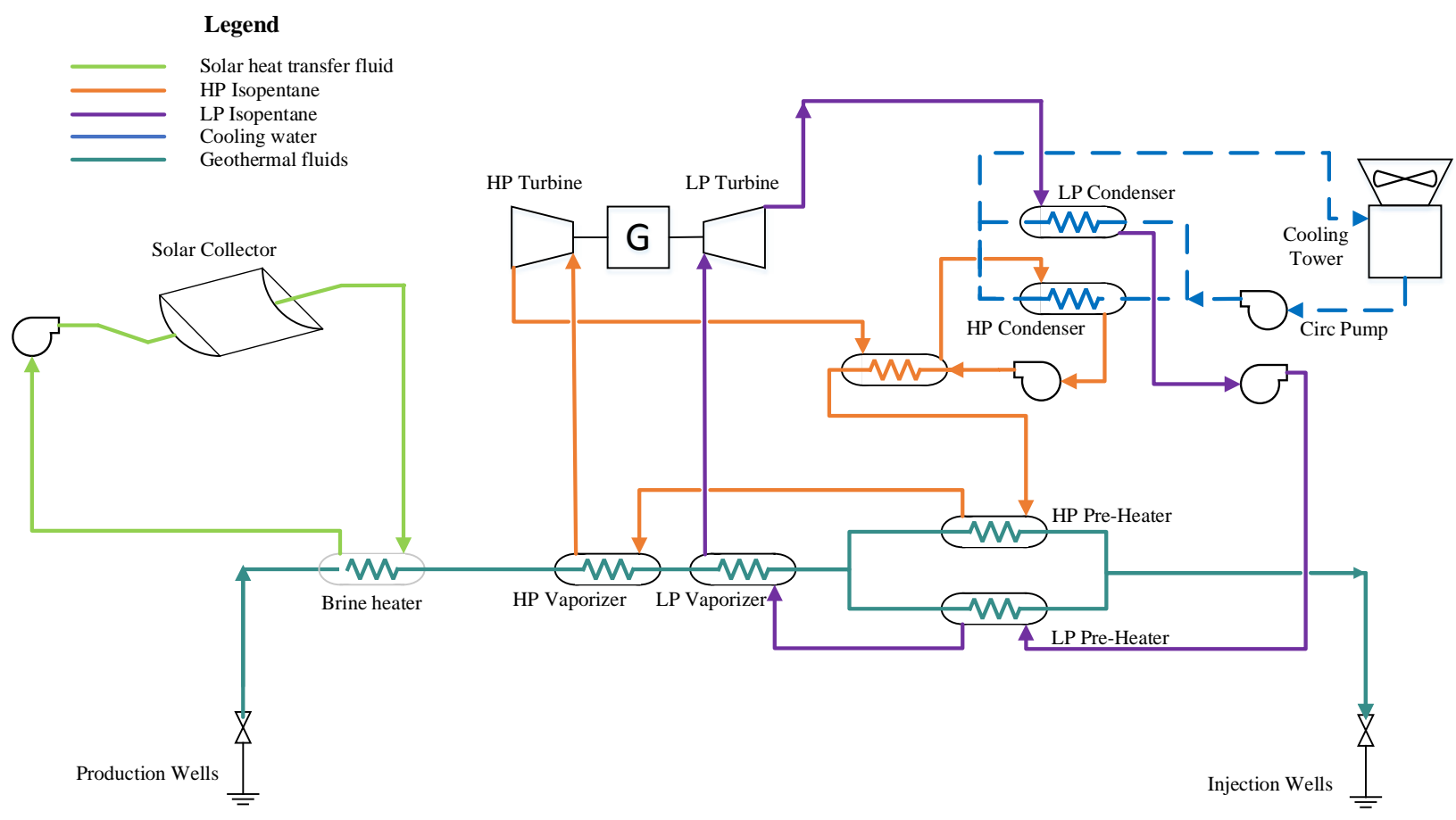

Figure 21. Case 2-Geothermal production fluids are heated directly by the solar field. 


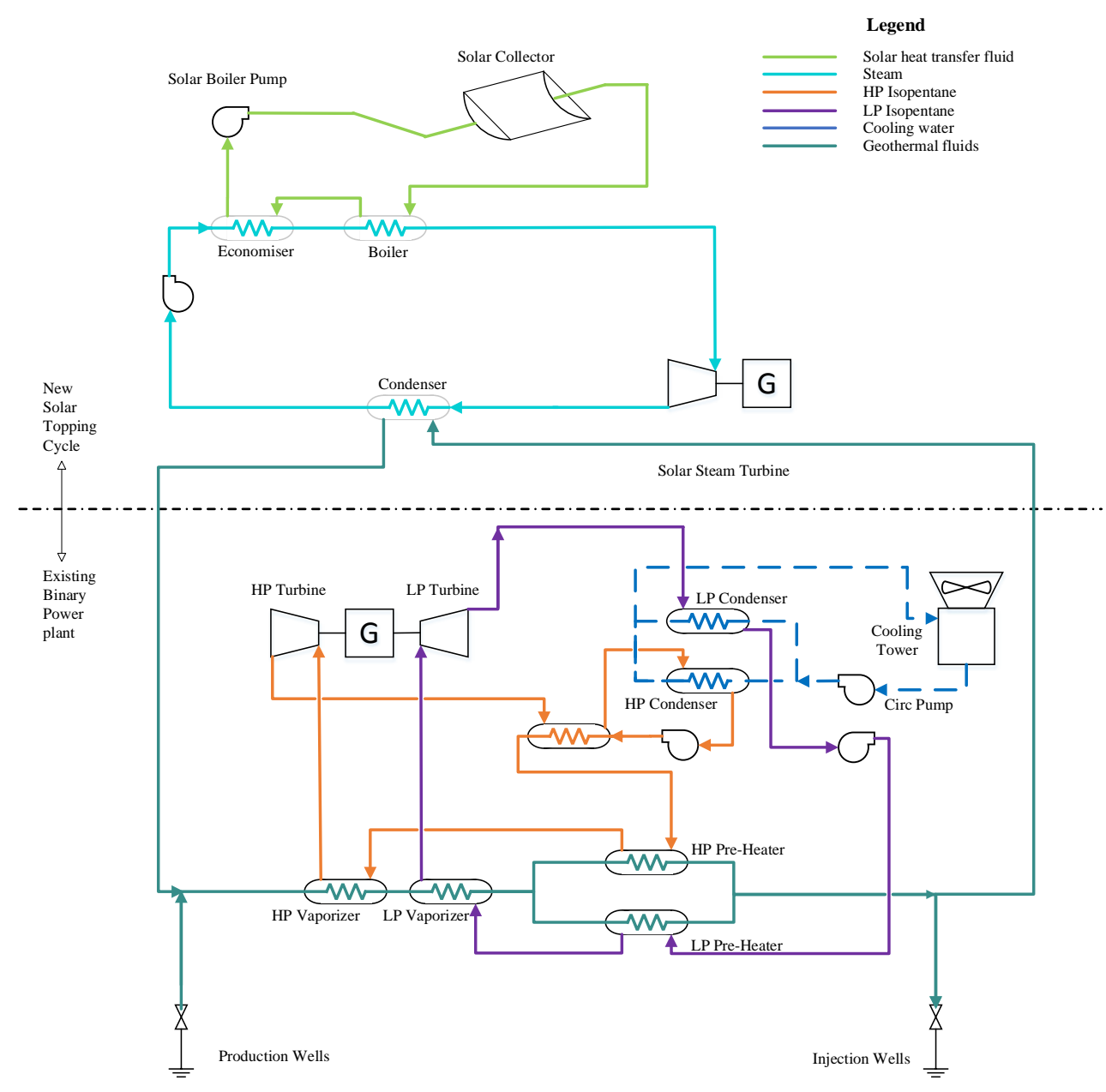

Figure 22. Case 4A-Injection brine is heated in the condenser of a topping steam turbine. The hot brine is recirculated and mixed with the production fluids. 


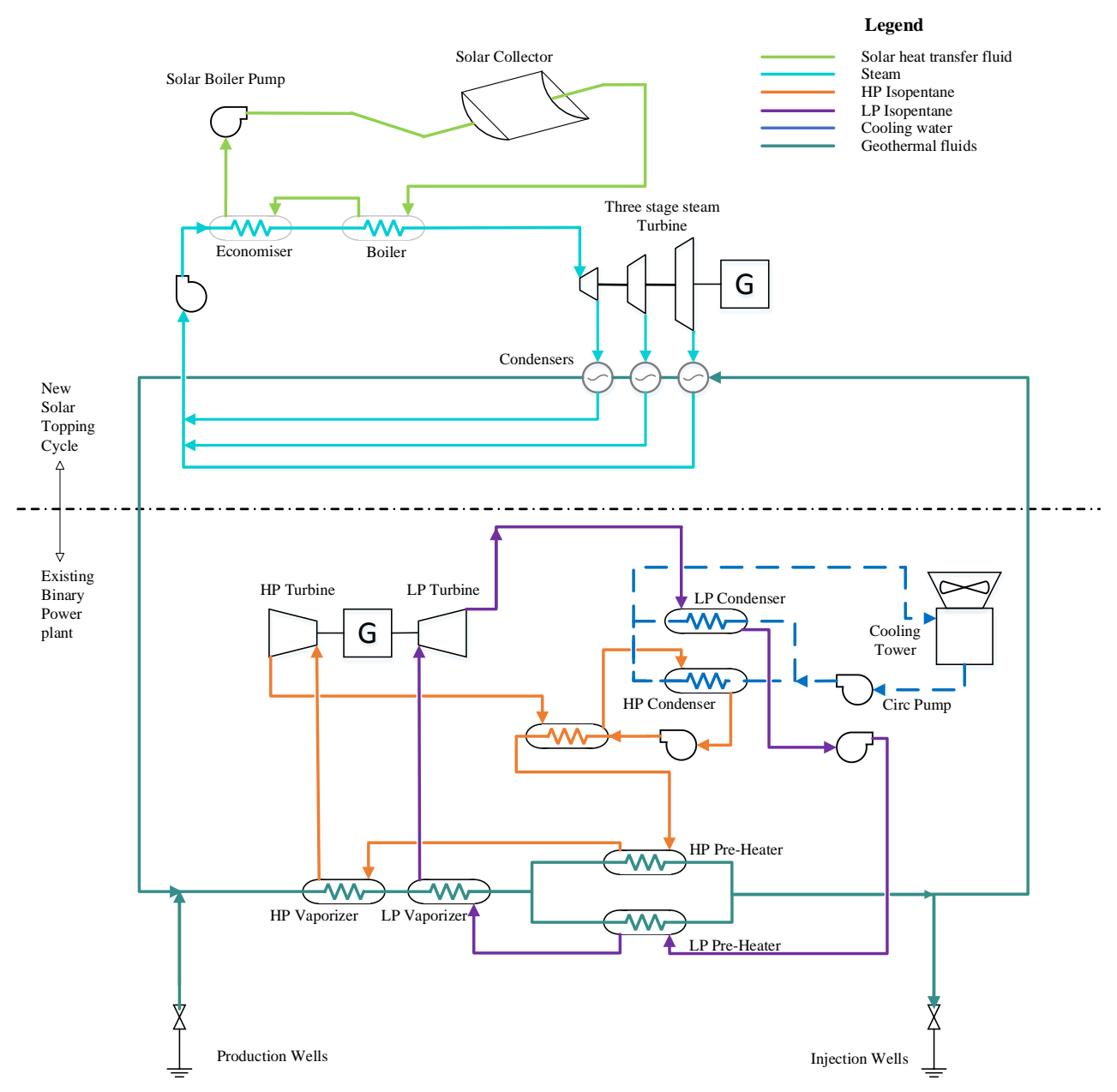

Figure 23. Case 4B-Injection brine is heated in the condensers of a three-stage topping steam turbine. The hot brine is recirculated and mixed with the production fluids. 


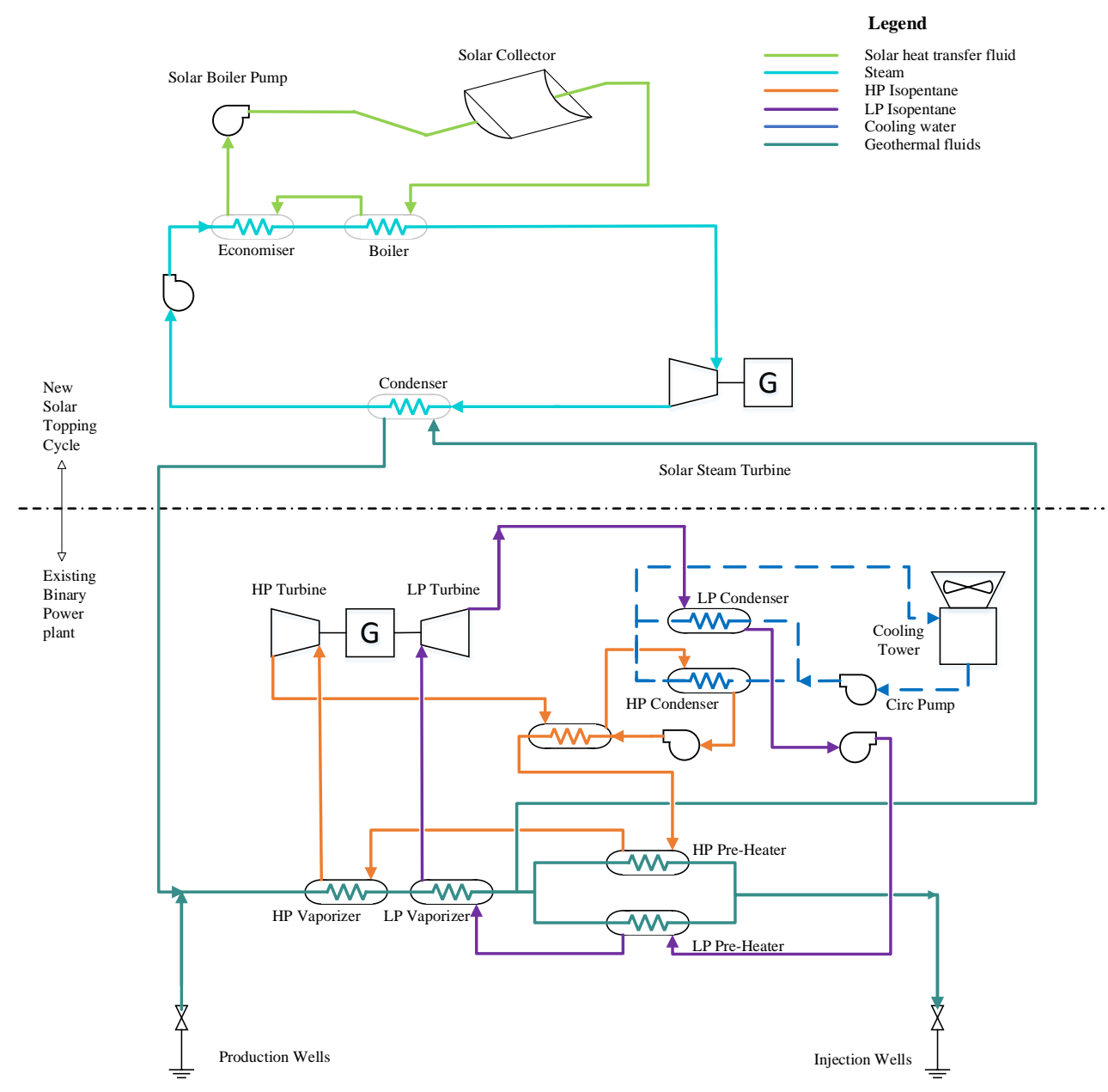

Figure 24. Case 5A-Brine is extracted before the binary-cycle preheaters. It is then heated in the condenser of the steam topping cycle and then mixed with the production fluids. 


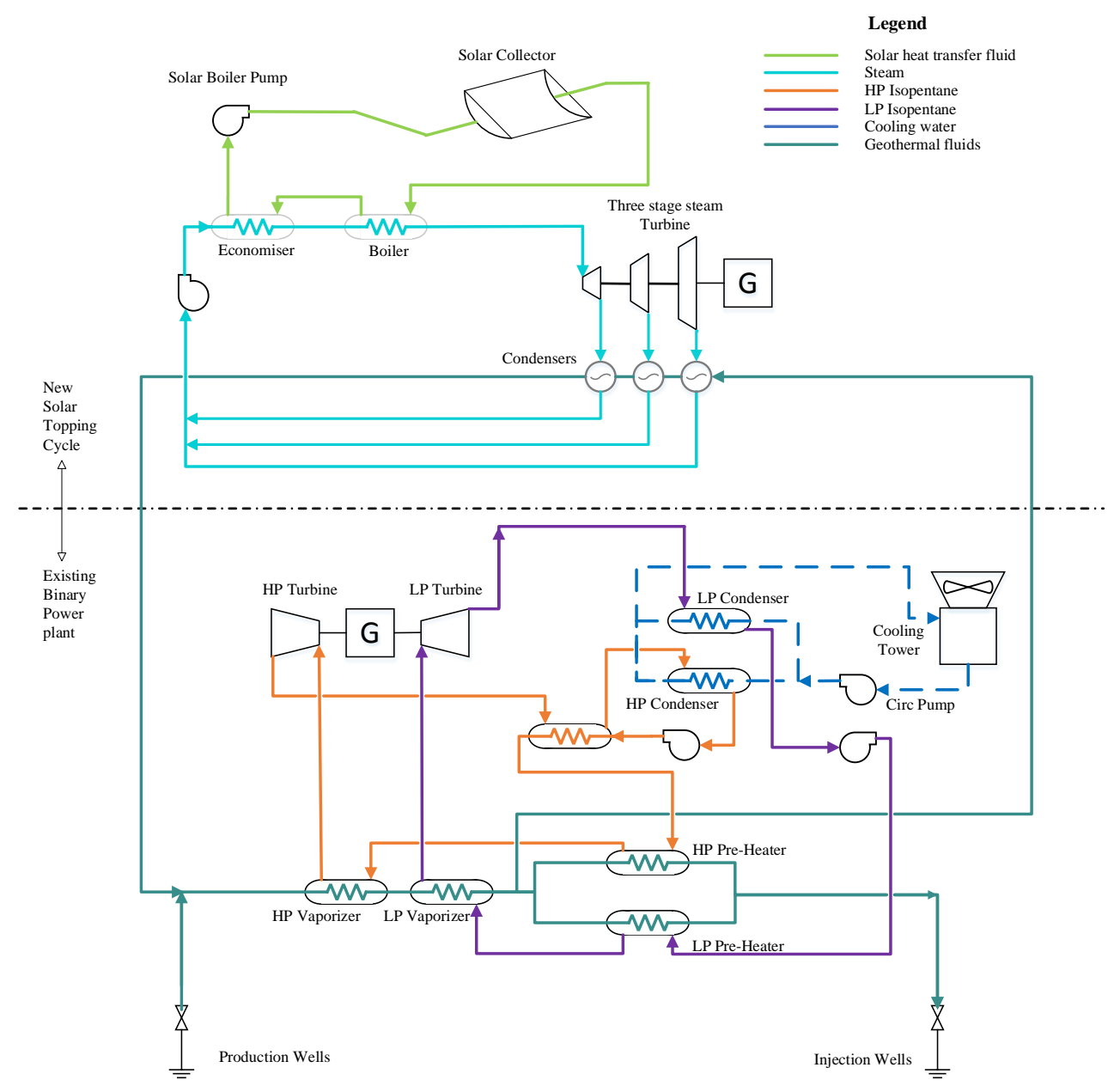

Figure 25. Case 5B-Brine is extracted before the binary-cycle preheaters. It is then heated in the condensers of a three-stage steam topping cycle and then mixed with the production fluids. 


\section{Screening Study}

The parameters of the screening study were to fix the brine flow and temperature at the current operating condition of 2,700 klbs/hr $(\mathrm{kph})$ and $272^{\circ} \mathrm{F}$ (compared to the original design condition of 3,150 kph and $280^{\circ} \mathrm{F}$ ). This resulted in a GBPP net generation of $10.69 \mathrm{MW}_{\mathrm{e}}$ at the original design-point atmospheric wet-bulb temperature of $39.9^{\circ} \mathrm{F}$. For each screening case, the size of the solar field was adjusted until the GBPP achieved an approximate design net output of 13.75 MWe (excluding geothermal production and injection pump loads), which required the solar heat input to the plant to result in a net GBPP output increase of $3.06 \mathrm{MWe}$. The solar heat input was modeled as simply thermal input to the cycle, with no parasitic loads or losses to obtain the thermal heat, e.g., no solar-field fluid pumps, and no pipe or collector heat losses.

With the net output of the GBPP fixed, the parameters that changed from case to case were the thermal input, the net electrical power generated by the cycle overall, and the incremental solar conversion efficiency. A summary of the screening study results is presented in Table 15. Because the solar collectors are the most expensive part of any solar energy system, the incremental solar efficiency and the ratio of thermal heat input to electrical power output are the most important metrics for this screening study.

Preliminary results are presented in Table 15 and indicate that Case 1 is the most promising configuration.

Table 15. Preliminary results comparing several hybrid geothermal-solar configurations. These results are for the case where the solar-field heat input restores the geothermal plant to its design point.

\begin{tabular}{|c|c|c|c|c|c|c|}
\hline Case & $\begin{array}{l}\text { Steam mass } \\
\text { flow, } \mathrm{kg} / \mathrm{s}\end{array}$ & $\begin{array}{l}\text { Steam-cycle net } \\
\text { power, } \mathrm{MW}_{\mathrm{e}}\end{array}$ & $\begin{array}{l}\text { Binary-cycle net } \\
\text { power, } \mathrm{MW}_{\mathrm{e}}\end{array}$ & $\begin{array}{c}\text { Brine exit } \\
\text { temperature, }{ }^{\circ} \mathrm{C}\end{array}$ & $\begin{array}{l}\text { Solar heat } \\
\text { input, } \mathrm{MW}_{\text {th }}\end{array}$ & $\begin{array}{c}\text { Efficiency, } \\
\eta_{\text {sol, } 1}, \%\end{array}$ \\
\hline $1 \mathrm{~A}$ & 7.72 & 3.84 & 13.76 & 65.6 & 19.74 & 35.0 \\
\hline 1B & \multicolumn{6}{|c|}{ Only considered in detailed study—see Table 7} \\
\hline $1 \mathrm{~B}$ & \multicolumn{6}{|c|}{ Only considered in detailed study—see Table 7} \\
\hline 2 & - & - & 13.78 & 62.1 & 19.16 & 16.1 \\
\hline 3 & \multicolumn{6}{|c|}{ Only considered in detailed study—see Table 7} \\
\hline $4 \mathrm{~A}$ & 11.9 & 3.59 & 13.74 & 65.6 & 27.53 & 24.1 \\
\hline 4B & 11.6 & 4.77 & 13.74 & 65.6 & 28.77 & 27.1 \\
\hline $5 A$ & 9.37 & 2.83 & 13.76 & 61.8 & 21.72 & 27.1 \\
\hline $5 B$ & 9.25 & 3.58 & 13.77 & 62.1 & 22.51 & 29.5 \\
\hline
\end{tabular}

Several points are worth noting:

1. Cycles that raise the temperature of the injected brine are essentially using solar heat to do so. This is neither cost effective nor beneficial, even over the long run. Conversely, cycles that lower the brine temperature increase the energy extraction from the brine, making better use of the very large investment and expense of getting geothermal brine to and from the reservoir, and reducing the required size of the solar-field investment. 
2. For brine-heating options, Case $5 \mathrm{~A}$ and $5 \mathrm{~B}$ represent substantial improvements in performance over the other brine-heating options. Conceptually, the reason for this is two-fold: 1) the recirculated brine is not heated from as cold a temperature, and 2) there is a reduced flow in the preheaters; thus, the heat exchangers are "oversized" and able to extract more heat from the geothermal brine.

3. Cases 4B and 5B are more efficient because of a multi-step heating process. This may or may not be practical to implement in a real plant.

4. The cheapest and simplest system to implement is Case 2 (brine preheating). However, this makes inefficient use of the most expensive component in the plant—-the solar field.

5. Including a topping steam turbine increases the cost and complexity but is cost-effective for the following reasons. The steam turbine is small as a result of both low mass flow rates and relatively high exhaust pressure, so inexpensive industrial steam turbines are viable. Any cycle that integrates solar and geothermal must have at least one heat exchanger. Although the Case 1A steam vaporizer has the disadvantage of high pressure, it also has the advantage of boiling heat-transfer coefficients. The steam condenser to isopentane vaporizer vessel is not an expensive heat exchanger: there is a condensing heat-transfer coefficient on one side, and a boiling heat-transfer coefficient on the other side. The con/vap heat exchanger also eliminates the need for large fouling factors, which is necessary to include on the brine heat exchanger(s) required with the other cycle options. Because there is clean fluid on both sides of the Case 1A heat exchangers, there is also the potential to use more cost-effective designs, such as all-welded plate-type. 


\section{Appendix B: Component Cost Estimates}

Table 16. List of equipment, equipment sizing, and installed capital costs for brine-preheating, dual-turbine topping-cycle, and single-turbine topping-cycle hybrid-plant configurations

\begin{tabular}{|c|c|c|c|c|c|c|}
\hline \multirow[b]{2}{*}{ Equipment } & \multicolumn{2}{|c|}{ Brine Preheating } & \multicolumn{2}{|c|}{$\begin{array}{l}\text { Dual-Turbine Steam } \\
\text { Topping Cycle }\end{array}$} & \multicolumn{2}{|c|}{$\begin{array}{l}\text { Single-Turbine Steam } \\
\text { Topping Cycle }\end{array}$} \\
\hline & $\begin{array}{l}\text { Equipment } \\
\text { Size }\end{array}$ & $\begin{array}{c}\text { Installed } \\
\text { Cost }\end{array}$ & $\begin{array}{l}\text { Equipment } \\
\text { Size }\end{array}$ & $\begin{array}{c}\text { Installed } \\
\text { Cost }\end{array}$ & $\begin{array}{l}\text { Equipment } \\
\text { Size }\end{array}$ & $\begin{array}{c}\text { Installed } \\
\text { Cost }\end{array}$ \\
\hline Site Improvements & $42,108 \mathrm{~m}^{2}$ & $\$ 1,052,700$ & $42,108 \mathrm{~m}^{2}$ & $\$ 1,052,700$ & $42,108 \mathrm{~m}^{2}$ & $\$ 1,052,700$ \\
\hline Solar Field & $42,108 \mathrm{~m}^{2}$ & $\$ 4,210,800$ & $42,108 \mathrm{~m}^{2}$ & $\$ 4,210,800$ & $42,108 \mathrm{~m}^{2}$ & $\$ 4,210,800$ \\
\hline HTF System & $42,108 \mathrm{~m}^{2}$ & $\$ 2,526,500$ & $42,108 \mathrm{~m}^{2}$ & $\$ 2,526,500$ & $42,108 \mathrm{~m}^{2}$ & $\$ 2,526,500$ \\
\hline HTF-Brine HX & $467 \mathrm{~m}^{2}$ & $\$ 208,400$ & - & - & - & - \\
\hline Economizer & - & - & $115 \mathrm{~m}^{2}$ & $\$ 386,600$ & $115 \mathrm{~m}^{2}$ & $\$ 386,600$ \\
\hline Vaporizer & - & - & $191 \mathrm{~m}^{2}$ & $\$ 202,100$ & $191 \mathrm{~m}^{2}$ & $\$ 202,100$ \\
\hline Superheater & - & - & $70 \mathrm{~m}^{2}$ & $\$ 280,900$ & $70 \mathrm{~m}^{2}$ & $\$ 280,900$ \\
\hline L1 Condenser & - & - & $1810 \mathrm{~m}^{2}$ & $\$ 485,100$ & $1,810 \mathrm{~m}^{2}$ & $\$ 485,100$ \\
\hline L2 Condenser & - & - & $42 \mathrm{~m}^{2}$ & $\$ 80,900$ & $42 \mathrm{~m}^{2}$ & $\$ 80,900$ \\
\hline L1 Feed Pump & - & - & $29 \mathrm{~m}^{3} / \mathrm{h}$ & $\$ 127,100$ & $29 \mathrm{~m}^{3} / \mathrm{h}$ & $\$ 127,100$ \\
\hline L2 Feed Pump & - & - & $6 \mathrm{~m}^{3} / \mathrm{h}$ & $\$ 109,600$ & $6 \mathrm{~m}^{3} / \mathrm{h}$ & $\$ 109,600$ \\
\hline L1 Steam Turbine & - & - & $4,222 \mathrm{~kW}$ & $\$ 2,111,000$ & $5,001 \mathrm{~kW}$ & $\$ 2,400,000$ \\
\hline L2 Steam Turbine & - & - & $1,014 \mathrm{~kW}$ & $\$ 1,115,400$ & - & - \\
\hline \multicolumn{7}{|l|}{ Total (USD) } \\
\hline $\begin{array}{l}\text { Additional Capacity } \\
\text { (kW) at } T_{w b, d e s i g n}\end{array}$ & \multicolumn{2}{|c|}{$3,080 \mathrm{~kW}$} & \multicolumn{2}{|c|}{$8,146 \mathrm{~kW}$} & \multicolumn{2}{|c|}{$7,910 \mathrm{~kW}$} \\
\hline
\end{tabular}

The installed costs reported by Aspen Process Economic Analyzer include allowances for the material and manpower contributions for the following factors:

- Equipment and setting

- Piping

- Civil

- Structural steel

- Instrumentation

- Electrical

- Insulation

- Paint.

These allowances are included as installation factors for each equipment item. In general, the installation factors (direct cost divided by equipment cost) are at least 1.2, if not considerably above. The highest installation factor reported was for the economizer unit of the steam boiler, where the installation factor reported by Aspen was 7.3. 